TITLE:

Capturing human trophoblast development with naive pluripotent stem cells in vitro( Dissertation_全文)

AUTHOR(S):

lo, Shingo

CITATION:

Io, Shingo. Capturing human trophoblast development with naive pluripotent stem cells in vitro. 京都大学, 2021, 博士(医学)

ISSUE DATE:

2021-11-24

URL:

https://doi.org/10.14989/doctor.k23569

RIGHT: 


\section{Cell Stem Cell}

\section{Capturing human trophoblast development with naive pluripotent stem cells in vitro}

\section{Graphical abstract}

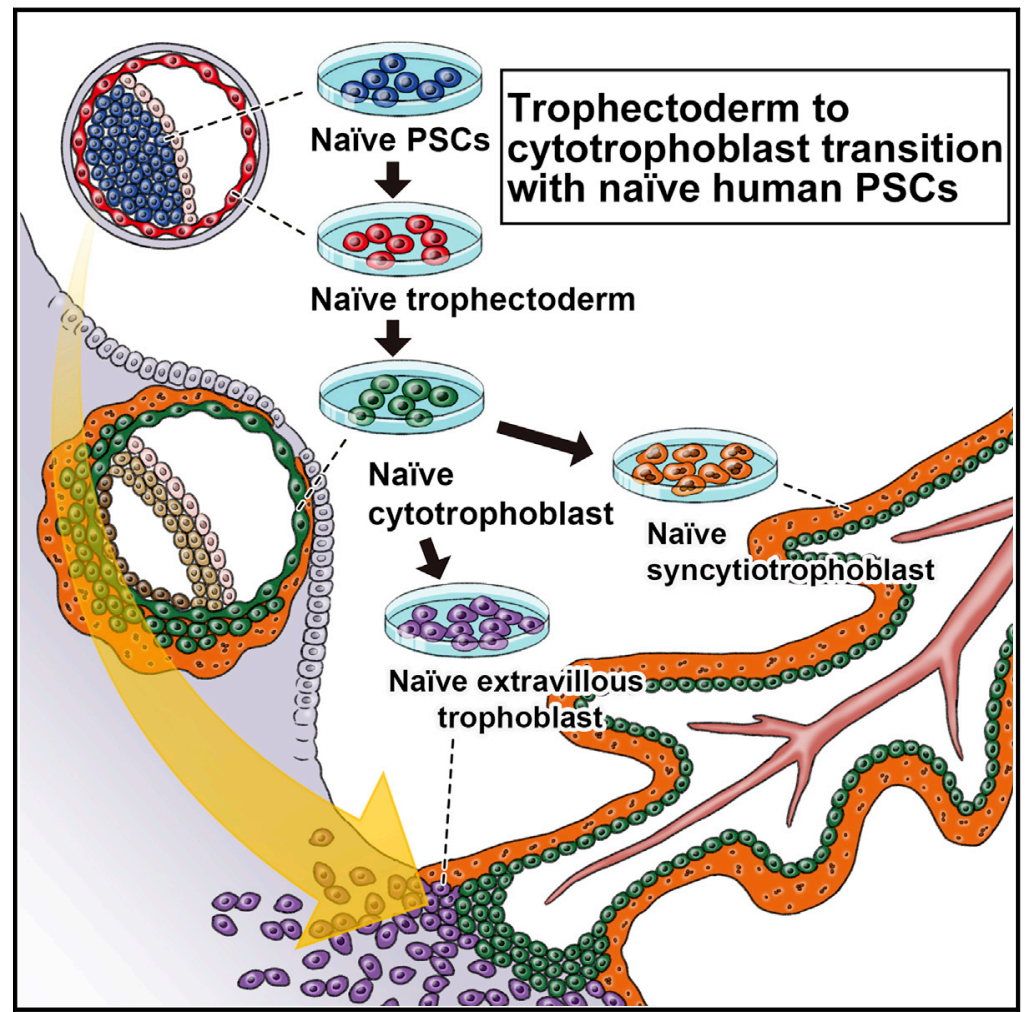

\section{Highlights}

- Trophectoderm can be generated from naive human pluripotent stem cells

- Human trophoblast stem cells represent post-implantation cytotrophoblast

- Trajectory of trophoblast from pre- to post-implantation is drawn by our model

- ACE is essential for specification and maintenance of cytotrophoblast stem cells

\section{Authors}

Shingo lo, Mio Kabata, Yoshiki lemura, ..., Takuya Yamamoto, Masaki Mandai, Yasuhiro Takashima

\section{Correspondence}

y.takashima@cira.kyoto-u.ac.jp

\section{In brief}

lo et al. propose an in vitro model that recapitulates transcriptome-wide transition from trophectoderm to cytotrophoblast. Trophectoderm at the stage of pre-implantation can be induced from naive human pluripotent stem cells. ACE culture conditions are an improved method to derive and maintain human trophoblast stem cells. 


\title{
Capturing human trophoblast development with naive pluripotent stem cells in vitro
}

\author{
Shingo lo, ${ }^{1,2,3}$ Mio Kabata, ${ }^{1}$ Yoshiki lemura, ${ }^{1}$ Katsunori Semi, ${ }^{1}$ Nobuhiro Morone, ${ }^{4}$ Atsutaka Minagawa, ${ }^{5}$ Bo Wang, ${ }^{5}$ \\ Ikuhiro Okamoto, 6,7 Tomonori Nakamura, ${ }^{6,7,8}$ Yoji Kojima, ${ }^{1,6,7}$ Chizuru Iwatani, ${ }^{9}$ Hideaki Tsuchiya, ${ }^{9}$ Belinda Kaswandy, ${ }^{1}$ \\ Eiji Kondoh, ${ }^{2}$ Shin Kaneko, ${ }^{5}$ Knut Woltjen, ${ }^{1}$ Mitinori Saitou, ${ }^{1,6,7}$ Takuya Yamamoto, $1,7,10,11$ Masaki Mandai, ${ }^{2}$ \\ and Yasuhiro Takashima ${ }^{1,12, *}$ \\ ${ }^{1}$ Department of Life Science Frontiers, CiRA, Kyoto University, Kyoto 606-8507, Japan \\ 2Department of Gynecology and Obstetrics, Kyoto University Graduate School of Medicine, Kyoto 606-8507, Japan \\ 3Japan Society for the Promotion of Science, Tokyo 102-0083, Japan \\ ${ }^{4}$ MRC Toxicology Unit, University of Cambridge, Cambridge CB2 1QR, UK \\ ${ }^{5}$ Department of Cell Growth and Differentiation, CiRA, Kyoto University, Kyoto 606-8507, Japan \\ 6Department of Anatomy and Cell Biology, Kyoto University Graduate School of Medicine, Kyoto 606-8501, Japan \\ ${ }^{7}$ Institute for the Advanced Study of Human Biology (ASHBi), Kyoto University, Kyoto 606-8501, Japan \\ 8The HAKUBI Center for Advanced Research, Kyoto University, Kyoto 606-8501, Japan \\ ${ }^{9}$ Research Center for Animal Life Science, Shiga University of Medical Science, Shiga 520-2192, Japan \\ ${ }^{10}$ AMED-CREST, AMED, Tokyo 100-0004, Japan \\ ${ }^{11}$ Medical Risk Avoidance Based on iPS Cells Team, RIKEN Center for Advanced Intelligence Projects (AIP), Kyoto 606-8507, Japan \\ ${ }^{12}$ Lead contact \\ *Correspondence: y.takashima@cira.kyoto-u.ac.jp \\ https://doi.org/10.1016/j.stem.2021.03.013
}

\section{SUMMARY}

Trophoblasts are extraembryonic cells that are essential for maintaining pregnancy. Human trophoblasts arise from the morula as trophectoderm (TE), which, after implantation, differentiates into cytotrophoblasts (CTs), syncytiotrophoblasts (STs), and extravillous trophoblasts (EVTs), composing the placenta. Here we show that naïve, but not primed, human pluripotent stem cells (PSCs) recapitulate trophoblast development. Naive PSC-derived TE and CTs (nCTs) recreated human and monkey TE-to-CT transition. nCTs self-renewed as CT stem cells and had the characteristics of proliferating villous CTs and CTs in the cell column of the first trimester. Notably, although primed PSCs differentiated into trophoblast-like cells (BMP4, A83-01, and PD173074 [BAP]-treated primed PSCs [pBAPs]), pBAPs were distinct from nCTs and human placentaderived CT stem cells, exhibiting properties consistent with the amnion. Our findings establish an authentic paradigm for human trophoblast development, demonstrating the invaluable properties of naive human PSCs. Our system provides a platform to study the molecular mechanisms underlying trophoblast development and related diseases.

\section{INTRODUCTION}

Trophoblasts compose the placenta and are essential extraembryonic cells from blastocyst through birth. Abnormal differentiation of trophoblasts during early pregnancy is thought to cause placenta-related complications (Burton and Jauniaux, 2017; Malhotra et al., 2016). However, it is difficult to analyze trophoblasts in the human uterus, especially during the first few weeks after implantation, because of technical difficulties and ethics restrictions.

Trophoblast development and physiology have been described based on mice, and early lethality (embryonic days 9.5 (E9.5)-14.5) in knockout lines is frequently associated with severe placental malformation (Perez-Garcia et al., 2018). However, human and mouse placentation differ in many ways. Fibroblast growth factor receptor 2 (FGFR2) is expressed in mouse tro- phectoderm (TE) of blastocysts, whereas FGFR1, FGFR2, and FGFR3 are not expressed in human TE (Kunath et al., 2014). Trophoblast stem (TS) cells cultured in FGF4 have been established in mice (Tanaka et al., 1998) and used to investigate trophoblast gene functions (Kuckenberg et al., 2010; Nishioka et al., 2009; Niwa et al., 2005; Perez-Garcia et al., 2018; Senner and Hemberger, 2010), but in humans, TS cells cannot be established in FGF4 (Kunath et al., 2014). In 2018, several groups reported successful culturing of trophoblasts from 5- to 9-week human placentas or blastocysts for long periods in vitro as twodimensional TS cells or three-dimensional trophoblast organoids (Haider et al., 2018; Okae et al., 2018; Turco et al., 2018). However, whether these cell lines resemble early-stage trophoblasts during peri-implantation development has not been confirmed.

Another approach to study early trophoblast development is to employ pluripotent stem cells (PSCs). Primed human PSCs 
A

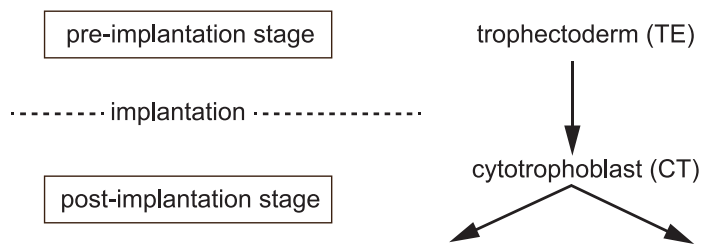

syncytiotrophoblast extravillous trophoblast

(ST)
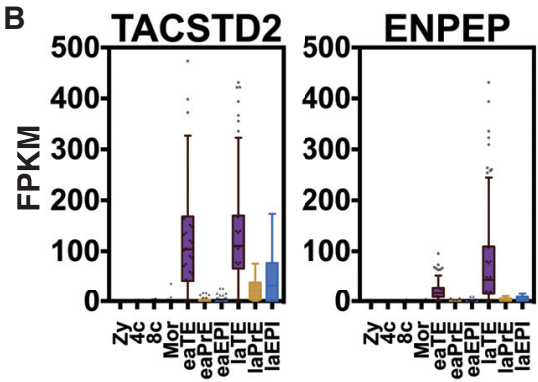

C

D

E
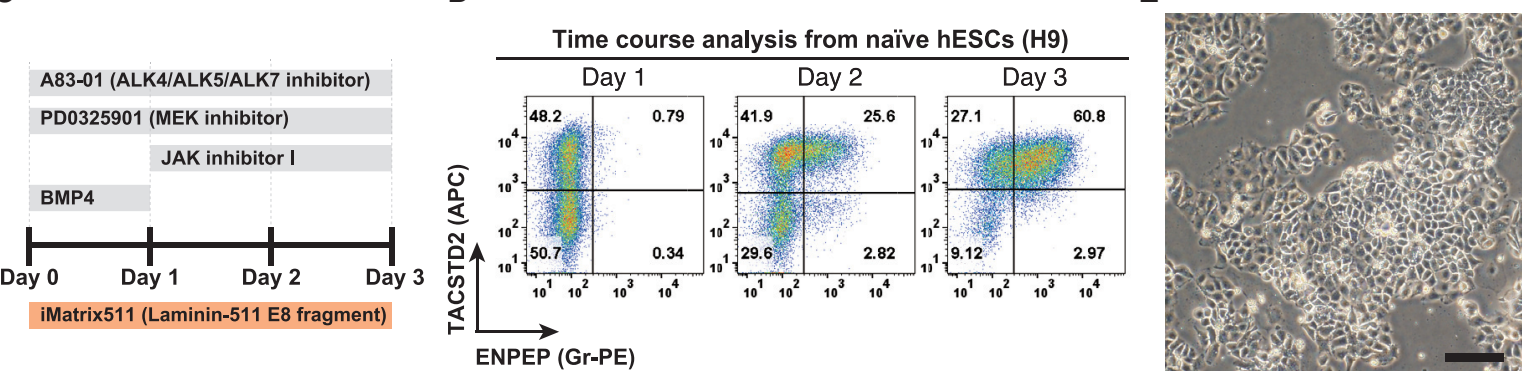

$\mathbf{F}$
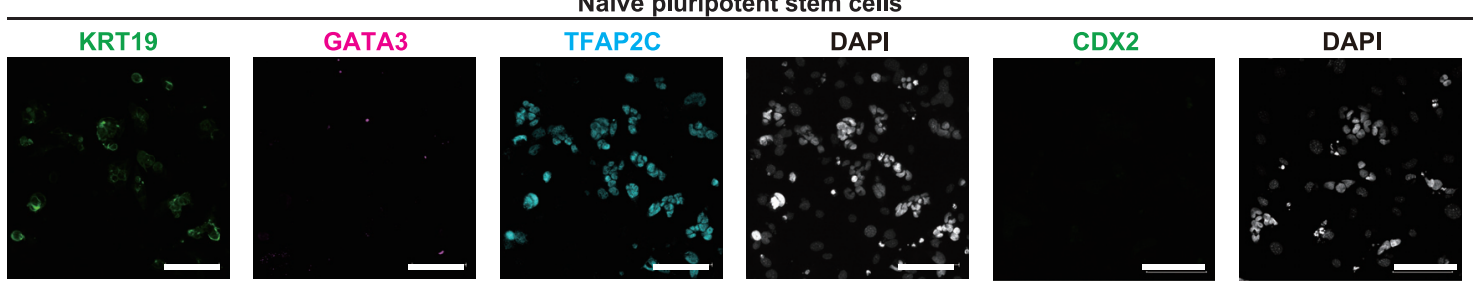

Day 3 of differentiation induction
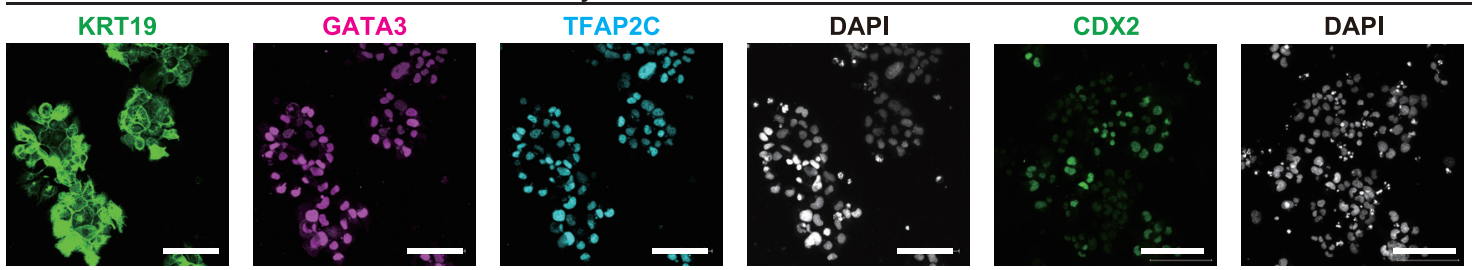

G

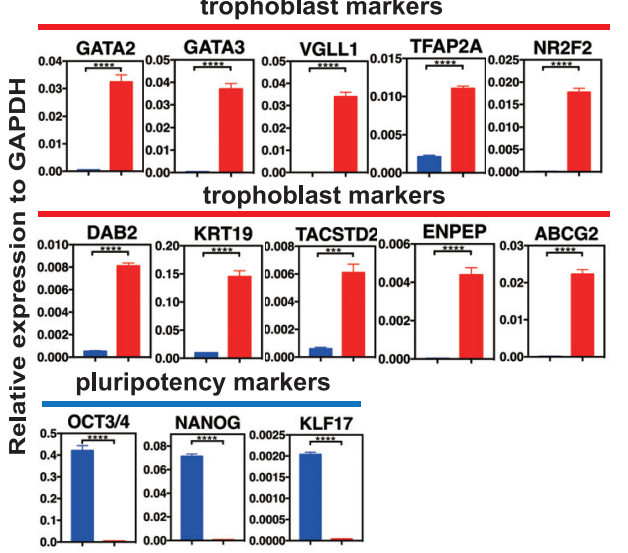

H

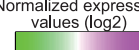

\begin{tabular}{llll}
-2 & -1 & 0 & 1 \\
\hline
\end{tabular}

Naive_Ex1

Naive_Ex2 nTE D1 Ex1 nTE_D1_Ex2 nTE_D2_Ex1 nTE_D2_Ex2 nTE_D3 Ex1 nTE_D3_Ex2

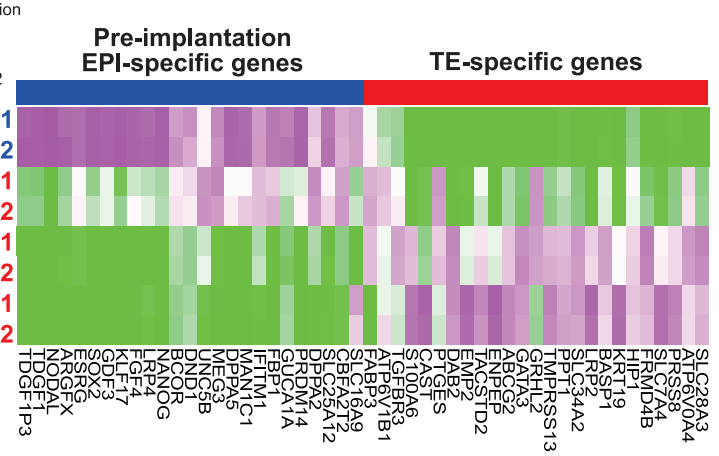


have been induced to trophoblast lineages by bone morphogenetic protein 4 (BMP4) (Xu et al., 2002). Subsequently, trophoblast-like cells have been generated with cocktails of BMP4, the ALK4/5/7 inhibitor A83-01, and the FGFR inhibitor PD173074 (BAP medium) (Amita et al., 2013; Yang et al., 2015). However, primed PSC-derived cells differed in human leukocyte antigen (HLA) class I and epigenetic properties from in vivo trophoblasts (Bernardo et al., 2011). Human trophoblast-like cells have also been reportedly generated from expanded potential stem cells (EPSCs) (Gao et al., 2019).

Recently, naive human PSCs were established. These cells have gene expression patterns consistent with human pre-implantation epiblast (EPI) and naive mouse PSCs, representing an earlier stage than conventional primed PSCs (Guo et al., 2016; Stirparo et al., 2018; Takashima et al., 2014; Theunissen et al., 2014). Although human trophoblasts arise from the morula as TE, single-cell RNA sequencing (scRNA-seq) data suggest that the fate determination of human cells might be late (Meistermann et al., 2019; Petropoulos et al., 2016). There are reports showing that naive human PSCs can differentiate into TS cells (Castel et al., 2020; Cinkornpumin et al., 2020; Dong et al., 2020). However, because TE, which is the starting point for trophoblast development from pre-implantation, was not identified, the process of trophoblast development from the pre-implantation stage and the in vivo identity of human TS cells remain unclear.

In the present study, we induced TE from naive human PSCs to establish an in vitro model of the trophoblast lineage. Naive PSC-derived TE differentiated successfully into cytotrophoblasts (CTs), which had a similar character as trophoblasts of cynomolgus monkey (Macaca fascicularis) embryos in vivo, trophoblasts of cultured human embryos, and placenta-derived TS cells. Furthermore, our analysis unveiled the counterpart of in vitro human TS cells as some parts of villous CTs (VCTs) and CTs in cell columns (CCCs) of in vivo first-trimester placenta. Finally, using this model, we investigated trophoblast development from TE to CTs during peri-implantation stages.

\section{RESULTS}

Derivation of TE-like cells from naive human PSCs Human trophoblasts arise from the morula as TE. After implantation, TE differentiates into CTs, syncytiotrophoblasts (STs), and extravillous trophoblasts (EVTs) (Figure 1A). We investigated whether naive human PSCs could differentiate into TE (Figures S1A and S1B). Using previously reported scRNA-seq data (Petropoulos et al., 2016; Stirparo et al., 2018), we identified TACSTD2 and ENPEP as cell surface marker genes of TE in pre-implantation human blastocysts (Figure 1B). TACSTD2 is expressed in TE of early (E5) and late blastocysts (E7), whereas EN$P E P$ expression is increased in TE of late blastocysts. Next we analyzed signaling receptors and inferred the necessary signaling pathways to develop an appropriate TE induction medium. We examined Nodal, FGF, Janus kinases (JAK)/ signal transducer and activator of transcription proteins (STAT), and BMP signaling receptors because these are known to be related to early development in mice and humans. Expression was evaluated by fragments per kilobase of transcript per million mapped reads (FPKM) and $F$ values (Figure $S 1 C$ ). The genes with the highest $\mathrm{F}$ value in each signaling pathway were $A C V R 1 B$, FGFR1, IL6R, and TGFBR3. TGFBR3 was highly expressed in TE of human embryos (Stirparo et al., 2018; Table S1), but ACVR1B, FGFR1, and IL6R were not expressed (Figure S1D). FGFR2, the receptor for FGF4, which is important for mouse TS cell induction (Kunath et al., 2014), was not expressed. These receptors exhibited similar patterns in cynomolgus monkey TE but not in mouse TE (Figures S1E and S1F; Nakamura et al., 2015, 2016).

Based on the above findings and previous reports (Amita et al., 2013; Cinkornpumin et al., 2020; Dong et al., 2020; Okae et al., 2018), we cultured naive human PSCs in a cocktail of A83-01, PD0325901 (PD03; a MEK inhibitor), JAK inhibitor I, and BMP4 for TE induction. Combinations of these factors partially upregulated trophoblast genes (Figure S1G). To optimize the four factors, we performed screening (Figure S1H-S1J; Table S2). The condition shown in Figure $1 \mathrm{C}$ induced TACSTD2 ${ }^{+}$ENPEP $^{+}$ cells most efficiently (Figure S1J). Under this condition, TACSTD $^{+}{ }^{+}$NPEP $^{-}$cells were observed on days 1 and 2 , and around $60 \%$ of TACSTD2 ${ }^{+}$ENPEP $^{+}$cells were induced on day 3 (Figure 1D). Cell morphology on day 3 was polygonal and flat, whereas tightly packed three-dimensional colonies of naive PSCs were not seen (Figures $1 \mathrm{E}$ and S1A). TE marker proteins were expressed on day 3 (Figure 1F; Blakeley et al., 2015; Chen et al., 2009). We sorted TACSTD2 ${ }^{+}$ENPEP $^{+}$cells on day 3 by flow cytometry and confirmed that TACSTD $2^{+}$ENPEP $^{+}$cells expressed trophoblast markers, whereas expression of pluripotent genes was decreased (Figure 1G). The top 25 EPI-specific genes (Petropoulos et al., 2016) were highly expressed in naive

Figure 1. Derivation of TE-like cells from naive human PSCs

(A) Schematic of trophoblast development. Trophectoderm (TE) in pre-implantation embryos differentiates into cytotrophoblasts (CTs) after implantation. Postimplantation CTs differentiate into syncytiotrophoblasts (STs) and extravillous trophoblasts (EVTs).

(B) Expression in FPKM (fragments per kilobase of transcript per million mapped reads) values of TACSTD2 and ENPEP (CD249) for human embryos (embryonic days 1 [E1]-E7). Zy, zygote; 4c, 4 cells; 8c, 8 cells; Mor, morula; eaTE, early TE (E5); eaPrE, early primitive endoderm (PrE; E5); eaEPI, early epiblast (EPI; E5); laTE, late TE (E7); laPrE, late PrE (E7); laEPI, late EPI (E7). Previously reported single-cell RNA-sequencing (scRNA-seq) data were reanalyzed (Stirparo et al., 2018). (C) Schematic of the TE induction protocol from naive human pluripotent stem cells (PSCs). Naive human PSCs were seeded on Laminin-511 E8 in serum-free medium (N2B27) with $2 \mu \mathrm{M}$ A83-01 (an ALK4/ALK5/ALK7 inhibitor), $2 \mu \mathrm{M}$ PD03 (a MEK inhibitor), $1 \mu \mathrm{M}$ Janus kinases inhibitor 1 (JAKi), and 10 ng/mL BMP4. (D) Flow cytometry analysis of naive human PSCs after TE induction.

(E) Bright image of naive PSC-derived cells on day 3 after TE induction. $n=10$. Scale bar, $100 \mu \mathrm{m}$.

(F) Immunofluorescence images of trophoblast markers in naive PSCs and naive PSC-derived cells on day 3 after TE induction. $n=3$. Scale bars, $100 \mu m$.

(G) qRT-PCR analysis for trophoblast genes in naive PSCs and naive PSC-derived TACSTD2 ${ }^{+} E N P E P{ }^{+}$cells on day $3 . n=3 .{ }^{* \star * \star} p \leq 0.0001 ;{ }^{\star \star *} p \leq 0.001$.

(H) Relative gene expression dynamics during TE induction. The top 25 EPI- and TE-specific genes were measured by RNA-seq. Human EPI- and TE-specific genes were identified previously (Petropoulos et al., 2016). Naive, naive PSCs; nTEs_D1 and nTEs_D2, naive PSC-derived TACSTD2 ${ }^{+}$ENPEP ${ }^{-}$cells on days 1 and 2, respectively; nTEs_D3, TACSTD2 ${ }^{+}$ENPEP $^{+}$cells on day 3; Ex1 and Ex2, samples 1 and 2, respectively. 
A

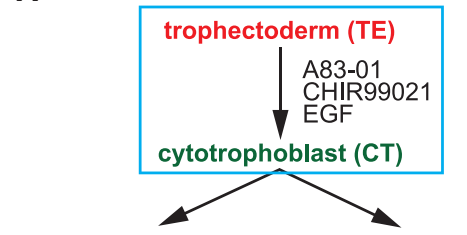

syncytiotrophoblast extravillous trophoblast (ST)

(EVT)

D

$\mathbf{F}$

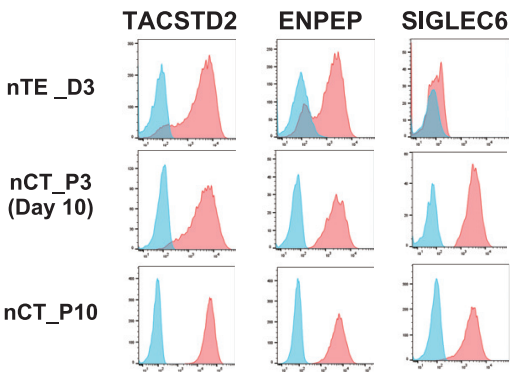

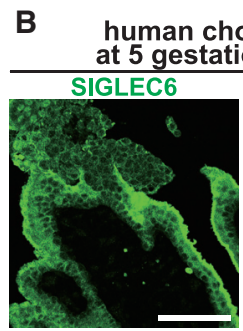

E
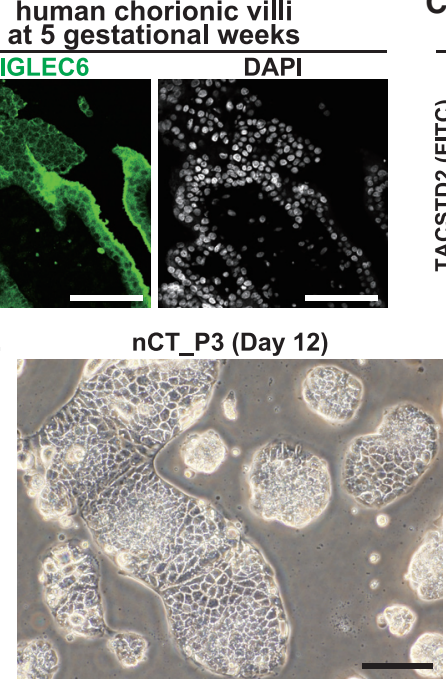
trophoblast markers

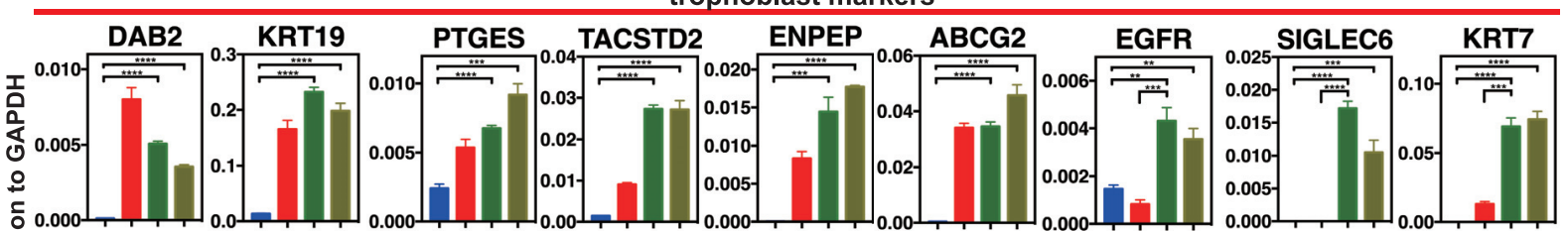

trophoblast markers

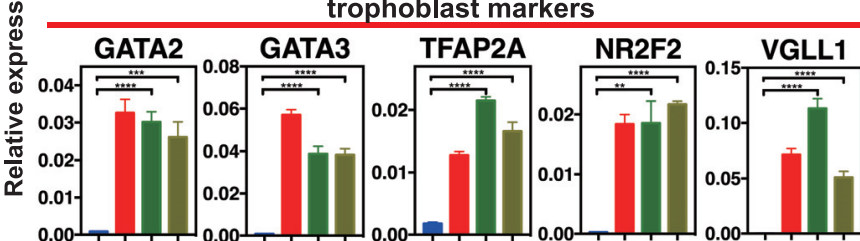

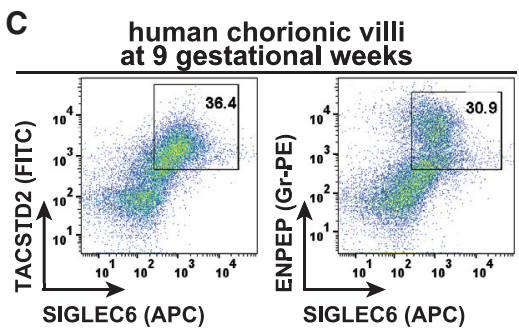

nCT_P15 (Day 45)

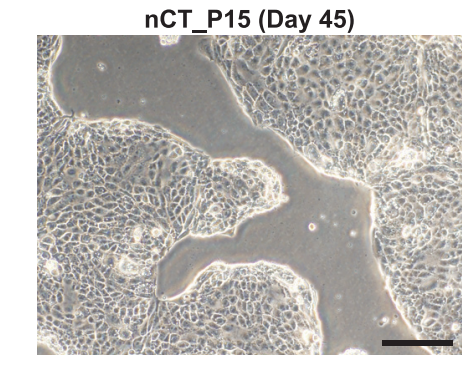

G
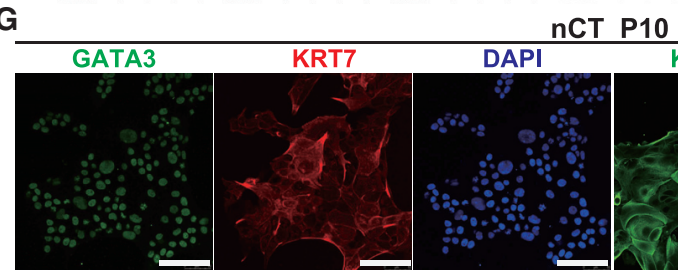

nCT P10
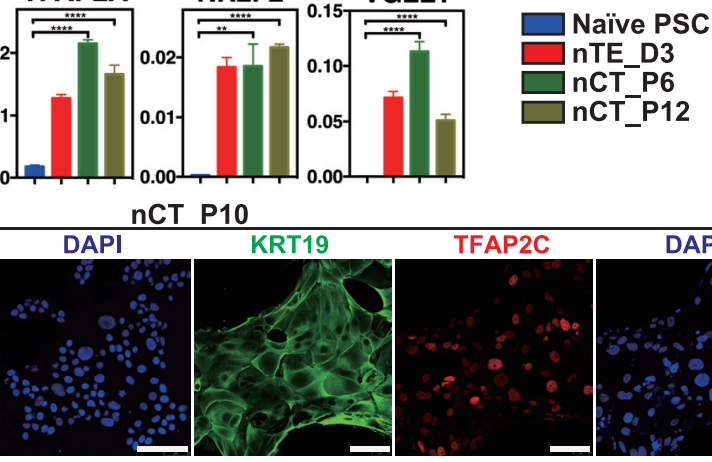

H
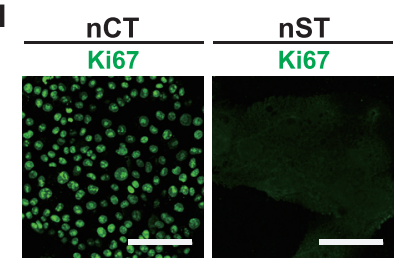

I

human chorionic vill
at 5 gestational week

human chorionic villi
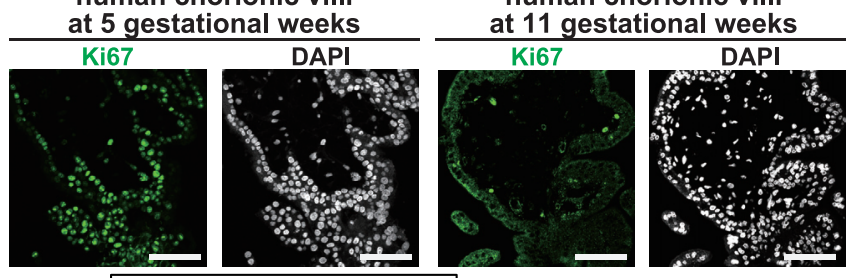

$\mathbf{J}$
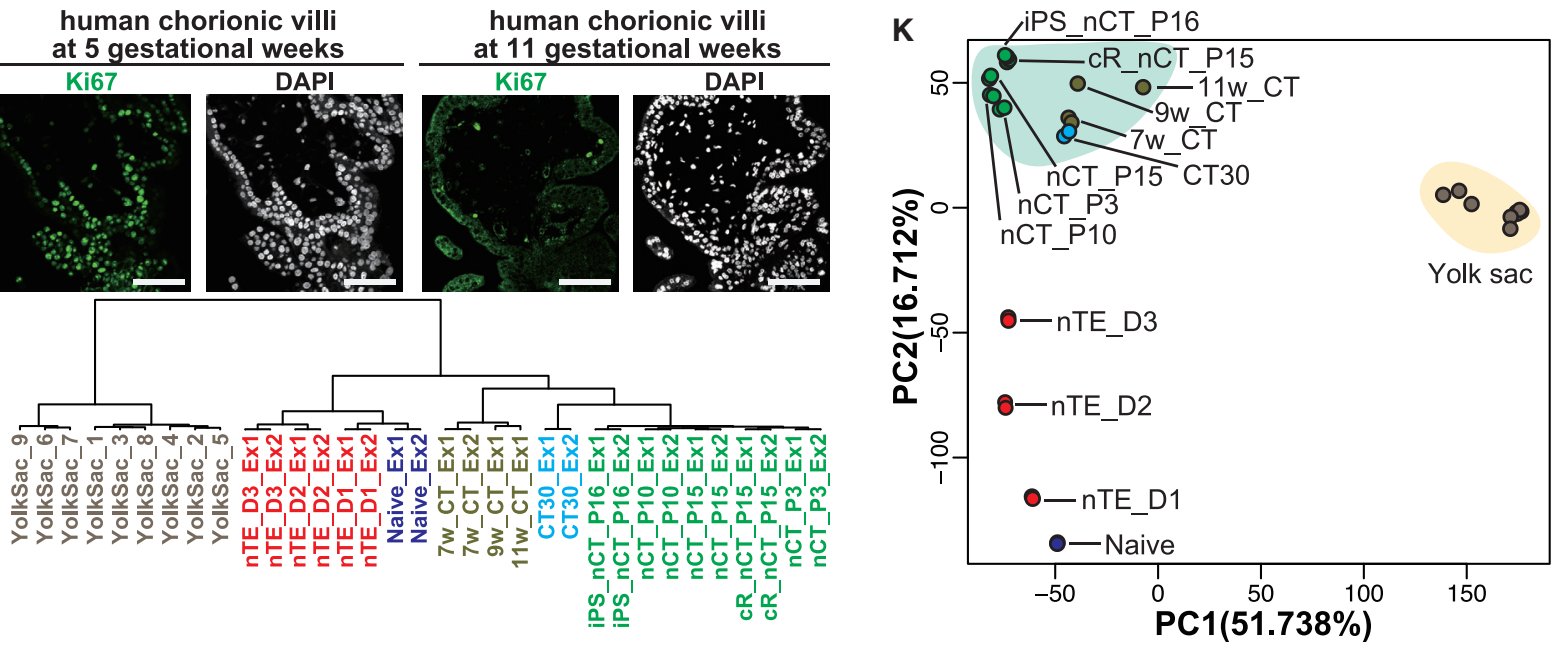

(legend on next page) 
PSCs, but expression declined with differentiation (Figure $1 \mathrm{H}$; Table S3). Expression of almost all TE-specific genes was increased on days 2 and $3($ Figure $1 \mathrm{H})$, suggesting that naive PSCs could differentiate into TE-like cells (nTEs). We confirmed downregulation of phosphorylated (p)SMAD2 under A83-01, of pERK1/2 under PD03, and of pSTAT3 under JAKi and transient upregulation of SMAD1/5 under BMP4 (Figure S1K). Furthermore, upregulation or downregulation of downstream genes in each signaling pathway suggested that these factors worked functionally under our condition (Figure S1L).

TACSTD2 $^{+}$ENPEP $^{+}$cells were induced in three naive human embryonic stem cell (ESC)/induced pluripotent stem cell (iPSC) lines (H9 ESCs, 409B2 iPSCs, and adipose-derived iPS cells (AdiPS cells)) established by two different naive induction procedures (chemical reset and 5i/L/A) (Figure S1M; Guo et al., 2017; Theunissen et al., 2014). PD03 could be replaced with an FGFR inhibitor, PD173074 (Figure S1N).

Naive PSC-derived TE differentiates into CTs We analyzed whether nTEs differentiate into post-implantation CTs (Figure 2A). TACSTD2 and ENPEP were expressed in CTs at 5 gestational weeks (Figure S2A). SIGLEC6, which has been reported to be expressed in trophoblasts of early pregnancy (Rumer et al., 2012), was detected in CTs (CCCs and VCTs) and STs at 5 gestational weeks (Figure 2B) but not in TE (Figure S2B). Flow cytometry confirmed that first-trimester placentas ( 9 and 11 gestational weeks) and the placenta-derived TS cell line CT30 (Okae et al., 2018) expressed TACSTD2, ENPEP, and SIGLEC6 (Figure 2C, S2C, and S2D). Expression of mouse Tacstd2, Enpep, and Siglec5 (the mouse ortholog for human SIGLEC6) was conserved in mouse pre-implantation TE (Figure S2E). We thus chose to use these three genes as markers for CTs. As expected, nTEs on day 3 were SIGLEC6 ${ }^{-}$(Figure 2D).

To determine the induction condition from TE to CTs, we observed protein expression and signaling transduction in human chorionic villi (7 gestational weeks) (Figure S2F). Consistent with previous studies (Haider et al., 2018; Okae et al., 2018; Turco et al., 2018), non-phosphorylated $\beta$-catenin was localized in the cell membrane of CCCs and VCTs, suggesting that Wnt is active. The pEGF receptor was strongly expressed in the cell membranes of CCCs, VCTs, and STs, whereas pSMAD2 was not accumulated in the nuclei of CCCs, VCTs, or STs (Figure S2G). We therefore cultured nTEs on day 3 in A83-01,
CHIR99021, and epidermal growth factor (EGF) (ACE) (Figure 2A). In ACE, nTEs differentiated into TACSTD2 ${ }^{+}$, ENPEP ${ }^{+}$, and SIGLEC6 ${ }^{+}$CT-like cells (naive CTs [nCTs]) on day 10 (Figure 2D). TACSTD2 ${ }^{+}$ENPEP ${ }^{+}$SIGLEC6 ${ }^{+}$cells were sorted on day 10 and continued to be cultured in ACE. nCTs continuously expressed TACSTD2, ENPEP, and SIGLEC6 (Figure 2D), and the morphology of nCTs was maintained for more than 10 passages and resembled that of placenta-derived TS cells (Figure 2E). Their chromosomes were normal (Figure S2H). nCTs expressed trophoblast markers over 10 passages (Figures $2 \mathrm{~F}$ and $2 \mathrm{G}$ ) and could be maintained for more than 35 passages and over 75 days like CT stem cells (Figure S2I; Video S1). In previous reports, Ki67 was expressed in CTs (Chang and Parast, 2017; Mühlhauser et al., 1993). Almost all nCTs expressed Ki67 (Figure $2 \mathrm{H}$ ). Interestingly, CCCs and some VCTs of human chorionic villi expressed Ki67 at 5 gestational weeks, but the number of $\mathrm{Ki} 67^{+}$cells decreased by 9 gestational weeks and had almost disappeared at 11 gestational weeks, indicating that our nCTs correspond to the early stage of CCCs and VCTs (Figures $2 \mathrm{I}$ and $\mathrm{S} 2 \mathrm{~J}$ ). We also tested each counteracting signaling molecule of ACE compounds. Activin A, XAV939, and gefitinib (an EGF receptor tyrosine kinase inhibitor) each reduced cell growth and viability (Figure S2K), indicating that all three ACE compounds are necessary to maintain nCTs.

Furthermore, TACSTD2 ${ }^{+}$ENPEP ${ }^{+}$SIGLEC ${ }^{+}$cells of placental chorionic villi at 7 and 9 gestational weeks were sorted and cultured in ACE (Figure S3A). Chorionic villus-derived (7 and 9 gestational weeks) CT cells (cCTs) cultured in ACE for more than 10 passages had a similar morphology as $\mathrm{nCT}$ s and TS cells (Figures S3A and S3B). cCTs expressed CT markers similarly as nCTs after 10 passages (Figures S3C and S3D) and were karyotypically stable (Figure S3E). cCTs differentiated into ST-like cells in forskolin (Figures S3F-S3H) and into EVT-like cells in A83-01 and Neuregulin-1 with Geltrex (Figures S3I and S3J).

Next we analyzed the global transcriptome of nTEs; nCTs; TACSTD2 $^{+}$ENPEP $^{+}$SIGLEC $^{+}$placental chorionic villi at 7, 9, and 11 gestational weeks; and CT30 cells, which we cultured under a condition reported previously (human TS condition, SAVECY) (Okae et al., 2018), and also the published RNA-seq data of first-trimester human yolk sacs (Cindrova-Davies et al., 2017). Unbiased hierarchical clustering (UHC) suggested that nCTs, CT30 cells, and placental chorionic villi have more similar gene expression profiles than nTEs and naive PSCs, which

Figure 2. Naive PSC-derived TE differentiates into CTs

(A) Schematic of human trophoblast lineages. nTEs were differentiated into nCTs (nTE-derived CTs) in A83-01, CHIR99021, and EGF (ACE) medium.

(B) Immunofluorescence images for SIGLEC6 on human chorionic villi at 5 gestational weeks. Scale bars, $100 \mu \mathrm{m}$. $\mathrm{n}=3$.

(C) Flow cytometry analysis for TACSTD2, ENPEP, and SIGLEC6 on human chorionic villi (9 gestational weeks).

(D) Flow cytometry analysis for TACSTD2, ENPEP, and SIGLEC6 during differentiation from nTEs to $n C T s . n=6$.

(E) Representative bright images of $n C T s$ at passages 3 (left) and 15 (right). Scale bars, $100 \mu \mathrm{m} . \mathrm{n}=10$.

(F) qRT-PCR analysis for trophoblast markers. $n=3 .{ }^{* \star \star *} p \leq 0.0001 ;{ }^{* \star *} p \leq 0.001 ;{ }^{* \star} p \leq 0.01$.

(G) Immunofluorescence images of nCTs for the trophoblast markers. Scale bars, $100 \mu \mathrm{m} . \mathrm{n}=3$.

(H) Immunofluorescence images of $\mathrm{nCT}$ s and $\mathrm{nST}$ for the proliferation marker Ki67. Scale bars, $100 \mu \mathrm{m}$. $\mathrm{n}=3$.

(I) Immunofluorescence images of first-trimester chorionic villi for the proliferation marker Ki67. Ki67 was expressed in the nuclei of CCCs and VCTs at 5 gestational weeks. Scale bars, $100 \mu \mathrm{m} . \mathrm{n}=3$.

(J) Unbiased hierarchical clustering (UHC) of the transcriptomes. Naive, naive PSCs; nTEs_D1 (D2 or D3), 1 (2 or 3) day(s) after induction of naive PSCs; iPS, 409B2; cR, naive PSCs established by chemical resetting medium (Guo et al., 2017); 7w_, 9w_, and 11w_CT, TACSTD ${ }^{+}$ENPEP $^{+}$SIGLEC6 ${ }^{+}$placental chorionic villi at 7, 9, and 11 gestational weeks, respectively; CT30, placenta-derived TS cells established by Okae et al. (2018); yolk sac, 7- to 12-gestational-week samples reported by Cindrova-Davies et al. (2017). Ex1 and Ex2, RNA was collected from samples 1 and 2, respectively.

(K) Principal-component analysis (PCA) of the indicated cell types during TE and CT induction of naive PSCs. Samples are the same as in (J). 
A

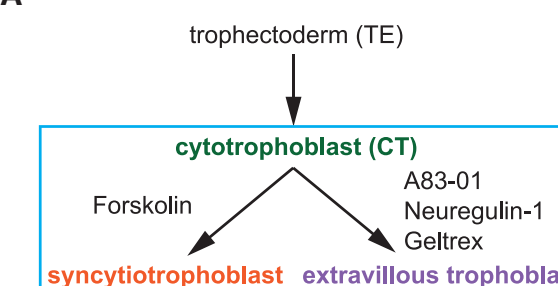

syncytiotrophoblast extravillous trophoblast (ST) (EVT)

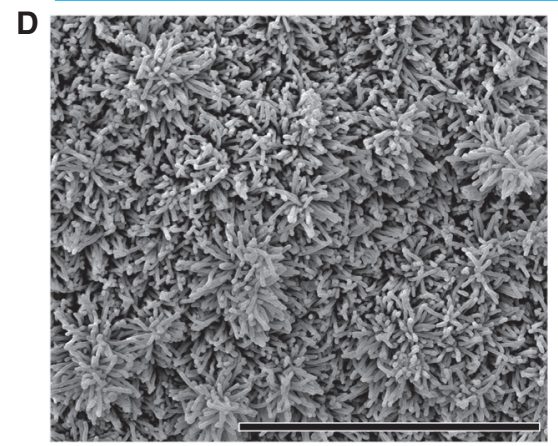

E

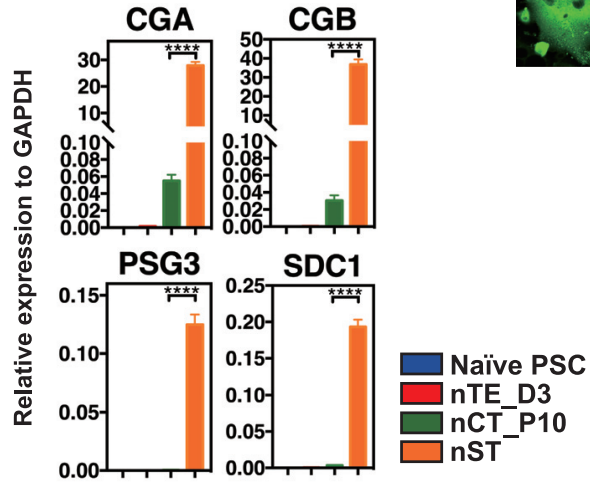

H
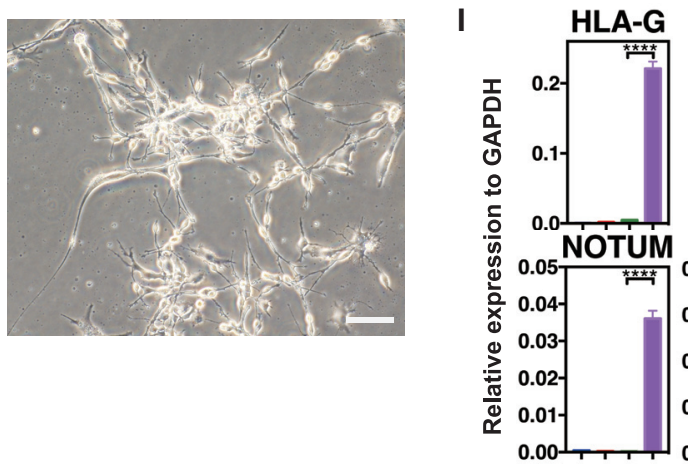

G
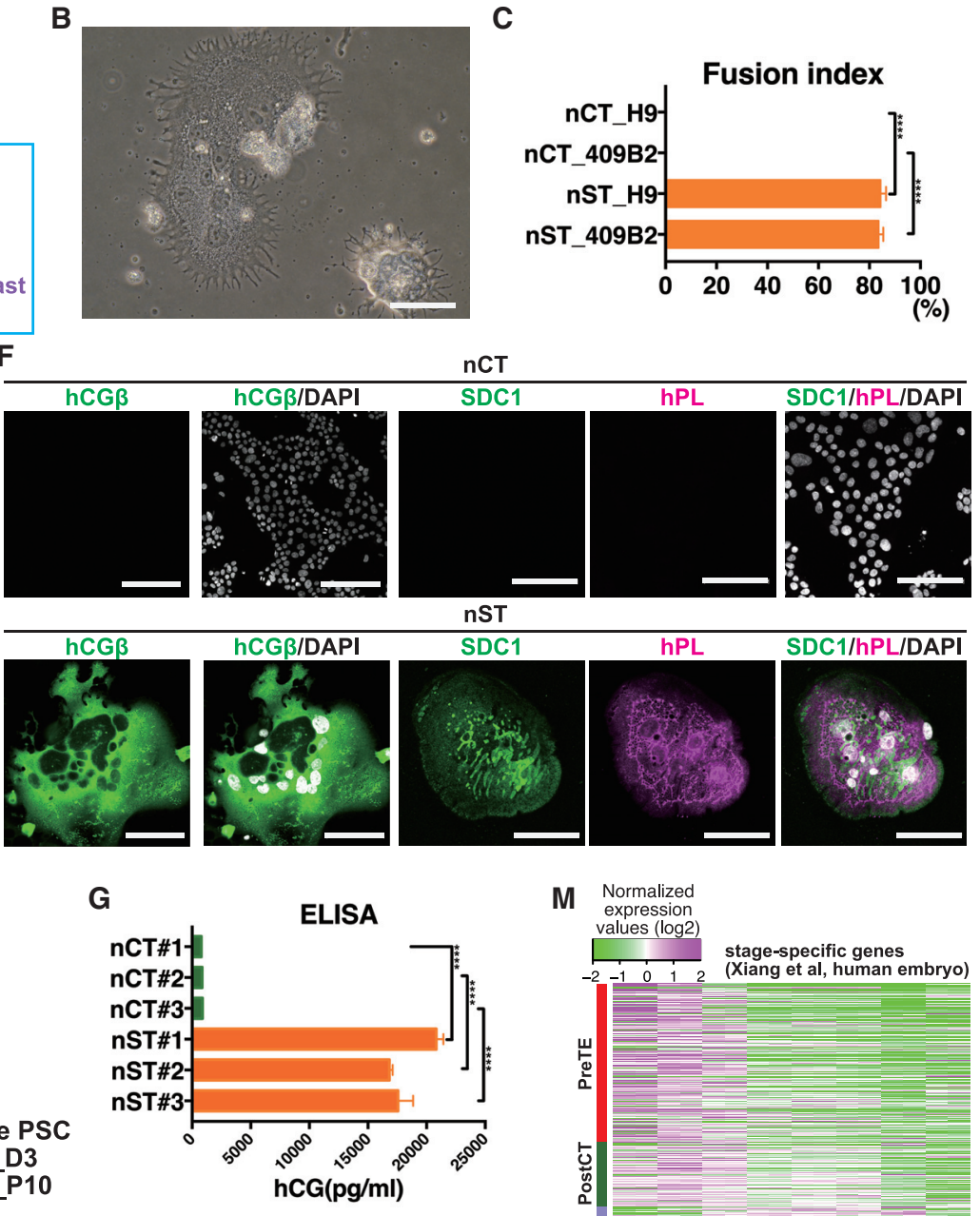

C

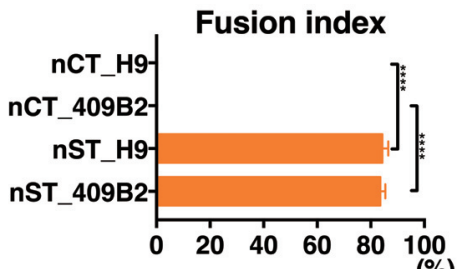

(\%) 
correspond to the pre-implantation developmental stage (Figure 2J). Principal-component analysis (PCA) revealed that various $\mathrm{nCT}$ lines have gene expression patterns similar to CT30 cells and chorionic villi (Figure 2K). nTEs were distant from nCTs and placental chorionic villi.

During differentiation, TE marker genes were downregulated even in TE induction medium (Figure S3K). Monitoring CDX2 expression using CDX2-GFP H9 ESCs (Figure S3L), CDX2GFP $^{+}$cells lost GFP expression after 7 or 10 days in TE induction medium, CT induction medium, or other conditions except for A83-01, CHIR99021, and lysophosphatidic acid (ACL), which was applied for mouse polar-like TS cells (Frias-Aldeguer et al., 2020; Figure S3M). However, half of the sorted cells in ACL lost GFP expression on day 7. Under counteracting signaling molecules in ACE, expression of CDX2-GFP was not maintained, and proliferation of CDX2-GFP ${ }^{+}$cells was reduced (Figures S3N and S3O). Thus, further analysis is required to establish CDX2 ${ }^{+}$ human TE-like stem cells.

We cultured nCTs in suspension (Turco et al., 2018). The morphology of nCT-derived organoids ( $\mathrm{nCT}$ organoids) was similar to that of trophoblast organoids derived from placenta (Figure S4A). nCT organoids were maintained for 2 months and more than 10 passages. $\mathrm{nCT}$ organoids expressed CT and ST markers and were surrounded by ITGA6 ${ }^{+}$CT-like cells, as reported previously (Haider et al., 2018; Okae et al., 2018; Turco et al., 2018; Figures S4B and S4C). These results show that $\mathrm{nCT}$ s could be maintained in the same way as placenta-derived three-dimensional organoids.

\section{nTE-derived CTs differentiate into STs and EVTs}

CTs are the bipotential progenitors of STs and EVTs in vivo. We checked the differentiation capacity of nCTs into STs and EVTs using an induction medium reported previously (Okae et al., 2018; Figure 3A). In forskolin medium, nCTs differentiated into multinucleated syncytia with a tentacular structure on the surface (Figure 3B). This morphology is similar to STs. The fusion index revealed that more than $80 \%$ of the cells were multinucleated nTE-derived ST-like cells (nSTs) (Figure 3C). Scanning electron microscopy showed that nSTs had similar microvilli as in vivo STs (Benirschke et al., 2012; Figure 3D). Several ST genes were upregulated in nSTs (Jokimaa et al., 1998; Figures 3E and 3F). In contrast, Ki67 was not expressed in nSTs, which is consistent with STs at 5 gestational weeks, suggesting that nSTs lost their proliferation ability (Figures $2 \mathrm{H}$ and $2 \mathrm{l}$ ).

nCTs upregulated CT-specific genes and nSTs upregulated ST-specific genes in E12 and E14 cultured human embryos in vitro (Zhou et al., 2019; Figure S4D). Finally, we found that human chorionic gonadotropin (hCG) was secreted from nSTs into the culture medium (Figure 3G).

We also cultured nCTs in EVT induction medium (Figure $3 \mathrm{~A}$ ), yielding EVT-like cells ( $n E V T s$ ). The morphology of nEVT was spindle-shape (Figure $3 \mathrm{H}$ ). nCT organoids also changed their morphology like EVT (Video S2). nEVT expressed EVT-related genes (Figure 3l). HLA-G is a marker of EVTs and is presumed to contribute to the immune tolerance of EVTs (Hunt et al., 2005). Indeed, HLA-G expression was detected in nEVTs (Figures $3 \mathrm{~J}$ and $3 \mathrm{~K}$ ). Co-culture with decidual natural killer (NK) cells showed that nCTs were killed after cytolysis but that nEVTs survived (Figure $3 \mathrm{~L}$ ), indicating immune tolerance of nEVTs.

Next we compared the gene expression patterns of nTEs, nCTs, nSTs, and nEVTs with in-vitro-cultured human embryos beyond implantation (Xiang et al., 2020). nTE_D1-3 expressed preTE-specific genes, nCTs downregulated preTE-specific genes, nEVTs upregulated EVT-specific genes, and nSTs expressed ST-specific genes (Figure 3M; Table S3). Furthermore, comparison of our cells with first-trimester CTs, STs, and EVTs (Vento-Tormo et al., 2018) showed that nCTs expressed CT marker genes. After differentiation, nSTs and nEVTs increased expression of ST and EVT genes, respectively (Figure S4E).

These data showed that nTEs could differentiate into a CT lineage that had a similar gene expression profile as post-implantation CTs and first-trimester CTs. We also observed that nCTs differentiated into STs and EVTs, even after more than 30 passages (Figures S4F and S4G).

\section{Primed PSC-derived TACSTD2 ${ }^{+}$ENPEP $^{+}$cells do not satisfy trophoblast criteria \\ Primed human PSCs, which corresponded to post-implantation EPI (Nakamura et al., 2016; Figures S5A and S5B; Table S3), have been reported to differentiate into trophoblast-like cells in BAP medium (Amita et al., 2013; Yang et al., 2015; Figure 4A). Indeed, in BAP medium, primed PSCs expressed TACSTD2 and ENPEP on days 2 and 3 (Figures $4 \mathrm{~B}$ and $4 \mathrm{C}$ ).}

Figure 3. nCTs differentiate into STs and EVTs

(A) Schematic of ST and EVT induction. nCTs were maintained in ACE medium. nCT-derived STs (nSTs) were induced in forskolin for 6 days. nCT-derived EVTs (nEVTs) were induced in A83-01, Neuregulin-1, and Geltrex for 8 days.

(B) Bright image of nSTs. $n=10$. Scale bar, $100 \mu \mathrm{m}$.

(C) Fusion efficiency of nSTs. H9 ESC- and 409B2 iPSC-derived nSTs were analyzed. Mean + SD $(n=3) .{ }^{\star \star \star *} p \leq 0.0001$.

(D) Scanning electron microscopy image of nSTs. Microvilli cover the $n S T$ surface. Scale bar, $10 \mu \mathrm{m}$. $\mathrm{n}=3$.

(E) qRT-PCR analysis for ST marker genes. $n=3$. ${ }^{\star \star \star *} p \leq 0.0001$.

(F) Immunofluorescence images of nCTs and nSTs. nSTs are multinuclear. Nuclei are shown in white. Scale bars, $100 \mu \mathrm{m}$. $\mathrm{n}=3$.

(G) Secretion of human chorionic gonadotropin (hCG) from nCTs and nSTs. Mean + SD $n=3 .{ }^{* \star \star} p \leq 0.0001$.

(H) Bright image of nEVTs. Scale bar, $100 \mu \mathrm{m} . \mathrm{n}=10$.

(I) qRT-PCR analysis for EVT marker genes. $n=3$. ${ }^{* \star \star *} \mathrm{p} \leq 0.0001$; ${ }^{\star \star \star} \mathrm{p} \leq 0.001$.

(J) Immunostaining of nEVTs. Scale bar, $100 \mu \mathrm{m} . \mathrm{n}=3$.

(K) Flow cytometry analysis of Human leukocyte antigen (HLA)-G in nCTs and nEVTs. $n=3$.

(L) Killing assays for immunotolerance. nCTs showed significant cytolysis mediated by decidual NK cells of 6-gestational-week placenta. nEVTs could evade NK cell immunity. Mean $\pm \operatorname{SEM}(n=3)$. ${ }^{*} \mathrm{p} \leq 0.05$.

(M) Relative gene expression of stage-specific genes defined by cultured human embryos (Xiang et al., 2020). PreTE, pre-implantation TE; PostCT, post-implantation CT. 
A

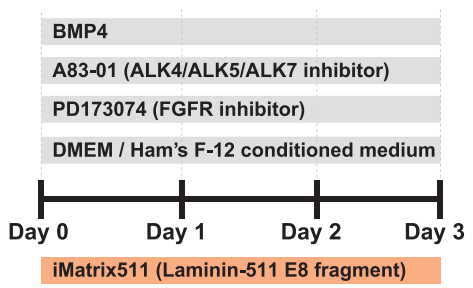

。

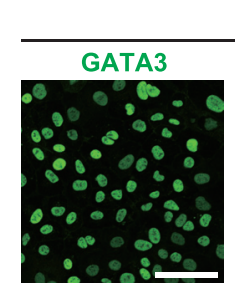

KRT19

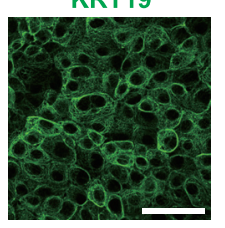

TFAP2C

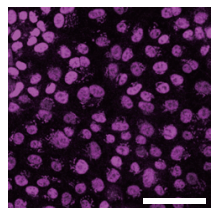

B

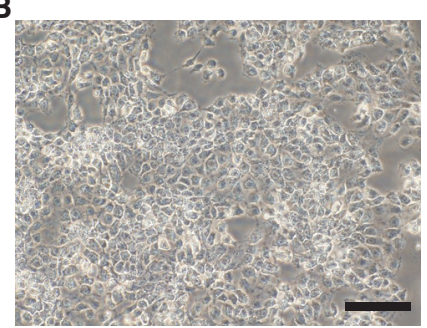

C

C Time course analysis from primed hESCs (H9)

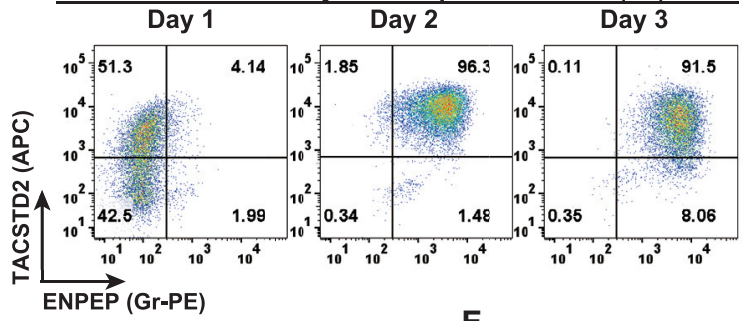

E pBAP in ACE_P10
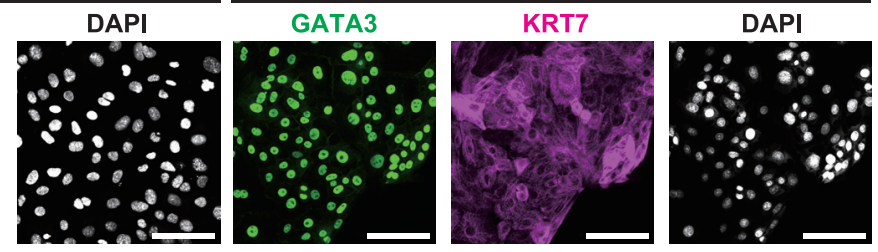

DAPI

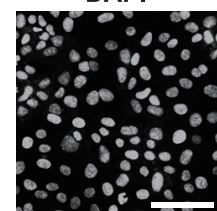

KRT19
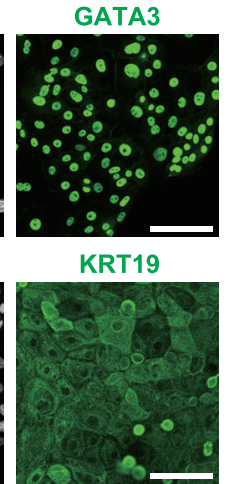

TFAP2C

DAPI
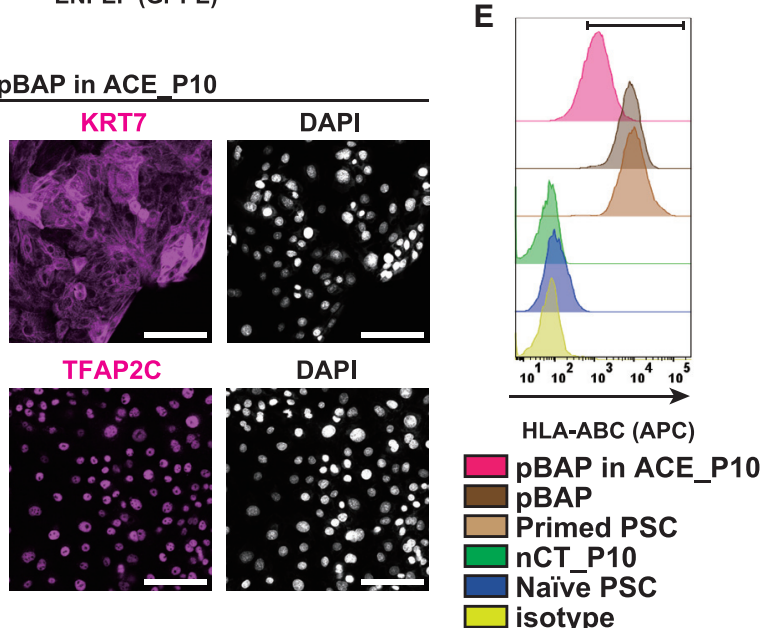

$\mathbf{F}$

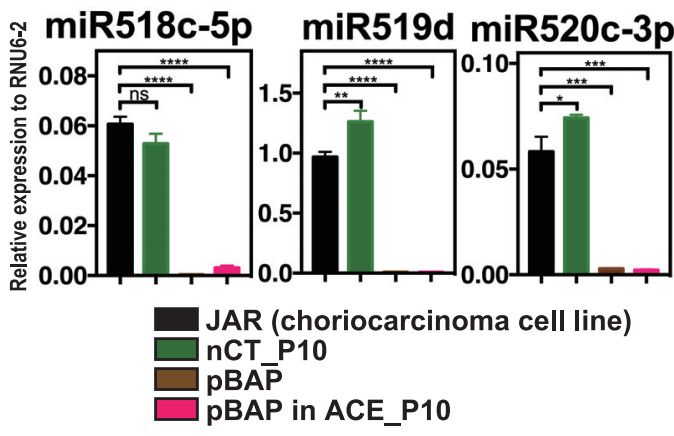

$\mathrm{G}_{\text {ELF5 }}$

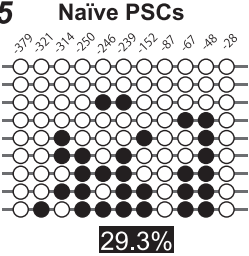

Primed PSCs

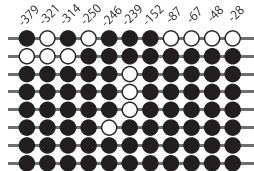

$85.2 \%$

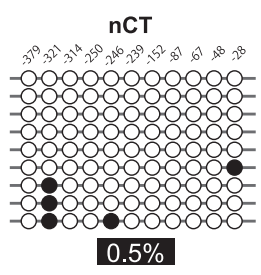

pBAP

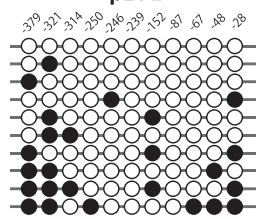

$22.7 \%$

H

first trimester trophoblast criteria

\begin{tabular}{|l|c|c|c|}
\hline & $\begin{array}{c}\text { chorionic villi } \\
\text {-derived } \\
\text { cytotrophoblast } \\
\text { stem cells (cCT) }\end{array}$ & $\begin{array}{c}\text { naive TE } \\
\text {-derived } \\
\text { cytotrophoblast } \\
\text { stem cells (nCT) }\end{array}$ & $\begin{array}{c}\text { BAP-treated } \\
\text { primed } \\
\text { pluripotent stem } \\
\text { cells (pBAP) }\end{array}$ \\
\hline HLA-class I & match & match & mismatch \\
\hline C19MC miRNA expression & match & match & mismatch \\
\hline Demethylation of ELF5 promoter & match & match & match \\
\hline protein expression of GATA3, TFAP2C, KRT7 & match & match & match \\
\hline
\end{tabular}


However, BAP-treated primed PSCs (pBAPs) differ from primary trophoblast cells (Bernardo et al., 2011). We evaluated in vitro cultured trophoblast cells according to four criteria for human first-trimester trophoblasts determined by primary trophoblast cells (Lee et al., 2016). pBAPs expressed trophoblast markers (Figure 4D) and could be cultured in ACE medium for 10 passages (Figure S5C). Even after 10 passages, pBAPs in ACE medium continuously expressed these genes (Figures $2 \mathrm{G}$ and 4D). Another criterion is no expression of HLA class I (Faulk and Temple, 1976; Goodfellow et al., 1976; Kawata et al., 1984). $H L A-A$ and $-B$ were not expressed in TE in embryos (Figure S5D). We also confirmed that SIGLEC6 ${ }^{+}$chorionic villi at 5 gestational weeks did not express HLA-ABC (Figure S5E). nCTs did not express HLA-ABC but pBAPs did (Figure 4E). Regarding expression of chromosome 19 microRNA (miRNA) cluster (C19MC) miRNA, nCTs showed a similar level of expression as the choriocarcinoma cell line JAR but pBAPs did not (Figure 4F). Finally, $\mathrm{nCT}$ and pBAPs showed demethylation of the ELF5 promoter region (Figure 4G). Even after 10 passages, pBAPs in ACE medium showed the same expression patterns as HLA-ABC and C19MC as pBAPs on day 3 (Figures 4E and 4F).

Further analysis revealed that our CCTs in ACE medium (Figure S3D) fulfilled all four criteria (Figures S5G-S5J). Naive PSCs in human TS medium (SAVECY, nTSs) (Cinkornpumin et al., 2020; Dong et al., 2020) expressed TACSTD2 and ENPEP (Figure S5F) and satisfied three criteria (Figures S5G-S5I) but expressed HLA-ABC (Figure S5J). Ours and other published RNAseq data suggested that $H L A-A$ and $-B$ are expressed in several nTS cell lines (Figure S5K). We also cultured primed PSCs under a two-step protocol of BMP4 and IWP2 (Horii et al., 2019) or ACE medium following nTE medium. Primed PSCs under both conditions did not satisfy the criteria of C19MC and HLA-ABC (Figures S5I and S5J). nTEs satisfied all criteria (Figures S5G-S5J). nTE conditions quickly and efficiently induced TACSTD2 ${ }^{+}$ENPEP ${ }^{+}$ cells (Figure S5L), and ACE medium kept HLA-ABC expression low (Figures S5M and S5N).

We concluded that nCTs satisfied the first-trimester trophoblast criteria as cCTs but pBAPs did not (Figure $4 \mathrm{H}$ ).

nCTs correspond to post-implantation CTs of cynomolgus monkeys and in vivo humans

To understand more detailed features of nTEs, nCTs, and pBAPs, we first evaluated the correlation with pre-implantation human embryos. nTEs had high correlation with human embryonic TE, but pBAPs and EPSC-derived cells had lower correlation (Gao et al., 2019; Figure 5A; Table S3).
Comparison of the gene expression levels between nTEs or $\mathrm{nCT}$ s and pBAPs revealed highly expressed genes as well as commonly expressed genes such as GATA2, GATA3, and TFAP2C (Figure 5B; Table S4). Among the enriched genes of nCTs was SIGLEC6, which we used as a marker of nCTs; ITGA6, which is widely used as a CT marker (Okae et al., 2018); and ITGA2, which has been reported to be expressed in proliferating trophoblasts at the base of CCCs (Lee et al., 2018). Furthermore, we identified that HAVCR1, HSD3B1, S100P, PEG3, PTGES, and ITGA6 were upregulated in nTEs and nCTs and that ITGA2 and SIGLEC6 were only expressed in nCTs. Flow cytometry, immunofluorescence, and qRT-PCR confirmed these results (Figures 5C, 5D, and S6A).

Next we observed the identified genes during early post-implantation in vivo. Because we cannot study early post-implantation CTs in the human uterus, we analyzed the embryos of non-human primate cynomolgus monkeys. We isolated early post-implantation cynomolgus monkey embryos (E15) as described previously, with ethics approval (Nakamura et al., 2016). Implanted embryos had a bilaminar disc-like structure with amniotic cells and rapidly growing CTs and STs (Figure 5E). nCT-enriched genes were expressed in CTs of cynomolgus monkeys at E15 (Figure 5F).

To compare nCTs with CTs in humans, we analyzed human chorionic villi at 5 gestational weeks, which is a later stage than our observations of cynomolgus monkey. Human CCCs and VCTs at 5 gestational weeks also expressed HAVCR1, ITGA6, ITGA2, and S100P as well as HSD3B and PTGES (Figure 5G).

These data indicate that nCTs and trophoblasts during early post-implantation of cynomolgus monkey embryos and firsttrimester placenta of human embryos share the same gene expression patterns but pBAPs do not.

\section{Primed PSC-derived cells express amnion-} related genes

Primed PSCs differentiate into amnion-like cells with BMP (Zheng et al., 2019); hence, we assumed that pBAPs might have the amnion-like property. Reported differentially expressed genes (DEGs) of the cynomolgus monkey amnion (Ma et al., 2019; Table S3) showed that pBAPs expressed over 200 DEGs at significantly higher levels than nTEs and nCTs (Figure 6A). TNC, CDH10, GABRP, IGFBP5, VTCN1, VIM, and HEY1 were identified as genes expressed at significantly higher levels in pBAPs than in nTEs or nCTs (Figure 6A). Next we compared nTEs, nCTs, and pBAPs with in vivo human amnion at a more developed stage (9 gestational weeks) (Roost et al., 2015).

Figure 4. Primed PSC-derived TACSTD2 ${ }^{+}$ENPEP $^{+}$cells do not satisfy trophoblast criteria

(A) Schematic of the BAP-treated primed PSC (pBAP) induction protocol from primed human PSCs.

(B) Bright image of pBAPs on day 3. Scale bar, $100 \mu \mathrm{m} . \mathrm{n}=10$.

(C) Flow cytometry analysis of TACSTD2 and ENPEP on days $1-3 . n=3$.

(D) Immunofluorescence images of pBAPs on day 3 and pBAPs in ACE (passage 10). Primed PSCs were cultured in BAP for 3 days and then cultured in ACE medium for 10 passages. Scale bars, $100 \mu \mathrm{m} . \mathrm{n}=3$.

(E) Flow cytometry analysis of expression of HLA-ABC. $n=3$.

(F) The expression of chromosome 19 microRNA (miRNA) cluster (C19MC) miRNA in JAR (a choriocarcinoma cell line), nCTs (passage [P] 10), pBAPs on day 3 , and pBAPs in ACE medium (P10). $n=3 .{ }^{* * \star *} p \leq 0.0001 ;{ }^{* * *} p \leq 0.001 ;{ }^{* *} p \leq 0.01 ;{ }^{*} p \leq 0.05$.

(G) Bisulfite sequencing of the ELF5 promoter region in naive PSCs, nCTs, primed PSCs, and pBAPs. Percentage values below indicate the ratio of methylation. Open circles, non-methylated CpG; closed circles, methylated CpG.

(H) Criteria for human first-trimester trophoblasts. Chorionic villus-derived cytotrophoblast stem cells (cCTs) and nCTs meet all criteria but pBAPs on day 3 do not. 
A
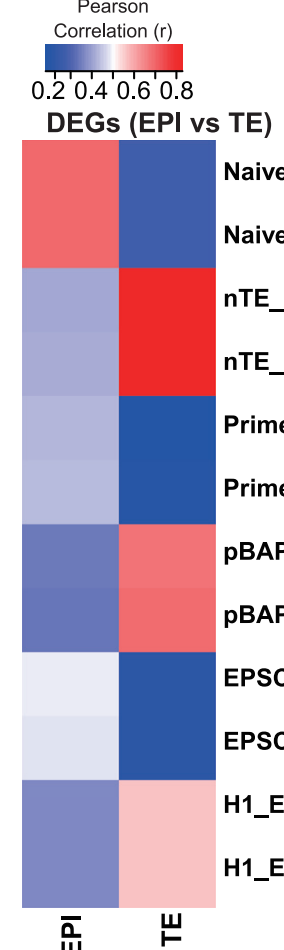

D

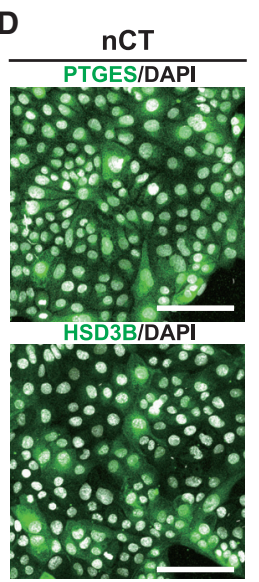

G
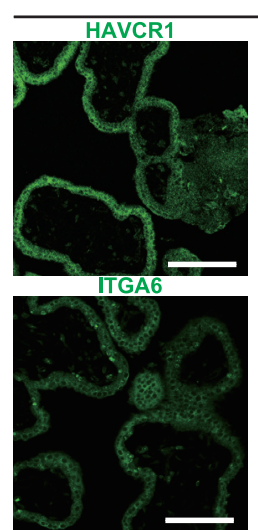

B
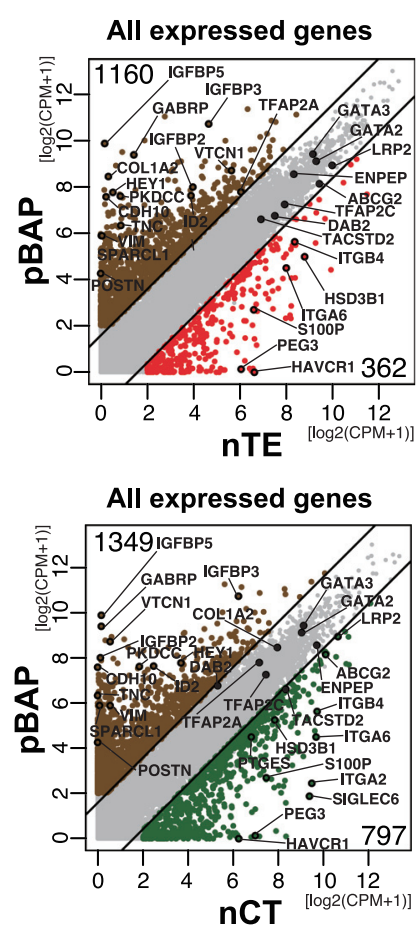

C

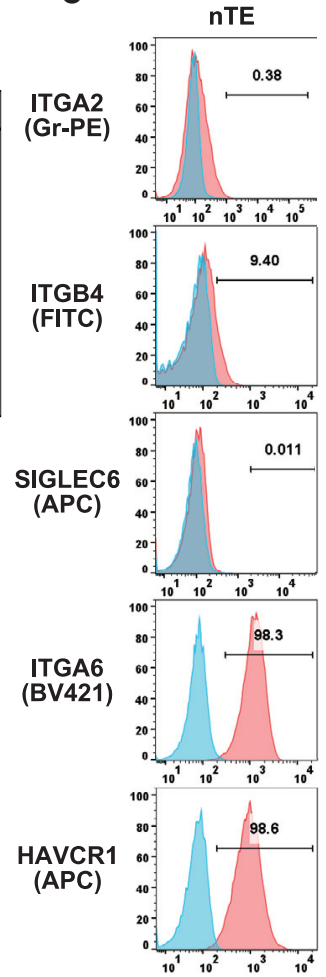

Naive_Ex1

Naive_Ex2

nTE_D3_Ex1

nTE_D3_Ex2

Primed_Ex1

Primed_Ex2

pBAP_D3_Ex1

PBAP_D3_Ex2

EPSC_day0_Ex1

EPSC_day0_Ex2

H1_EPSC_day4_Ex1

H1_EPSC_day4_Ex2

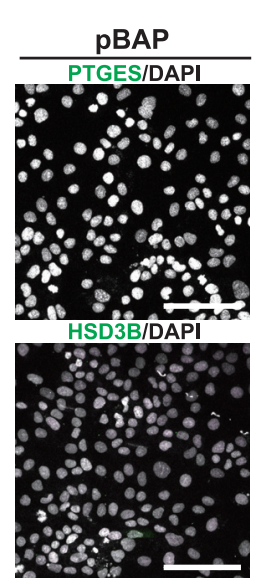

E

primitive

yolk sac

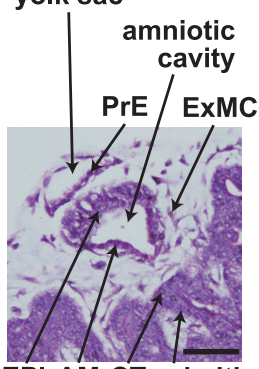

EPI AM CT primitive

ST

$\mathbf{F}$
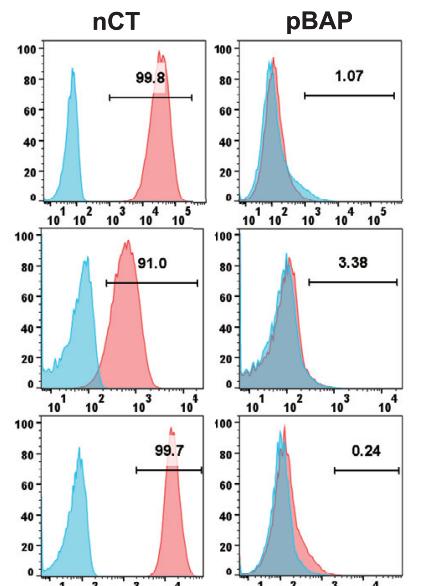

$\begin{array}{llll}10^{1} & 10^{2} & 10^{3} & 10^{4}\end{array}$
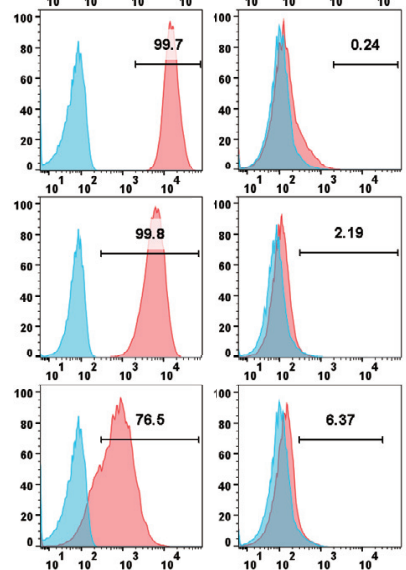

cynomolgus monkey embryo (embryonic day 15)

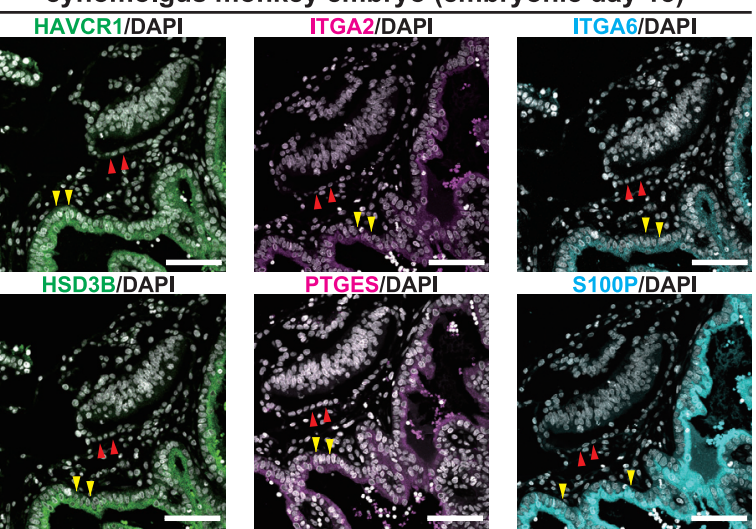

human chorionic villi at $\mathbf{5}$ gestational weeks
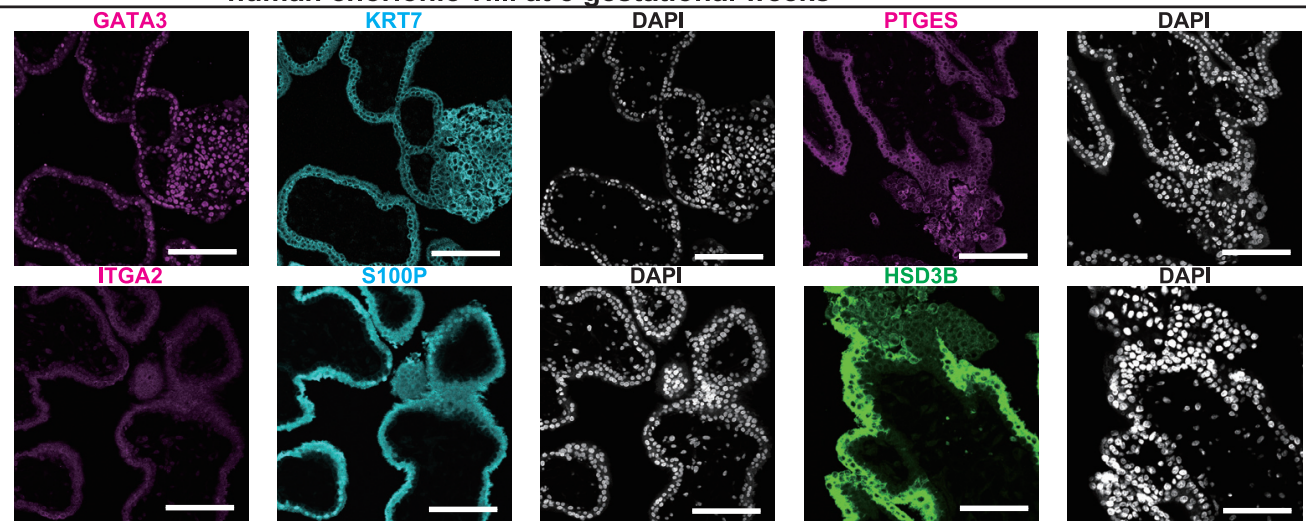

(legend on next page) 
Genes expressed predominantly in amnion were highly upregulated in pBAPs compared with nTEs and nCTs (Figure 6B; Table S3).

qRT-PCR confirmed that pBAPs expressed the amnion genes (Figure 6A and 6B) much more strongly than nTEs or nCTs (Figures $6 \mathrm{C}$ and S6B). VTCN1, TNC, and VIM were detected in pBAP by flow cytometry and immunofluorescence (Figures 6D and 6E), although there were common genes expressed by nCTs and pBAPs (Figures 4D, 6A, and S6C). Finally, immunofluorescence staining of chorionic villi at 5 gestational weeks showed that VTCN1 and TNC were not detected and that VIM was only expressed in stromal cells but not in CCCs, VCTs, or STs (Figure 6F).

We concluded that, in gene expression, pBAPs bear similarity to amniotic cells rather than CTs.

\section{An in vitro differentiation model captures trophoblast} gene dynamics from pre- to post-implantation

When an embryo implants into the uterus, TE contacts the endometrium and is thought to differentiate into CTs, which migrates to the maternal decidua. We examined the dynamics of gene expression using our in vitro model. To map the developmental coordinate axis of nTEs, nCTs, and previously reported TS cells (Cinkornpumin et al., 2020; Dong et al., 2020; Okae et al., 2018), we compared them with cynomolgus monkey embryos in vivo (Nakamura et al., 2016). nTEs_D2 have the highest correlation with late TE at the pre-implantation stage (PreL-TE) (Figure 7A; Table S3). As differentiation progressed, the correlation gradually shifted from pre-implantation to post-implantation (Figure 7A). The reported naive PSC-derived TS cells (Cinkornpumin et al., 2020; Dong et al., 2020) had strong correlation to postCTs, similar to nCTs and CT30 cells, suggesting that all naive, blastocyst-derived, and placenta-derived human TS cells are post-CT counterparts.

Further, we compared the gene expression profiles of nTEs_D2 and nCTs_P3 by looking at differences between preimplantation TE and post-implantation CTs (Figure 7B). 215 genes were highly expressed in nTEs and 298 genes in nCTs (Table S4). The enrichment of Gene Ontology (GO) indicated that nTE-enriched genes are associated with development, whereas $\mathrm{nCT}$-enriched genes are related to movement and migration (Figure S6D), suggesting that $\mathrm{nCT}$-enriched genes are related to movement and migration as in vivo CTs migrate to the maternal decidua.

Next we applied nTE- and nCT-enriched genes to human trophoblast development of cultured human embryos (Zhou et al., 2019). Trophoblasts that expressed nTE-enriched genes decreased from E6 to E14, and trophoblasts that expressed nCT-enriched genes increased (Figure 7C). The dynamics of 22 individual genes showed a similar trend in embryo culture (Figures S6E and S6G) and in vitro transition (Figures S6F and $\mathrm{S} 6 \mathrm{H})$. Furthermore, qRT-PCR confirmed the precise gene expression dynamics of nTE-enriched genes and nCTenriched genes (Figure 7D). HAND1 and CDX2 were expressed in nTEs and quickly decreased with development, whereas key enriched genes of nCTs increased gradually in ACE medium.

To reveal the global gene expression profiles of the TE-to-CT transition, we performed scRNA-seq of nTEs on days 2 and 3 and $\mathrm{nCT}$ on days 5 and 10 using 10X Genomics. 14,164 cells were analyzed by Seurat. t-Distributed stochastic neighbor embedding (t-SNE) divided the cells into 9 populations (Figure $7 \mathrm{E}$ ). Feature plots of EPI and trophoblast genes suggested that CL5 mainly expressed EPI genes, CL2 and CL3 expressed TE genes, and CLO and CL4 expressed CT genes (Figures 7F and S7A). Trajectories calculated by Monocle 2 revealed cell transition from CL5 to CL4 or CL6 (Figure 7G). Correlation analysis against cynomolgus monkey trophoblast showed that CL3 has the strongest correlation to preL-TE, whereas CLO, CL4, and CL6 had the strongest correlation to post-CTs (Figure $7 \mathrm{H}$; Table S3). The gene sets defined by human embryo cultures (Xiang et al., 2020) revealed that pre-TE genes were expressed in CL3 and CL2, which were composed of nTEs_D2, whereas post-CT genes were more expressed in CL1 and CL0, which were mainly composed of nCTs_D5 (Figure 7I). Individual gene expression profiles also showed the expression dynamics during the transition from nTEs to nCTs (Figure 7J). Interestingly, CL6 and CL7, which expressed ST genes, were segregated from CL3 and CL2 of pre-TE and from CL4 of post-CTs, indicating that CL4 of the ST-like population emerged from pre-TE. This may be early STs, which were shown in Carnegie sections of embryos just after implantation.

Finally we analyzed DEGs and GO during the nTE-to-nCT and CT-to-ST transitions (Figures S7B and S7C). HAND1, GATA2, GATA3, TBX3, and TEAD1 were upregulated from CL5 to CL3 (Figure S7D). From CL1 to CL0, which may correspond to the earliest time of the TE-to-CT transition, HAND1 was downregulated quickly, and PEG10 and PEG3 were upregulated (Figure S7D). DPP4, EGFR, and ITGA2 (Figure 7D) were detected as DEGs from CLO to CL4. Thus, our culture system revealed the molecular dynamics from pre-implantation TE to post-implantation CTs.

Figure 5. nCTs correspond to post-implantation CTs of cynomolgus monkeys and in vivo humans

(A) Correlation coefficients of human EPI and TE in pre-implantation embryos with naive PSCs, nTEs, primed PSCs, pBAPs, and expanded potential stem cells (EPSCs) (days 0 and 4). Analysis was performed on differentially expressed genes (DEGs) of EPI versus TE in human embryos (Stirparo et al., 2018).

(B) Scatterplots of the average gene expression levels between nTEs_D3 and pBAPs_D3 (top) and between nCTs_P3 and pBAPs_D3 (bottom). Solid black lines indicate 3-fold changes. Key genes are annotated, and the number of enriched genes are indicated. Brown circles, enriched genes in pBAPs; red circles, enriched genes in nTEs; green circles, enriched genes in nCTs. CPM, counts per million.

(C) Flow cytometry analysis of nTEs, nCTs, and pBAPs for the key trophoblast-enriched genes in (B). Blue, an unstained control. $n=3$.

(D) Protein expression of two key trophoblast-enriched genes, PTGES and HSD3B. Scale bars, $100 \mu \mathrm{m}$.

(E) Hematoxylin and eosin staining of paraffin sections of cynomolgus embryos on E15. AM, amniotic cell; CT, cytotrophoblast; EPI, post-implantation epiblast; ExMC, extraembryonic mesenchyme; PrE, post-implantation primitive endoderm; primitive ST, primitive syncytiotrophoblast. Scale bars, 100 mm.

(F) Immunofluorescence images of paraffin sections of cynomolgus embryos on E15. Scale bars, $100 \mu \mathrm{m}$. Yellow arrowheads indicate trophoblasts. Red arrowheads indicate amnion.

(G) Immunofluorescence images of human chorionic villi at 5 gestational weeks. Scale bars, $100 \mu \mathrm{m}$. $\mathrm{n}=3$. 
A

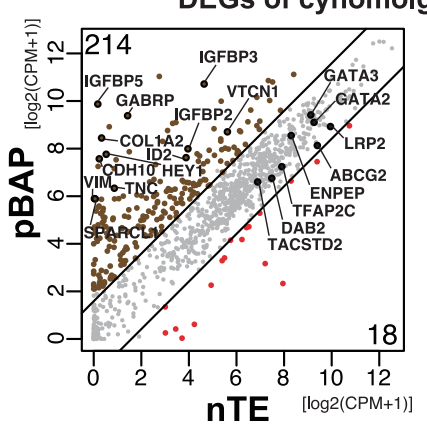

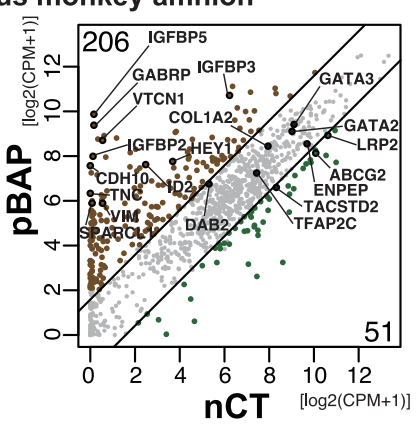

B

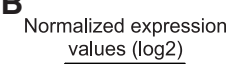

values $(\log 2)$

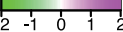

Human $9 \mathrm{gw}$ amnion-predominantly expressed genes

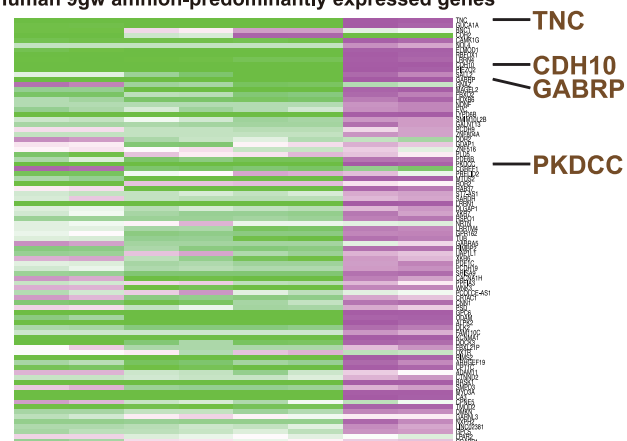

- POSTN

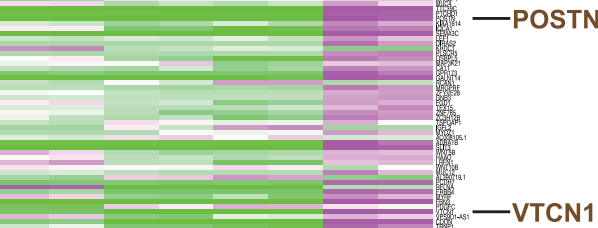

-VTCN1

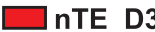

$\triangle \mathrm{nCT}$ P3

nCT P10 $\square$ pBAP

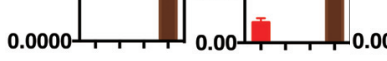

D

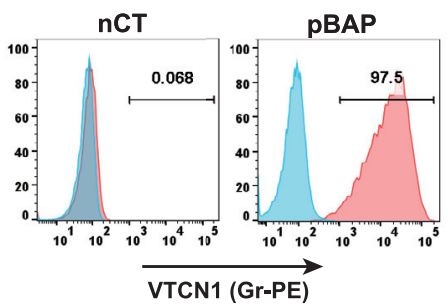

E

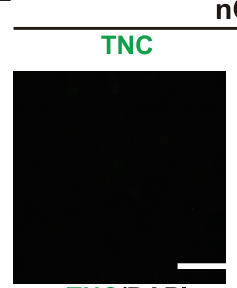

$\mathrm{nCT}$

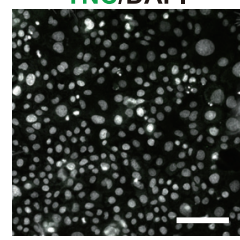

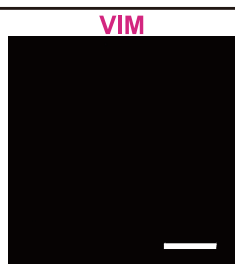

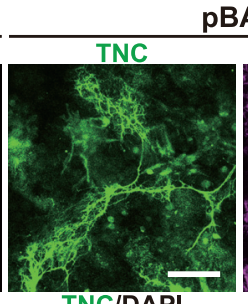
TNC/DAPI

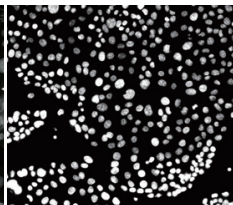

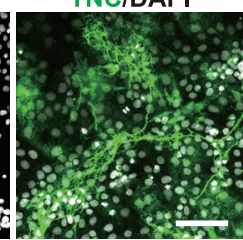

pBAP

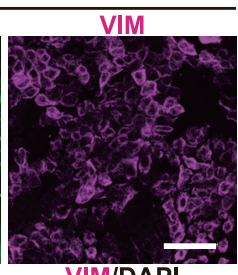

VIM/DAPI
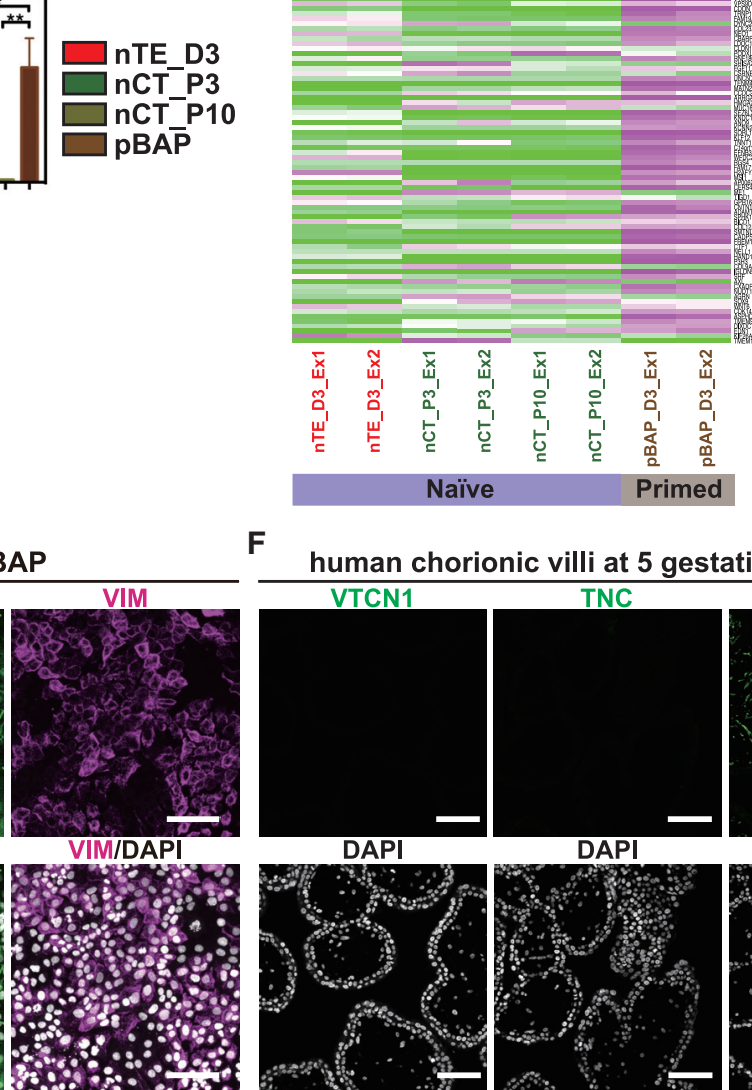

$\mathbf{F}$

human chorionic villi at 5 gestational weeks
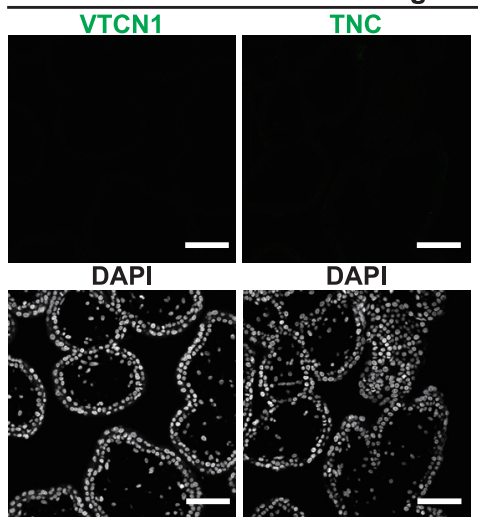

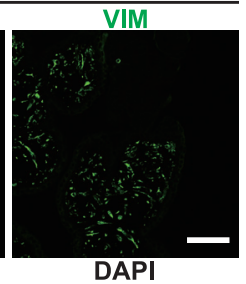

Figure 6. Primed PSC-derived cells express amnion-related genes

(A) Scatterplots of the average gene expression levels for DEGs of cynomolgus monkey amnion (Ma et al., 2019) between nTEs_D3 and pBAPs_D3 (left) and between nCTs_P10 and pBAPs_D3 (right). pBAPs, nTEs, and nCTs share common genes. Key genes are annotated, and the number of enriched genes are indicated in the top left of each plot. Brown circles, enriched genes in pBAPs; red circles, enriched genes in nTEs; green circles, enriched genes in nCTs; solid black lines, 3-fold changes.

(B) Relative gene expression dynamics of nTEs, nCTs, and pBAPs. Genes expressed predominantly in amnion were identified by comparing human amnion and placenta at 9 gestational weeks (Roost et al., 2015). The top 300 genes expressed predominantly in amnion and CPM of more than 1 in at least one sample are shown. 


\section{DISCUSSION}

We succeeded in establishing an in vitro model for differentiation of naive human PSCs into the trophoblast lineage from TE to STs and EVTs via CTs (Figure 7K). This model allows observation of the entire trophoblast development from pre-implantation to postimplantation.

Our re-analysis of previously reported scRNA-seq data of cynomolgus monkey and human embryos revealed that trophoblast and amnion share many common genes (Figures 4D and S6C). Previous reports also suggested that the amnion expresses hCG, which is known to be expressed in STs (Plouzek et al., 1993; Thiede and Choate, 1963; Thiede and Fierer, 1966; Xiang et al., 2020). In addition, HLA-G, a major EVT marker, is also expressed in human amnion (Hammer et al., 1997; Strom and Gramignoli, 2016). These facts may explain why pBAPs express hCG and HLA-G. However, our analysis identified that genes such as IGFBP5 and GABRP in pBAPs and HAVCR1 and ITGA2 in nCTs were differentially expressed between amnion and trophoblast. Thus, our results show that cells induced from primed PSCs have gene expression patterns more similar to amnion than CTs post-implantation and during the first trimester (Figure 7K).

Recently, several groups established culture models of human embryos beyond the implantation stage (Deglincerti et al., 2016; Shahbazi et al., 2016; Xiang et al., 2020; Zhou et al., 2019). However, culturing human embryos beyond 14 days is prohibited (Hyun et al., 2020; Sawai et al., 2020). In the present study, we succeeded in inducing and purifying naive PSC-derived TE that expressed CDX2. Our findings are corroborated by a parallel study (Guo et al., 2021). Our results demonstrated that the gene expression of TE in pre-implantation blastocyst is different from those of CTs in post-implantation embryos. This finding indicates that human nCTs, recent naive PSC-derived TS cells (Cinkornpumin et al., 2020; Dong et al., 2020), blastocyst- or placentaderived TS cells (Okae et al., 2018), and trophoblast organoids (Haider et al., 2018; Turco et al., 2018) correspond to CTs of post-implantation rather than pre-implantation TE. Furthermore, comparison of gene expression patterns of nCTs and chorionic villi revealed that some cells of CCCs and VCTs are counterparts to CT stem cells. This finding is supported by a previous report showing that ITGA2 ${ }^{+}$cells in chorionic villi are proliferating trophoblasts that can differentiate into EVTs and STs (Lee et al., 2018).

Our model allows us to analyze the transcriptome-wide transition from TE to CTs, which cannot be done using conventional TS cells. By using human PSCs, including iPSCs, we can readily collect a large number of samples and perform various experiments, including gene modification. Our study thus contributes a major research tool to the study of human early development that is in agreement with current ethics regulations and extends research aimed at treatment, including diseases related to the placenta.

\section{Limitations of study}

We thoroughly compared our in vitro model with in vivo human placental tissues and cynomolgus monkey embryos just after implantation. However, the number of in vivo samples was limited, and the gestational dates of in vivo samples could not be controlled accurately. We compared previously published scRNA-seq data of cynomolgus monkey embryos, human embryos, and their cultures. Because only a few reports exist in which different methods of scRNA-seq were done, further data and analysis are needed.

There is no epigenetic data of in vivo human trophoblast development, and E14-E21 human embryos cannot be accessed. Our model cannot compare these two points to in vivo counterpart. Finally, a small portion of amnion may contribute to or transdifferentiate into trophoblasts.

\section{STAR $\star M E T H O D S$}

Detailed methods are provided in the online version of this paper and include the following:

- KEY RESOURCES TABLE

- RESOURCE AVAILABILITY

O Lead contact

O Materials availability

Data and code availability

- EXPERIMENTAL MODEL AND SUBJECT DETAILS

○ Pluripotent Stem Cell Cultures

O Cynomolgus Monkey Specimens

○ Clinical Samples

- METHOD DETAILS

O Differentiation into nTEs

Culture of nCTs

O Differentiation into nSTs

Differentiation into nEVTs

Culture of $\mathrm{nCT}$ organoids

Differentiation into nEVT from nCT organoids

Culture of BAP-treated primed pluripotent stem cells

C Culture of BMP4- and IWP2-treated primed pluripotent stem cells

O Culture of human trophoblast stem cells

O Culture of JAR

O Generation of CDX2-GFP reporter cell line

O Isolation of human cytotrophoblast

Bisulfite sequencing of ELF5 promoter

Immunocytochemistry

Immunohistochemistry

Conventional scanning electron microscopy

O Karyotype analysis

Flow cytometry

Q Quantitative real-time PCR (mRNA \& miRNA)

Western blot analysis

o Fusion event analysis

(C) qRT-PCR analysis of $n T E s, n C T s$, and pBAPs for the key enriched genes in (A) and (B). $n=3 .{ }^{\star \star \star *} p \leq 0.0001 ;{ }^{* \star} p \leq 0.01$

(D) Flow cytometry analysis for the pBAP-enriched gene VTCN1. Blue, an unstained control. $n=5$.

(E) Immunofluorescence images of $n C T s$ and pBAPs_D3 for the key pBAP-enriched genes in (A). Scale bars, $100 \mu \mathrm{m} . \mathrm{n}=3$.

(F) Immunofluorescence images of human chorionic villi at 5 gestational weeks. Scale bars, $100 \mu \mathrm{m}$. $\mathrm{n}=3$. 
A Pearson

Correlation (r) Cynomolgus monkey T, Trophoblast 0.30 .40 .50 .6 ontogenic genes
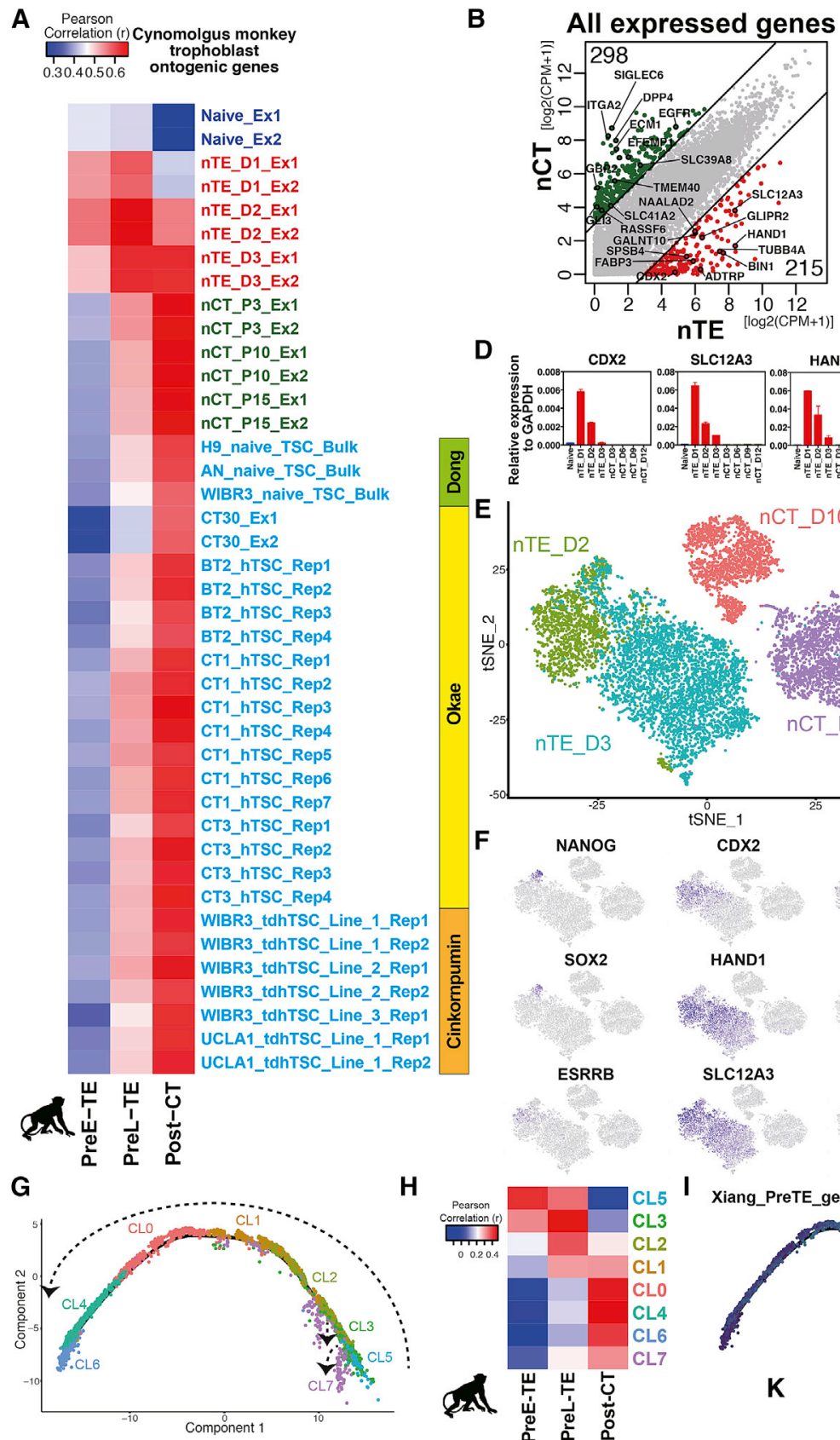

C
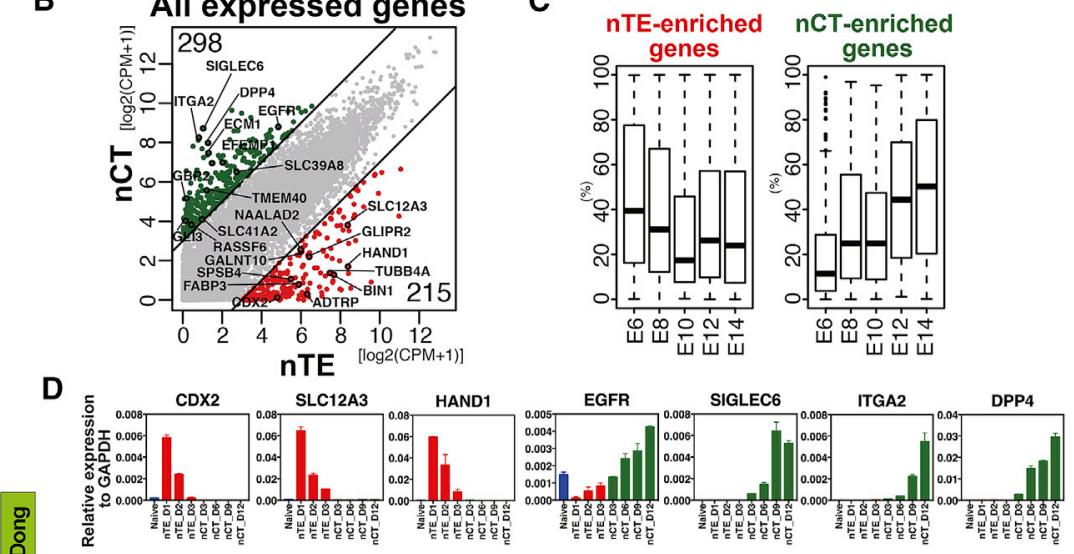

E
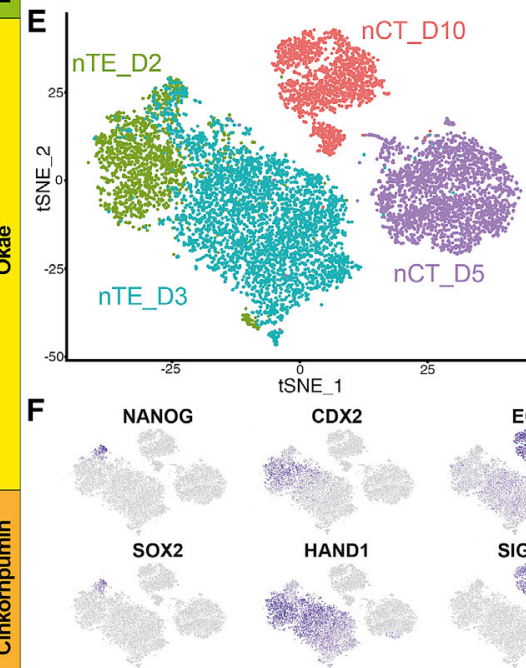

ESRRB
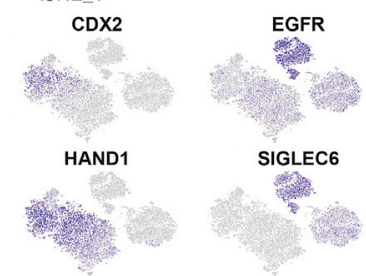

SIGLEC6

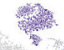

SLC12A3

ITGA2

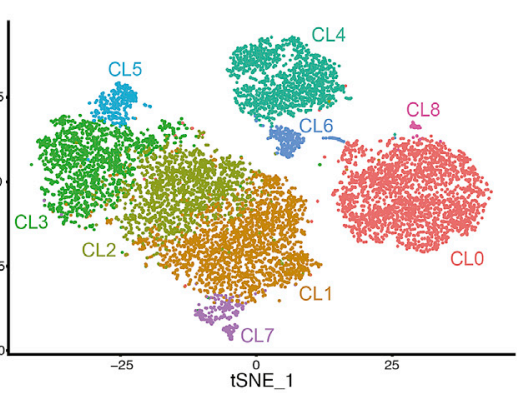

$\begin{array}{lll}\text { DPP4 } & \text { SDC1 }\end{array}$
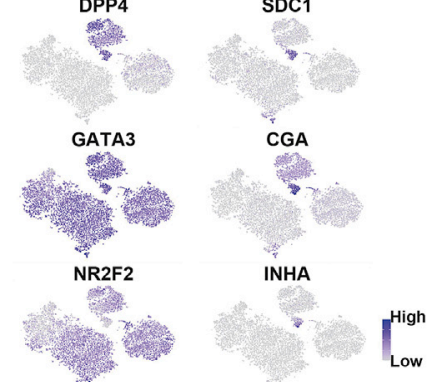

H

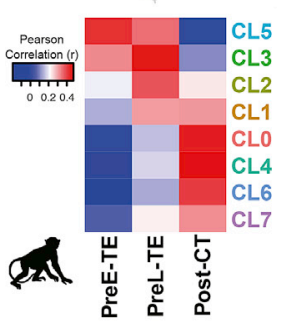

Xiang_PreTE_genes -0.20 .00 .20 .40 .6$

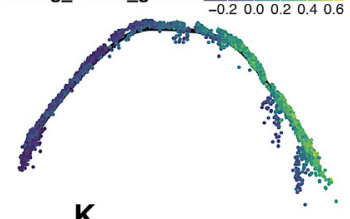

Xiang_PostCT_genes 0.20 .00 .20 .40 .6

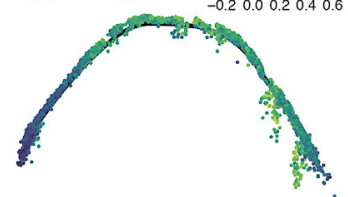

K

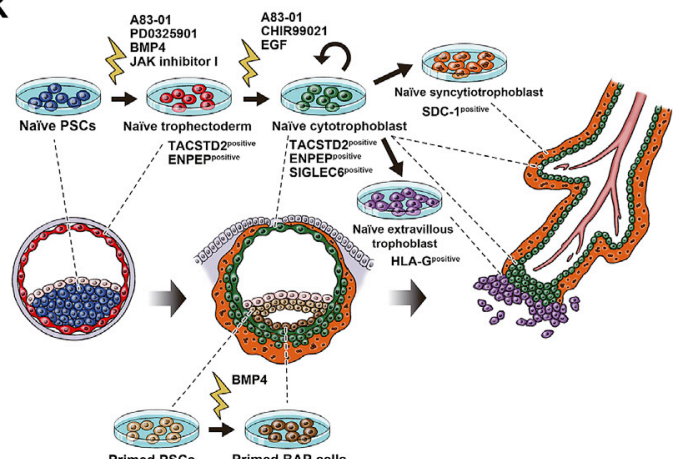

J

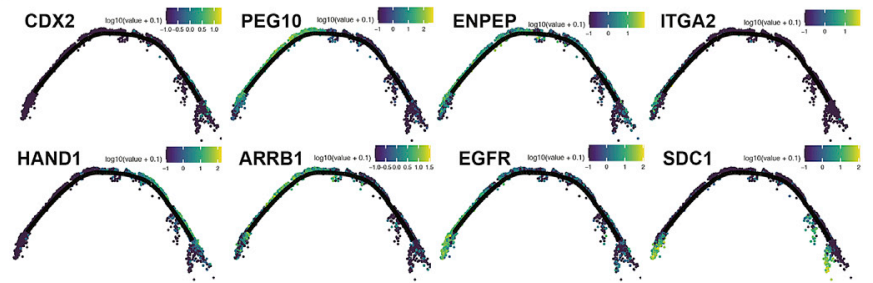

(legend on next page) 
O ELISA of hCG

O Killing assay

O Time-lapse analysis

RNA sequencing and data analysis

Single cell RNA sequencing and data analysis

- Comparison of gene expressions between humans and cynomolgus monkeys

- QUANTIFICATION AND STATISTICAL ANALYSIS

\section{SUPPLEMENTAL INFORMATION}

Supplemental Information can be found online at https://doi.org/10.1016/j. stem.2021.03.013.

\section{ACKNOWLEDGMENTS}

The authors are grateful to all people who donated placental tissue for the research. The authors thank Naoyuki Kawamura, Akeo Kawamura (Kawamura Ladies Clinic), and Hironori Hamada (Adachi Clinic) for obtaining and documenting informed consent. We thank Ge Guo and Austin Smith for sharing data and discussions prior to publication. The authors thank Hiroaki Okae and Takahiro Arima for the CT30 cell line and Keisuke Okita for the 409B2 iPS cell line. The authors thank Tetsuro Watabe for helpful discussions. The authors thank all Takashima lab members for helpful discussions and assistance. We thank Kanae Mitsunaga for the flow cytometry analysis; Shunsuke Kihara for the imaging analysis; and Tim Smith, Maria G. Martin (University of Cambridge), and Ai Hirase-Hirabayashi (Kyoto University) for technical support. The authors are grateful to Peter Karagiannis for critical reading and English editing of the manuscript and Misaki Ouchida for scientific illustrations. This work was supported by MEXT KAKENHI (JP16H02465, JP2OH05762, and JP2OH05361) and AMED (JP20bm0704035 and JP20bm0104001 to Y.T. and JP20bm0704032 to T.Y.), the iPS Cell Research Fund, the Takeda Science Foundation, The Naito Foundation (to Y.T.), and a Grant-in-Aid for JSPS Research Fellows (JP19J13503 to S.I.).

\section{AUTHOR CONTRIBUTIONS}

Conceptualization, S.I. and Y.T.; methodology, S.I. and Y.T.; investigation, S.I., Y.I., K.S., B.K. (cell culture and molecular work), M.K., T.Y. (RNA-seq analysis),
A.M., B.W., S.K. (killing assay), C.I., I.O., Y.K., T.N., H.T., M.S. (cynomolgus monkey experiments), N.M. (electron microscopy), and S.I. and K.W. (gene editing); writing, S.I. and Y.T.; editing, M.S., T.Y., E.K., and M.M.

\section{DECLARATION OF INTERESTS}

S.I. and Y.T. are co-inventors on a patent describing the generation of trophectoderm-like cells from naïve human pluripotent stem cells.

\section{INCLUSION AND DIVERSITY}

We worked to ensure diversity in experimental samples through the selection of the cell lines.

Received: September 25, 2020

Revised: February 5, 2021

Accepted: March 15, 2021

Published: April 7, 2021

\section{REFERENCES}

Amita, M., Adachi, K., Alexenko, A.P., Sinha, S., Schust, D.J., Schulz, L.C., Roberts, R.M., and Ezashi, T. (2013). Complete and unidirectional conversion of human embryonic stem cells to trophoblast by BMP4. Proc. Natl. Acad. Sci. USA 110, E1212-E1221.

Anders, S., Pyl, P.T., and Huber, W. (2015). HTSeq-a Python framework to work with high-throughput sequencing data. Bioinformatics 31, 166-169.

Benirschke, K., Burton, G.J., and Baergen, R.N. (2012). Basic Structure of the Villous Trees. Pathology of the Human Placenta (Springer), pp. 55-100.

Bernardo, A.S., Faial, T., Gardner, L., Niakan, K.K., Ortmann, D., Senner, C.E., Callery, E.M., Trotter, M.W., Hemberger, M., Smith, J.C., et al. (2011). BRACHYURY and CDX2 mediate BMP-induced differentiation of human and mouse pluripotent stem cells into embryonic and extraembryonic lineages. Cell Stem Cell 9, 144-155.

Blakeley, P., Fogarty, N.M., del Valle, I., Wamaitha, S.E., Hu, T.X., Elder, K., Snell, P., Christie, L., Robson, P., and Niakan, K.K. (2015). Defining the three cell lineages of the human blastocyst by single-cell RNA-seq. Development $142,3151-3165$.

Figure 7. In vitro differentiation model captures trophoblast development from pre-implantation to post-implantation

(A) The correlation coefficients of naive PSCs, nTEs_D1, nTEs_2, nTEs_3, nCTs_P3, nCTs_P10, nCTs_P15, placenta-derived TS cells (Okae et al., 2018), blastocyst-derived TS cells (Okae et al., 2018), and reported naive PSC-derived TS cells (Dong et al., 2020, Cinkornpumin et al., 2020) with cynomolgus monkey embryos. The RNA-seq data from this study, Dong et al. (2020), and Cinkornpumin et al. (2020) were compared with the scRNA-seq data of trophoblast cells for cynomolgus monkey trophoblast ontogenic genes (Nakamura et al., 2016). PreE- and PreL-TE, pre-implantation early and late TE, respectively; Post-CT, postimplantation CT; CT1, CT3, and CT30, placenta-derived TS cells; BT2, blastocyst-derived TS cells.

(B) Scatterplot of the average level for all expressed genes between nTEs_D2 and nCTs_P3. Key genes are annotated, and the number of enriched genes are indicated. Red circles, enriched genes in nTEs; green circles, enriched genes in nCTs; solid black lines, 8-fold changes.

(C) The expression dynamics of all nTE- and nCT-enriched genes ( 298 and 215 genes, respectively) during human embryo cultures. The expression of all nTE- and nCT-enriched genes in (B) was analyzed in trophoblast cells of human embryo cultures from E6-E14 (Zhou et al., 2019). The y axis shows the percentage of expressing cells per total cells on each embryonic day. All enriched genes were combined.

(D) The expression dynamics of nTE- and nCT-enriched genes from nTEs to nCTs. TACSTD2 ${ }^{+}$ENPEP ${ }^{+}$(nTEs_D3) were sorted on day 3 and re-cultured in ACE medium.

(E) t-SNE plots for nTEs_D2, nTEs_D3, nCTs_D5, and nCTs_D10 samples (left) and clustering with all samples (nine clusters, right). TACSTD2 ${ }^{+}$cells were sorted on days 2 and 3. nTEs_D3 were re-cultured in ACE medium and collected on days 5 and 10 (nCTs_D5 and nCTs_D10, respectively). These cells were analyzed by scRNA-seq (10X Genomics) ( $n=14,164$ cells).

(F) Gene expression levels of pluripotency, TE, post-CT, and ST markers during the nTE-to-nCT transition in (E).

(G) Single-cell trajectory constructed by Monocle 2. Cells are labeled by clusters in (E).

(H) Correlation coefficients of the average gene expression in each cluster with those in cynomolgus embryos using a cynomolgus monkey trophoblast ontogenic gene set.

(I) Module scores for preTE and postCT genes defined by Xiang et al. (2020) labeled in the trajectory in (G).

(J) Developmental path and gene expression patterns of pluripotency, TE, post-CT, and ST markers.

(K) In vitro developmental model for trophoblasts and CT stem cells. After an embryo implants into the uterus, TE differentiates into CTs, STs, and EVTs. Naive PSCs differentiate into TACSTD2 ${ }^{+}$ENPEP $^{+}{ }^{n T E s}$ by A83-01, PD03, BMP4, and JAK inhibitor in vitro. nTEs then differentiate into TACSTD2 ${ }^{+}$ENPEP $^{+}$SIGLEC6 ${ }^{+}$ $\mathrm{nCT}$ in ACE medium. nCTs can be maintained as CT stem cells and differentiate into HLA-G ${ }^{+}$EVTs and SDC1 ${ }^{+} \mathrm{STs}$. The gene expression patterns indicate that $\mathrm{nCTs}$ correspond to in-vivo-proliferating CCCs and VCTs. Primed PSCs in BMP4 differentiate into PBAPs, which express amnion-related genes. 


\section{$\infty$ CellPress}

Burton, G.J., and Jauniaux, E. (2017). The cytotrophoblastic shell and complications of pregnancy. Placenta 60, 134-139.

Butler, A., Hoffman, P., Smibert, P., Papalexi, E., and Satija, R. (2018). Integrating single-cell transcriptomic data across different conditions, technologies, and species. Nat. Biotechnol. 36, 411-420.

Castel, G., Meistermann, D., Bretin, B., Firmin, J., Blin, J., Loubersac, S., Bruneau, A., Chevolleau, S., Kilens, S., Chariau, C., et al. (2020). Induction of Human Trophoblast Stem Cells from Somatic Cells and Pluripotent Stem Cells. Cell Rep. 33, 108419.

Chang, C.W., and Parast, M.M. (2017). Human trophoblast stem cells: Real or not real? Placenta 60 (Suppl 1), S57-S60.

Chen, A.E., Egli, D., Niakan, K., Deng, J., Akutsu, H., Yamaki, M., Cowan, C., Fitz-Gerald, C., Zhang, K., Melton, D.A., and Eggan, K. (2009). Optimal timing of inner cell mass isolation increases the efficiency of human embryonic stem cell derivation and allows generation of sibling cell lines. Cell Stem Cell 4, 103-106.

Cindrova-Davies, T., Jauniaux, E., Elliot, M.G., Gong, S., Burton, G.J., and Charnock-Jones, D.S. (2017). RNA-seq reveals conservation of function among the yolk sacs of human, mouse, and chicken. Proc. Natl. Acad. Sci. USA 114, E4753-E4761.

Cinkornpumin, J.K., Kwon, S.Y., Guo, Y., Hossain, I., Sirois, J., Russett, C.S., Tseng, H.W., Okae, H., Arima, T., Duchaine, T.F., et al. (2020). Naive Human Embryonic Stem Cells Can Give Rise to Cells with a Trophoblast-like Transcriptome and Methylome. Stem Cell Reports 15, 198-213.

Cong, L., Ran, F.A., Cox, D., Lin, S., Barretto, R., Habib, N., Hsu, P.D., Wu, X., Jiang, W., Marraffini, L.A., and Zhang, F. (2013). Multiplex genome engineering using CRISPR/Cas systems. Science 339, 819-823.

Deglincerti, A., Croft, G.F., Pietila, L.N., Zernicka-Goetz, M., Siggia, E.D., and Brivanlou, A.H. (2016). Self-organization of the in vitro attached human embryo. Nature 533, 251-254.

Dong, C., Beltcheva, M., Gontarz, P., Zhang, B., Popli, P., Fischer, L.A., Khan, S.A., Park, K.M., Yoon, E.J., Xing, X., et al. (2020). Derivation of trophoblast stem cells from naïve human pluripotent stem cells. eLife 9, e52504.

Faulk, W.P., and Temple, A. (1976). Distribution of $\beta 2$ microglobulin and HLA in chorionic villi of human placentae. Nature 262, 799-802.

Frankish, A., Diekhans, M., Ferreira, A.-M., Johnson, R., Jungreis, I., Loveland, J., Mudge, J.M., Sisu, C., Wright, J., Armstrong, J., et al. (2019). GENCODE reference annotation for the human and mouse genomes. Nucleic Acids Res. 47 (D1), D766-D773.

Frias-Aldeguer, J., Kip, M., Vivié, J., Li, L., Alemany, A., Korving, J., Darmis, F., van Oudenaarden, A., Geijsen, N., and Rivron, N.C. (2020). Embryonic signals perpetuate polar-like trophoblast stem cells and pattern the blastocyst axis. bioRxiv. https://doi.org/10.1101/510362.

Gao, X., Nowak-Imialek, M., Chen, X., Chen, D., Herrmann, D., Ruan, D., Chen, A.C.H., Eckersley-Maslin, M.A., Ahmad, S., Lee, Y.L., et al. (2019). Establishment of porcine and human expanded potential stem cells. Nat. Cell Biol. 21, 687-699.

Goodfellow, P.N., Barnstable, C.J., Bodmer, W.F., Snary, D., and Crumpton, M.J. (1976). Expression of HLA system antigens on placenta. Transplantation 22, 595-603.

Guo, G., von Meyenn, F., Santos, F., Chen, Y., Reik, W., Bertone, P., Smith, A., and Nichols, J. (2016). Naive Pluripotent Stem Cells Derived Directly from Isolated Cells of the Human Inner Cell Mass. Stem Cell Reports 6, 437-446.

Guo, G., von Meyenn, F., Rostovskaya, M., Clarke, J., Dietmann, S., Baker, D., Sahakyan, A., Myers, S., Bertone, P., Reik, W., et al. (2017). Epigenetic resetting of human pluripotency. Development 144, 2748-2763.

Guo, G., Stirparo, G.G., Strawbridge, S.E., Spindlow, D., Yang, J., Clarke, J., Dattani, A., Yanagida, A., Li, M.A., and Myers, S. (2021). Human naive epiblast cells possess unrestricted lineage potential. Cell Stem Cell 28, this issue, 1040-1056.

Haider, S., Meinhardt, G., Saleh, L., Kunihs, V., Gamperl, M., Kaindl, U., Ellinger, A., Burkard, T.R., Fiala, C., Pollheimer, J., et al. (2018). SelfRenewing Trophoblast Organoids Recapitulate the Developmental Program of the Early Human Placenta. Stem Cell Reports 11, 537-551.
Hammer, A., Hutter, H., Blaschitz, A., Mahnert, W., Hartmann, M., UchanskaZiegler, B., Ziegler, A., and Dohr, G. (1997). Amnion epithelial cells, in contrast to trophoblast cells, express all classical HLA class I molecules together with HLA-G. Am. J. Reprod. Immunol. 37, 161-171.

Horii, M., Bui, T., Touma, O., Cho, H.Y., and Parast, M.M. (2019). An Improved Two-Step Protocol for Trophoblast Differentiation of Human Pluripotent Stem Cells. Curr. Protoc. Stem Cell Biol. 50, e96.

Huang, W., Sherman, B.T., and Lempicki, R.A. (2009). Systematic and integrative analysis of large gene lists using DAVID bioinformatics resources. Nat. Protoc. 4, 44-57.

Hunt, J.S., Petroff, M.G., McIntire, R.H., and Ober, C. (2005). HLA-G and immune tolerance in pregnancy. FASEB J. 19, 681-693.

Hyun, I., Munsie, M., Pera, M.F., Rivron, N.C., and Rossant, J. (2020). Toward Guidelines for Research on Human Embryo Models Formed from Stem Cells. Stem Cell Reports 14, 169-174.

Jokimaa, V., Inki, P., Kujari, H., Hirvonen, O., Ekholm, E., and Anttila, L. (1998). Expression of syndecan-1 in human placenta and decidua. Placenta 19, 157-163.

Kawata, M., Parnes, J.R., and Herzenberg, L.A. (1984). Transcriptional control of HLA-A,B,C antigen in human placental cytotrophoblast isolated using trophoblast- and HLA-specific monoclonal antibodies and the fluorescenceactivated cell sorter. J. Exp. Med. 160, 633-651.

Kim, D., Paggi, J.M., Park, C., Bennett, C., and Salzberg, S.L. (2019). Graphbased genome alignment and genotyping with HISAT2 and HISAT-genotype. Nat Biotechnol 37, 907-915.

Kuckenberg, P., Buhl, S., Woynecki, T., van Fürden, B., Tolkunova, E., Seiffe, F., Moser, M., Tomilin, A., Winterhager, E., and Schorle, H. (2010). The transcription factor TCFAP2C/AP-2gamma cooperates with CDX2 to maintain trophectoderm formation. Mol. Cell. Biol. 30, 3310-3320.

Kunath, T., Yamanaka, Y., Detmar, J., MacPhee, D., Caniggia, I., Rossant, J., and Jurisicova, A. (2014). Developmental differences in the expression of FGF receptors between human and mouse embryos. Placenta 35, 1079-1088.

Lee, C.Q., Gardner, L., Turco, M., Zhao, N., Murray, M.J., Coleman, N., Rossant, J., Hemberger, M., and Moffett, A. (2016). What Is Trophoblast? A Combination of Criteria Define Human First-Trimester Trophoblast. Stem Cell Reports 6, 257-272.

Lee, C.Q.E., Turco, M.Y., Gardner, L., Simons, B.D., Hemberger, M., and Moffett, A. (2018). Integrin $\alpha 2$ marks a niche of trophoblast progenitor cells in first trimester human placenta. Development 145, dev162305.

Ma, H., Zhai, J., Wan, H., Jiang, X., Wang, X., Wang, L., Xiang, Y., He, X., Zhao, Z.A., Zhao, B., et al. (2019). In vitro culture of cynomolgus monkey embryos beyond early gastrulation. Science 366, eaax7890.

Malhotra, S.S., Banerjee, P., and Gupta, S.K. (2016). Regulation of trophoblast differentiation during embryo implantation and placentation: Implications in pregnancy complications. J. Reprod. Health Med. 2, S26-S36.

Martin, M. (2011). Cutadapt removes adapter sequences from highthroughput sequencing reads. EMBnet.journal 17, 10-12.

McCarthy, D.J., Chen, Y., and Smyth, G.K. (2012). Differential expression analysis of multifactor RNA-Seq experiments with respect to biological variation. Nucleic Acids Res. 40, 4288-4297.

Meistermann, D., Loubersac, S., Reignier, A., Firmin, J., Campion, V.F., Kilens, S., Lelièvre, Y., Lammers, J., Feyeux, M., Hulin, P., et al. (2019). Spatio-temporal analysis of human preimplantation development reveals dynamics of epiblast and trophectoderm. bioRxiv. https://doi.org/10.1101/604751.

Mühlhauser, J., Crescimanno, C., Kaufmann, P., Höfler, H., Zaccheo, D., and Castellucci, M. (1993). Differentiation and proliferation patterns in human trophoblast revealed by c-erbB-2 oncogene product and EGF-R. J. Histochem. Cytochem. 41, 165-173.

Nakamura, T., Yabuta, Y., Okamoto, I., Aramaki, S., Yokobayashi, S., Kurimoto, K., Sekiguchi, K., Nakagawa, M., Yamamoto, T., and Saitou, M. (2015). SC3-seq: a method for highly parallel and quantitative measurement of single-cell gene expression. Nucleic Acids Res. 43, e60.

Nakamura, T., Okamoto, I., Sasaki, K., Yabuta, Y., Iwatani, C., Tsuchiya, H., Seita, Y., Nakamura, S., Yamamoto, T., and Saitou, M. (2016). A 
developmental coordinate of pluripotency among mice, monkeys and humans. Nature 537, 57-62.

Nakamura, T., Yabuta, Y., Okamoto, I., Sasaki, K., Iwatani, C., Tsuchiya, H., and Saitou, M. (2017). Single-cell transcriptome of early embryos and cultured embryonic stem cells of cynomolgus monkeys. Sci. Data 4, 170067.

Nishioka, N., Inoue, K., Adachi, K., Kiyonari, H., Ota, M., Ralston, A., Yabuta, N., Hirahara, S., Stephenson, R.O., Ogonuki, N., et al. (2009). The Hippo signaling pathway components Lats and Yap pattern Tead4 activity to distinguish mouse trophectoderm from inner cell mass. Dev. Cell 16, 398-410.

Niwa, H., Toyooka, Y., Shimosato, D., Strumpf, D., Takahashi, K., Yagi, R., and Rossant, J. (2005). Interaction between Oct3/4 and Cdx2 determines trophectoderm differentiation. Cell 123, 917-929.

Okae, H., Toh, H., Sato, T., Hiura, H., Takahashi, S., Shirane, K., Kabayama, Y., Suyama, M., Sasaki, H., and Arima, T. (2018). Derivation of Human Trophoblast Stem Cells. Cell Stem Cell 22, 50-63.e6.

Okita, K., Matsumura, Y., Sato, Y., Okada, A., Morizane, A., Okamoto, S., Hong, H., Nakagawa, M., Tanabe, K., Tezuka, K., et al. (2011). A more efficient method to generate integration-free human iPS cells. Nat. Methods 8, 409-412.

Perez-Garcia, V., Fineberg, E., Wilson, R., Murray, A., Mazzeo, C.I., Tudor, C., Sienerth, A., White, J.K., Tuck, E., Ryder, E.J., et al. (2018). Placentation defects are highly prevalent in embryonic lethal mouse mutants. Nature 555, 463-468.

Petropoulos, S., Edsgärd, D., Reinius, B., Deng, Q., Panula, S.P., Codeluppi, S., Plaza Reyes, A., Linnarsson, S., Sandberg, R., and Lanner, F. (2016). Single-Cell RNA-Seq Reveals Lineage and X Chromosome Dynamics in Human Preimplantation Embryos. Cell 165, 1012-1026.

Plouzek, C.A., Leslie, K.K., Stephens, J.K., and Chou, J.Y. (1993). Differential gene expression in the amnion, chorion, and trophoblast of the human placenta. Placenta 14, 277-285.

Qiu, X., Mao, Q., Tang, Y., Wang, L., Chawla, R., Pliner, H.A., and Trapnell, C. (2017). Reversed graph embedding resolves complex single-cell trajectories. Nat. Methods 14, 979-982.

Roost, M.S., van Iperen, L., Ariyurek, Y., Buermans, H.P., Arindrarto, W., Devalla, H.D., Passier, R., Mummery, C.L., Carlotti, F., de Koning, E.J., et al. (2015). KeyGenes, a Tool to Probe Tissue Differentiation Using a Human Fetal Transcriptional Atlas. Stem Cell Reports 4, 1112-1124.

Rumer, K.K., Post, M.D., Larivee, R.S., Zink, M., Uyenishi, J., Kramer, A., Teoh, D., Bogart, K., and Winn, V.D. (2012). Siglec-6 is expressed in gestational trophoblastic disease and affects proliferation, apoptosis and invasion. Endocr. Relat. Cancer 19, 827-840.

Sawai, T., Minakawa, T., Pugh, J., Akatsuka, K., Yamashita, J.K., and Fujita, M. (2020). The moral status of human embryo-like structures: potentiality matters?: The moral status of human synthetic embryos. EMBO Rep. 21, e50984. Senner, C.E., and Hemberger, M. (2010). Regulation of early trophoblast differentiation - lessons from the mouse. Placenta 31, 944-950.

Shahbazi, M.N., Jedrusik, A., Vuoristo, S., Recher, G., Hupalowska, A., Bolton, V., Fogarty, N.N.M., Campbell, A., Devito, L., Ilic, D., et al. (2016). Self-organization of the human embryo in the absence of maternal tissues. Nat. Cell Biol. 18, 700-708.

Stirparo, G.G., Boroviak, T., Guo, G., Nichols, J., Smith, A., and Bertone, P. (2018). Integrated analysis of single-cell embryo data yields a unified transcriptome signature for the human pre-implantation epiblast. Development 145, dev158501.

Strom, S.C., and Gramignoli, R. (2016). Human amnion epithelial cells expressing HLA-G as novel cell-based treatment for liver disease. Hum. Immunol. 77, 734-739.

Takashima, Y., Guo, G., Loos, R., Nichols, J., Ficz, G., Krueger, F., Oxley, D., Santos, F., Clarke, J., Mansfield, W., et al. (2014). Resetting transcription factor control circuitry toward ground-state pluripotency in human. Cell 158, 1254-1269.

Tanaka, S., Kunath, T., Hadjantonakis, A.K., Nagy, A., and Rossant, J. (1998). Promotion of trophoblast stem cell proliferation by FGF4. Science 282, 2072-2075.

Theunissen, T.W., Powell, B.E., Wang, H., Mitalipova, M., Faddah, D.A., Reddy, J., Fan, Z.P., Maetzel, D., Ganz, K., Shi, L., et al. (2014). Systematic identification of culture conditions for induction and maintenance of naive human pluripotency. Cell Stem Cell 15, 471-487.

Theunissen, T.W., Friedli, M., He, Y., Planet, E., O’Neil, R.C., Markoulaki, S., Pontis, J., Wang, H., louranova, A., Imbeault, M., et al. (2016). Molecular criteria for defining the naive human pluripotent state. Cell Stem Cell 19, 502-515.

Thiede, H.A., and Choate, J.W. (1963). Chorionic Gonadotropin Localization in the Human Placenta by Immunofluorescent Staining. II. Demonstration of Hcg in the Trophoblast and Amnion Epithelium of Immature and Mature Placentas. Obstet. Gynecol. 22, 433-443.

Thiede, H.A., and Fierer, M.B. (1966). Detection of HCG in the amnion by biologic and immunologic assay. Obstet. Gynecol. 27, 363-368.

Turco, M.Y., Gardner, L., Kay, R.G., Hamilton, R.S., Prater, M., Hollinshead, M.S., McWhinnie, A., Esposito, L., Fernando, R., Skelton, H., et al. (2018). Trophoblast organoids as a model for maternal-fetal interactions during human placentation. Nature 564, 263-267.

Vento-Tormo, R., Efremova, M., Botting, R.A., Turco, M.Y., Vento-Tormo, M., Meyer, K.B., Park, J.-E., Stephenson, E., Polański, K., Goncalves, A., et al. (2018). Single-cell reconstruction of the early maternal-fetal interface in humans. Nature 563, 347-353.

Wolf, D.P., Thormahlen, S., Ramsey, C., Yeoman, R.R., Fanton, J., and Mitalipov, S. (2004). Use of assisted reproductive technologies in the propagation of rhesus macaque offspring. Biol. Reprod. 71, 486-493.

Wong, C.C., Loewke, K.E., Bossert, N.L., Behr, B., De Jonge, C.J., Baer, T.M. and Reijo Pera, R.A. (2010). Non-invasive imaging of human embryos before embryonic genome activation predicts development to the blastocyst stage. Nat. Biotechnol. 28, 1115-1121.

Xiang, L., Yin, Y., Zheng, Y., Ma, Y., Li, Y., Zhao, Z., Guo, J., Ai, Z., Niu, Y., Duan, K., et al. (2020). A developmental landscape of 3D-cultured human pre-gastrulation embryos. Nature 577, 537-542.

Xu, R.H., Chen, X., Li, D.S., Li, R., Addicks, G.C., Glennon, C., Zwaka, T.P., and Thomson, J.A. (2002). BMP4 initiates human embryonic stem cell differentiation to trophoblast. Nat. Biotechnol. 20, 1261-1264.

Yamasaki, J., Iwatani, C., Tsuchiya, H., Okahara, J., Sankai, T., and Torii, R. (2011). Vitrification and transfer of cynomolgus monkey (Macaca fascicularis) embryos fertilized by intracytoplasmic sperm injection. Theriogenology $76,33-38$.

Yan, L., Yang, M., Guo, H., Yang, L., Wu, J., Li, R., Liu, P., Lian, Y., Zheng, X., Yan, J., et al. (2013). Single-cell RNA-Seq profiling of human preimplantation embryos and embryonic stem cells. Nat. Struct. Mol. Biol. 20, 1131-1139.

Yang, Y., Adachi, K., Sheridan, M.A., Alexenko, A.P., Schust, D.J., Schulz, L.C., Ezashi, T., and Roberts, R.M. (2015). Heightened potency of human pluripotent stem cell lines created by transient BMP4 exposure. Proc. Natl. Acad. Sci. USA 112, E2337-E2346.

Zheng, Y., Xue, X., Shao, Y., Wang, S., Esfahani, S.N., Li, Z., Muncie, J.M. Lakins, J.N., Weaver, V.M., Gumucio, D.L., and Fu, J. (2019). Controlled modelling of human epiblast and amnion development using stem cells. Nature 573, 421-425.

Zhou, F., Wang, R., Yuan, P., Ren, Y., Mao, Y., Li, R., Lian, Y., Li, J., Wen, L., Yan, L., et al. (2019). Reconstituting the transcriptome and DNA methylome landscapes of human implantation. Nature 572, 660-664. 


\section{STAR $\star$ METHODS}

\section{KEY RESOURCES TABLE}

\begin{tabular}{|c|c|c|}
\hline REAGENT or RESOURCE & SOURCE & IDENTIFIER \\
\hline \multicolumn{3}{|l|}{ Antibodies } \\
\hline $\begin{array}{l}\text { Mouse monoclonal anti-CD249 (ENPEP), } \\
\text { PE conjugated (clone 2D3/APA) }\end{array}$ & BD Biosciences & Cat\#564533; RRID: AB_2738838 \\
\hline $\begin{array}{l}\text { Mouse monoclonal anti-CD249 (ENPEP), } \\
\text { BV421 conjugated (clone 2D3/APA) }\end{array}$ & BD Biosciences & Cat\#744872; RRID: AB_2742549 \\
\hline $\begin{array}{l}\text { Recombinant anti-TROP2 (TACSTD2), } \\
\text { biotin conjugated (clone REA916) }\end{array}$ & Miltenyi Biotec & Cat\#130-115-054; RRID: AB_2726879 \\
\hline $\begin{array}{l}\text { Recombinant anti-TROP2 (TACSTD2), } \\
\text { Alexa Fluor } 488 \text { conjugated (clone } 77220 \text { ) }\end{array}$ & R\&D systems & Cat\#FAB650G; RRID: not available \\
\hline $\begin{array}{l}\text { Mouse monoclonal anti-HLA-ABC, APC } \\
\text { conjugated (clone W6/32) }\end{array}$ & Biolegend & Cat\#311410; RRID: AB_314879 \\
\hline $\begin{array}{l}\text { Mouse monoclonal anti-HLA-ABC, Pacific } \\
\text { Blue conjugated (clone W6/32) }\end{array}$ & Biolegend & Cat\#311418; RRID: AB_493669 \\
\hline $\begin{array}{l}\text { Recombinant anti-human TIM-1 (HAVCR1), } \\
\text { APC conjugated (clone REA384) }\end{array}$ & Miltenyi Biotec & Cat\#130-106-025; RRID: AB_2654146 \\
\hline $\begin{array}{l}\text { Recombinant anti-human CD327 } \\
\text { (SIGLEC6), biotin conjugated (clone } \\
\text { REA852) }\end{array}$ & Miltenyi Biotec & Cat\#130-112-708; RRID: AB_2725881 \\
\hline $\begin{array}{l}\text { Rat monoclonal anti-human/mouse CD49f } \\
\text { (ITGA6), BV421 conjugated (clone GoH3) }\end{array}$ & Biolegend & Cat\#313623; RRID: AB_2562243 \\
\hline $\begin{array}{l}\text { Mouse monoclonal anti-human CD49b } \\
\text { (ITGA2), PE conjugated (clone HAS3) }\end{array}$ & $\mathrm{R} \& \mathrm{D}$ systems & Cat\#FAB1233P; RRID: AB_357010 \\
\hline $\begin{array}{l}\text { Recombinant anti-human CD104 (ITGB4), } \\
\text { FITC conjugated (clone REA236) }\end{array}$ & Miltenyi Biotec & Cat\#130-101-433; RRID: AB_2654401 \\
\hline $\begin{array}{l}\text { Mouse monoclonal anti-HLA-G, PE } \\
\text { conjugated (clone MEM-G/9) }\end{array}$ & Abcam & Cat\#ab24384; RRID: AB_448029 \\
\hline $\begin{array}{l}\text { Rat monoclonal anti-Streptavidin, APC } \\
\text { conjugated }\end{array}$ & Biolegend & Cat\#405207; RRID: not available \\
\hline $\begin{array}{l}\text { Mouse monoclonal anti-CD249 (ENPEP), } \\
\text { purified (clone 2D3/APA) }\end{array}$ & BD Biosciences & Cat\#564532; RRID: AB_2738837 \\
\hline $\begin{array}{l}\text { Recombinant anti-TROP2 (TACSTD2), } \\
\text { purified (clone 77220) }\end{array}$ & R\&D systems & Cat\#MAB650; RRID: AB_2205665 \\
\hline $\begin{array}{l}\text { Rabbit polyclonal anti-human CD327 } \\
\text { (SIGLEC6) }\end{array}$ & Atlas Antibodies & Cat\#HPA009084; RRID: AB_1079967 \\
\hline Rabbit polyclonal anti-TFAP2C & Santa Cruz Biotechnology & Cat\#sc-8977; RRID: AB_2286995 \\
\hline $\begin{array}{l}\text { Mouse monoclonal anti-HLA-G (clone } \\
\text { MEM-G/9) }\end{array}$ & Santa Cruz Biotechnology & Cat\#sc-51678; RRID: AB_677250 \\
\hline $\begin{array}{l}\text { Mouse monoclonal anti-human CDX2 } \\
\text { (clone CDX2-88) }\end{array}$ & Abcam & Cat\#ab157524; RRID: AB_2721036 \\
\hline Goat polyclonal anti-human GATA3 & R\&D systems & Cat\#AF2605; RRID: AB_2108571 \\
\hline $\begin{array}{l}\text { Mouse monoclonal anti-human GATA3 } \\
\text { (clone 1A12-1D9) }\end{array}$ & Thermo Fisher Scientific & Cat\#MA1-028; RRID: AB_2536713 \\
\hline $\begin{array}{l}\text { Rabbit monoclonal anti-KRT7 (clone } \\
\text { EPR17078) }\end{array}$ & Abcam & Cat\#181598; RRID: AB_2783822 \\
\hline $\begin{array}{l}\text { Mouse monoclonal anti-KRT19 (clone } \\
\text { RCK108) }\end{array}$ & Dako & Cat\#M0888; RRID: AB_2234418 \\
\hline Rat monoclonal anti-CD138 (SDC1) (clone & R\&D systems & Cat\#MAB2780; RRID: AB_2182840 \\
\hline
\end{tabular}




\begin{tabular}{|c|c|c|}
\hline \multicolumn{3}{|l|}{ Continued } \\
\hline REAGENT or RESOURCE & SOURCE & IDENTIFIER \\
\hline $\begin{array}{l}\text { Mouse monoclonal anti-human CD365 } \\
\text { (HAVCR1) (clone 219211) }\end{array}$ & R\&D systems & Cat\#MAB1750; RRID: AB_2116559 \\
\hline $\begin{array}{l}\text { Rabbit polyclonal anti-placental } \\
\text { lactogen (hPL) }\end{array}$ & Abcam & Cat\#ab15554; RRID: AB_301963 \\
\hline $\begin{array}{l}\text { Mouse monoclonal anti-hCG beta antibody } \\
\text { (clone } 5 \mathrm{H} 4-\mathrm{E} 2 \text { ) }\end{array}$ & Abcam & Cat\#ab9582; RRID: AB_296507 \\
\hline $\begin{array}{l}\text { Mouse monoclonal anti-TFAP2A } \\
\text { (clone 3B5) }\end{array}$ & Santa Cruz Biotechnology & Cat\#sc-12726; RRID: AB_667767 \\
\hline Mouse monoclonal anti-PTGES (clone A-3) & Santa Cruz Biotechnology & Cat\#sc-166308; RRID: AB_2175049 \\
\hline Mouse monoclonal anti-HSD3B (37-2) & Santa Cruz Biotechnology & Cat\#sc-100466; RRID: AB_1118475 \\
\hline Mouse monoclonal anti-ITGA2 (C-9) & Santa Cruz Biotechnology & Cat\#sc-74466; RRID: AB_1124939 \\
\hline Rat monoclonal anti-ITGA6 (GOH3) & Santa Cruz Biotechnology & Cat\#sc-19622; RRID: AB_668055 \\
\hline Mouse monoclonal anti-VIM (V9) & Santa Cruz Biotechnology & Cat\#sc-6260; RRID: AB_628437 \\
\hline $\begin{array}{l}\text { Rat monoclonal anti-Tenascin C (TNC) } \\
\text { (clone 578) }\end{array}$ & R\&D systems & Cat\#MAB2138; RRID: AB_2203818 \\
\hline Goat polyclonal anti-OCT-3/4 (N-19) & Santa Cruz Biotechnology & Cat\#sc-8628; RRID: AB_653551 \\
\hline $\begin{array}{l}\text { Mouse monoclonal anti-NANOG (clone } \\
\text { hNANOG.2) }\end{array}$ & Thermo Fisher Scientific & Cat\#14-5768-82; RRID: AB_467572 \\
\hline Rabbit polyclonal anti-KLF17 & Atlas Antibodies & Cat\#HPA024629; RRID: AB_1668927 \\
\hline Rat monoclonal anti-Ki67 (clone SolA15) & Thermo Fisher Scientific & Cat\#14-5698-82; RRID: AB_10854564 \\
\hline $\begin{array}{l}\text { Rabbit monoclonal anti-TP63 } \\
\text { (clone D2K8X) }\end{array}$ & Cell Signaling Technology & Cat\#13109; RRID: AB_2637091 \\
\hline Rabbit polyclonal anti-VGLL1 & Atlas Antibodies & Cat\#HPA042403; RRID: AB_2677980 \\
\hline $\begin{array}{l}\text { Rabbit monoclonal anti-S100P (clone } \\
\text { EPR6143) }\end{array}$ & Abcam & Cat\#ab133554; RRID: not available \\
\hline $\begin{array}{l}\text { Rabbit monoclonal anti-non-phospho } \\
\text { (Active) } \beta \text {-Catenin (Ser33/37/ } \\
\text { Thr41) (D13A1) }\end{array}$ & Cell Signaling & Cat\#8814; RRID: AB_11127203 \\
\hline $\begin{array}{l}\text { Rabbit polyclonal anti-phospho-EGF } \\
\text { Receptor (Tyr1068) }\end{array}$ & Cell Signaling & Cat\#2234; RRID: AB_331701 \\
\hline $\begin{array}{l}\text { Rabbit monoclonal anti-phospho-Smad2 } \\
\text { (Ser465/467) (E8F3R) }\end{array}$ & Cell Signaling & Cat\#18338; RRID: AB_2798798 \\
\hline $\begin{array}{l}\text { Rabbit polyclonal anti-phospho-Smad2 } \\
\text { (Ser465/467) }\end{array}$ & Cell Signaling & Cat\#3101; RRID: AB_331673 \\
\hline $\begin{array}{l}\text { Rabbit monoclonal anti-phospho-SMAD1/5 } \\
\text { (Ser463/465) (41D10) }\end{array}$ & Cell Signaling & Cat\#9516; RRID: AB_491015 \\
\hline $\begin{array}{l}\text { Rabbit monoclonal anti-phospho-p44/42 } \\
\text { MAPK (Erk1/2) (Thr202/Tyr204) } \\
\text { (D13.14.4E) XP }\end{array}$ & Cell Signaling & Cat\#4370; RRID: AB_2315112 \\
\hline $\begin{array}{l}\text { Rabbit polyclonal anti-phospho- } \\
\text { STAT3(Thy705) }\end{array}$ & Cell Signaling & Cat\#9131; RRID: AB_331586 \\
\hline Mouse monoclonal anti-alpha-Tubulin & Sigma-Aldrich & Cat\#T6199; RRID: AB_477583 \\
\hline Anti-rabbit IgG, HRP-linked antibody & Cell Signaling & Cat\#7074; RRID: AB_2099233 \\
\hline Anti-mouse IgG, HRP-linked antibody & Cell Signaling & Cat\#7076; RRID: AB_330924 \\
\hline $\begin{array}{l}\text { DAPI (4',6-Diamidino-2-phenylindole } \\
\text { dihydrochloride) }\end{array}$ & Sigma-Aldrich & Cat\#D9542; RRID: not available \\
\hline $\begin{array}{l}\text { Donkey anti-mouse IgG, AlexaFluor 488- } \\
\text { conjugated }\end{array}$ & Thermo Fisher Scientific & Cat\#A21202; RRID: AB_141607 \\
\hline $\begin{array}{l}\text { Donkey anti-rabbit IgG, AlexaFluor 555- } \\
\text { conjugated }\end{array}$ & Thermo Fisher Scientific & Cat\#A31572; RRID: AB_162543 \\
\hline $\begin{array}{l}\text { Donkey anti-goat IgG, AlexaFluor 555- } \\
\text { conjugated }\end{array}$ & Thermo Fisher Scientific & Cat\#A21422; RRID: AB_141822 \\
\hline
\end{tabular}




\begin{tabular}{|c|c|c|}
\hline \multicolumn{3}{|l|}{ Continued } \\
\hline REAGENT or RESOURCE & SOURCE & IDENTIFIER \\
\hline $\begin{array}{l}\text { Donkey anti-Rat IgG, AlexaFluor 488- } \\
\text { conjugated }\end{array}$ & Thermo Fisher Scientific & Cat\#A21208; RRID: AB_141709 \\
\hline $\begin{array}{l}\text { Donkey anti-mouse IgG, AlexaFluor } 647- \\
\text { conjugated }\end{array}$ & Thermo Fisher Scientific & Cat\#A31571; RRID: AB_162542 \\
\hline $\begin{array}{l}\text { Donkey anti-rabbit IgG, AlexaFluor } 647- \\
\text { conjugated }\end{array}$ & Thermo Fisher Scientific & Cat\#A31573; RRID: AB_2536183 \\
\hline $\begin{array}{l}\text { Donkey anti-goat IgG, AlexaFluor } 647- \\
\text { conjugated }\end{array}$ & Thermo Fisher Scientific & Cat\#A21447; RRID: AB_141844 \\
\hline \multicolumn{3}{|l|}{ Bacterial and virus strains } \\
\hline Competent high $\mathrm{DH} 5 \alpha$ & TOYOBO & Cat\#DNA-903 \\
\hline \multicolumn{3}{|l|}{ Chemicals, peptides, and recombinant proteins } \\
\hline iMatrix 511 silk (Laminin-E8) & Nippi, Japan & Cat\#892021 \\
\hline $\begin{array}{l}\text { Geltrex LDEV-Free, hESC-Qualified, } \\
\text { reduced growth factor basement } \\
\text { membrane matrix }\end{array}$ & Thermo Fisher Scientific (Invitrogen) & Cat\#A1413302 \\
\hline Collagen IV & Corning & Cat\#354233 \\
\hline Trypsin & Thermo Fisher Scientific (Invitrogen) & Cat\#15090-046 \\
\hline Collagenase IV & Thermo Fisher Scientific (Invitrogen) & Cat\#17104-019 \\
\hline $0.1 \mathrm{~mol} / \mathrm{I}-\mathrm{Calcium}$ Chloride Solution & Nacalai tesque, Kyoto, Japan & Cat\#16973-64 \\
\hline Accutase & Sigma-Aldrich & Cat\#A6964 \\
\hline $\begin{array}{l}\text { 2.5g/l-Trypsin/1 mmol//-EDTA Solution, with } \\
\text { Phenol Red }\end{array}$ & Nacalai tesque, Kyoto, Japan & Cat\#32777-15 \\
\hline TrypLE Express Enzyme & Thermo Fisher Scientific & Cat\#12604021 \\
\hline Stem-Cellbanker & Takara Bio & Cat\#CB045 \\
\hline Cell Banker 1 & Takara Bio & Cat\#CB011 \\
\hline $\begin{array}{l}\text { Deoxyribonuclease I from bovine pancreas } \\
\text { Type IV (DNase) }\end{array}$ & Sigma-Aldrich & Cat\#D5025 \\
\hline $\begin{array}{l}\text { HBSS, 10X, no Calcium, no Magnesium, no } \\
\text { Phenol Red }\end{array}$ & Thermo Fisher Scientific (Invitrogen) & Cat\#14185052 \\
\hline Bovine Serum Albumin & Sigma-Aldrich & Cat\#A2153 \\
\hline Normal Donkey Serum & Jackson ImmunoResearch & Cat\#017-000-121; RRID: AB_2337258 \\
\hline Tween-20 & Nacalai tesque, Kyoto, Japan & Cat\#23926-35 \\
\hline Fetal bovine serum & Thermo Fisher Scientific & Cat\#10437028 \\
\hline Knockout Serum Replacement & Thermo Fisher Scientific (Invitrogen) & Cat\#10828028 \\
\hline DMEM/Ham's F-12 & Nacalai tesque, Kyoto, Japan & Cat\#08460-95 \\
\hline NDiff227 & Takara Bio & Cat\#Y40002 \\
\hline $\begin{array}{l}\text { MEM non-essential amino acids } \\
\text { (NEAA) (100X) }\end{array}$ & Thermo Fisher Scientific (Invitrogen) & Cat\#11140-050 \\
\hline L-glutamine & Thermo Fisher Scientific (Invitrogen) & Cat\#25030081 \\
\hline L-ascorbic acid & Sigma-Aldrich & Cat\#A4403 \\
\hline 2-Mercaptoethanol (2ME) & Sigma-Aldrich & Cat\#M3148 \\
\hline $\begin{array}{l}\text { 7.5w/v\% Albumin D-PBS (-) Solution, from } \\
\text { Bovine Serum (BSA) }\end{array}$ & Wako & Cat\#012-23881 \\
\hline $\begin{array}{l}\text { Insulin, Transferrin, Selenium, } \\
\text { Ethanolamine Solution (ITS -X), 100X }\end{array}$ & Life Technologies & Cat\#51500-056 \\
\hline Insulin, Transferrin, Selenium (ITS -G), 100X & Life Technologies & Cat\#41400-045 \\
\hline $\begin{array}{l}\text { recombinant human basic fibroblast growth } \\
\text { factor }\end{array}$ & Oriental Yeast & Cat\#NIB47079000 \\
\hline CHIR99021 & Sigma-Aldrich & Cat\#SML1046 \\
\hline PD0325901 & Tocris & Cat\#4192 \\
\hline recombinant human LIF & Peprotech & Cat\#300-05 \\
\hline
\end{tabular}




\begin{tabular}{|c|c|c|}
\hline \multicolumn{3}{|l|}{ Continued } \\
\hline REAGENT or RESOURCE & SOURCE & IDENTIFIER \\
\hline Gö6983 & Tocris & Cat\#2285 \\
\hline Y-27632 (hydrochloride) & Cayman & Cat\#10005583 \\
\hline WH-4-023 & A Chemtek & Cat\#H620061 \\
\hline SB590885 & R\&D systems & Cat\#2650 \\
\hline SB431542 & Tocris & Cat\#1614 \\
\hline A83-01 & Tocris & Cat\#2939 \\
\hline recombinant human BMP-4 protein & R\&D systems & Cat\#314-BP \\
\hline JAK inhibitor I & Merck & Cat\#420099 \\
\hline recombinant human EGF protein & R\&D systems & Cat\#236-EG \\
\hline Forskolin & Wako & Cat\#067-02191 \\
\hline NRG1 & Cell Signaling & Cat\#5218SC \\
\hline PD173074 & Selleck Chemicals & Cat\#S1264 \\
\hline recombinant human/mouse/rat Activin A & R\&D systems & Cat\#338-AC-010 \\
\hline TGF- $\beta 1$ & Sigma-Aldrich & Cat\#T7039 \\
\hline XAV939 & Selleck Chemicals & Cat\#S1180 \\
\hline Gefitinib & Cayman & Cat\#13166 \\
\hline Oleoyl-L-a-lysophosphatidic acid (LPA) & Sigma-Aldrich & Cat\#L7260 \\
\hline Valproic acid sodium salt & Sigma-Aldrich & Cat\#P4543 \\
\hline IWP-2 & Sigma-Aldrich & Cat\#10536 \\
\hline BMP Inhibitor IV, LDN-193189 & Merck & Cat\#509882 \\
\hline Human IL-6 & Oriental Bio & Cat\#NIB47066000 \\
\hline Human IL-7 & Peprotech & Cat\#200-07 \\
\hline Human IL-15 & Peprotech & Cat\#200-15 \\
\hline Human IFN- $\gamma$ & Peprotech & Cat\#300-02 \\
\hline Phytohemagglutinin PHA-P & Sigma-Aldrich & Cat\#L1668 \\
\hline MEM $\alpha$, nucleosides & Thermo Fisher Scientific & Cat\#12571063 \\
\hline Advanced RPMI 1640 medium & Life Technologies & Cat\#12633-012 \\
\hline Stemfit AK02N & Reprocell & Cat\#RCAK02N \\
\hline KnockOut DMEM & Thermo Fisher Scientific & Cat\#10829-018 \\
\hline Ham's F-12 Nutrient Mix & Thermo Fisher Scientific & Cat\#11765-054 \\
\hline $\mathrm{NaHCO}_{3}, 7.5 \%$ solution & Thermo Fisher Scientific & Cat\#25080094 \\
\hline Tissue-Tek Mayer's hematoxylin solution & Sakura fineteck, Tokyo, Japan & Cat\#8650-2 \\
\hline Tissue-Tek Eosin solution & Sakura fineteck Tokyo, Japan & Cat\#8659 \\
\hline Normal goat serum (10\%) & Life Technologies & Cat\#50062Z \\
\hline VECTASHIELD Antifade Mounting Medium & Vector Laboratories & Cat\#H-1000 \\
\hline RIPA buffer & Nacalai tesque, Kyoto, Japan & Cat\#08714-04 \\
\hline $\begin{array}{l}\text { Phosphatase Inhibitor Cocktail (EDTA } \\
\text { free) (100x) }\end{array}$ & Nacalai tesque, Kyoto, Japan & Cat\#07575-51 \\
\hline Luminata Forte Western HRP substrate & Merck & Cat\#WBLUF0500 \\
\hline $\begin{array}{l}\text { Bolt } 4 \text { to } 12 \% \text {, Bis-Tris, } 1.0 \mathrm{~mm} \text {, Mini } \\
\text { Protein Gel }\end{array}$ & Thermo Fisher Scientific & Cat\#NW04125BOX \\
\hline N-Acetyl-L-cysteine & Sigma-Aldrich & Cat\#A9165 \\
\hline Recombinant human R-spondin 1 & R\&D systems & Cat\#4645-RS \\
\hline Recombinant human HGF & Peprotech & Cat\#100-39 \\
\hline PGE2 & Sigma-Aldrich & Cat\#P0409 \\
\hline RBC Lysis Buffer, 10X & Santa Cruz Biotechnology & Cat\#sc-296258 \\
\hline $\begin{array}{l}\text { Paraformaldehyde, } 16 \% \text { w/v aq. soln., } \\
\text { methanol free }\end{array}$ & Wako & Cat\#043368 \\
\hline 1mol/l-HEPES Buffer Solution & Nacalai tesque, Kyoto, Japan & Cat\#17557-94 \\
\hline
\end{tabular}




\begin{tabular}{|c|c|c|}
\hline \multicolumn{3}{|l|}{ Continued } \\
\hline REAGENT or RESOURCE & SOURCE & IDENTIFIER \\
\hline 20\% Glutaraldehyde Solution & Wako & Cat\#072-02262 \\
\hline Sodium Chloride & Nacalai tesque, Kyoto, Japan & Cat\#31320-05 \\
\hline Calcium Chloride & Nacalai tesque, Kyoto, Japan & Cat\#06729-55 \\
\hline $0.1 \mathrm{~mol} / \mathrm{I}-$ Cacodylate Buffer Solution & Nacalai tesque, Kyoto, Japan & Cat\#37238-25 \\
\hline Potassium hexacyanoferrate (II) trihydrate & Sigma-Aldrich & Cat\#P3289 \\
\hline $\begin{array}{l}\text { Osmium tetroxide solution for electron } \\
\text { microscopy, } 4 \% \text { in } \mathrm{H} 2 \mathrm{O}\end{array}$ & Sigma-Aldrich & Cat\#75632 \\
\hline Hexamethyldisilazane & Sigma-Aldrich & Cat\#440191 \\
\hline Potassium Chloride & Nacalai tesque, Kyoto, Japan & Cat\#28538-62 \\
\hline Methanol & Nacalai tesque, Kyoto, Japan & Cat\#21915-35 \\
\hline Acetic acid & Nacalai tesque, Kyoto, Japan & Cat\#00212-56 \\
\hline Metaphase Arresting Solution & Genial Helix & Cat\#GGS-JL008 \\
\hline $\begin{array}{l}\text { Giemsa's Azure Eosin Methylene Blue } \\
\text { solution }\end{array}$ & Sigma-Aldrich & Cat\#109204 \\
\hline \multicolumn{3}{|l|}{ Critical commercial assays } \\
\hline hCG ELISA kit & Abcam & Cat\#ab100533 \\
\hline MycoAlert Mycoplasma Detection Kit & Lonza & Cat\#LT07-118 \\
\hline RNeasy Mini Kit & QIAGEN & Cat\#74106 \\
\hline SuperScript IV Reverse Transcriptase & Thermo Fisher Scientific & Cat\#18090050 \\
\hline TaqMan Fast Universal PCR Master Mix & Thermo Fisher Scientific & Cat\#4364103 \\
\hline PowerUp Sybr Green Master Mix & Thermo Fisher Scientific & Cat\#A25743 \\
\hline miRNeasy Mini Kit & QIAGEN & Cat\#217004 \\
\hline TruSeq Stranded mRNA LT Sample Prep Kit & Illumina & Cat\#RS-122-2101 \\
\hline NextSeq 500 High Output v2.5 Kit & Illumina & Cat\#FC-404-2005 \\
\hline miScript II RT Kit & QIAGEN & Cat\#218161 \\
\hline $\begin{array}{l}\text { 10x Chromium Single Cell } 30 \text { GEM, Library } \\
\text { \& Gel Bead Kit v3 }\end{array}$ & 10x Genomics & Cat\#PN-1000075 \\
\hline DNeasy Blood \& Tissue Kit & QIAGEN & Cat\#69504 \\
\hline EpiTect Bisulfite Kit & QIAGEN & Cat\#59104 \\
\hline Wizard SV Gel and PCR Clean-Up System & Promega & Cat\#A9285 \\
\hline $\begin{array}{l}\text { N-SPC Non-Radioactive Cellular } \\
\text { Cytotoxicity Assay Kit }\end{array}$ & Techno Suzuta, Nagasaki, Japan & Cat\#NSPC-01 \\
\hline \multicolumn{3}{|l|}{ Deposited data } \\
\hline RNA seq analysis & This paper & GEO: GSE144994 \\
\hline Single-cell RNA-Seq analysis & This paper & GEO: GSE167924 \\
\hline $\begin{array}{l}\text { Single-cell RNA-Seq profiling of human } \\
\text { preimplantation embryos and embryonic } \\
\text { stem cells }\end{array}$ & Yan et al., 2013 & $\begin{array}{l}\text { European Nucleotide Archive: } \\
\text { PRJNA153427 }\end{array}$ \\
\hline $\begin{array}{l}\text { Defining the three cell lineages of the human } \\
\text { blastocyst by single-cell RNA-seq }\end{array}$ & Blakeley et al., 2015 & ArrayExpress: E-GEOD-66507 \\
\hline $\begin{array}{l}\text { KeyGenes, a Tool to Probe Tissue } \\
\text { Differentiation Using a Human Fetal } \\
\text { Transcriptional Atlas }\end{array}$ & Roost et al., 2015 & GEO: GSE66302 \\
\hline $\begin{array}{l}\text { SC3-seq: a method for highly parallel and } \\
\text { quantitative measurement of single-cell } \\
\text { gene expression }\end{array}$ & Nakamura et al., 2015 & GEO: GSE63266 \\
\hline $\begin{array}{l}\text { A developmental coordinate of pluripotency } \\
\text { among mice, monkeys, and humans }\end{array}$ & Nakamura et al., 2016 & GEO: GSE74767 \\
\hline $\begin{array}{l}\text { Single-Cell RNA-Seq Reveals Lineage and } \\
X \text { Chromosome Dynamics in Human }\end{array}$ & Petropoulos et al., 2016 & ArrayExpress: E-MTAB-3929 \\
\hline
\end{tabular}

$X$ Chromosome Dynamics in Human

Preimplantation Embryos 


\begin{tabular}{|c|c|c|}
\hline \multicolumn{3}{|l|}{ Continued } \\
\hline REAGENT or RESOURCE & SOURCE & IDENTIFIER \\
\hline $\begin{array}{l}\text { RNA-seq reveals conservation of function } \\
\text { among the yolk sacs of human, mouse, and } \\
\text { chicken }\end{array}$ & Cindrova-Davies et al., 2017 & $\begin{array}{l}\text { European Nucleotide Archive: } \\
\text { PRJEB18767 }\end{array}$ \\
\hline $\begin{array}{l}\text { Establishment of porcine and human } \\
\text { expanded potential stem cells }\end{array}$ & Gao et al., 2019 & ArrayExpress: E-MTAB-7253 \\
\hline $\begin{array}{l}\text { Reconstituting the transcriptome and DNA } \\
\text { methylome landscapes of human } \\
\text { implantation }\end{array}$ & Zhou et al., 2019 & GEO: GSE109555 \\
\hline $\begin{array}{l}\text { Derivation of trophoblast stem cells from } \\
\text { naive human pluripotent stem cells }\end{array}$ & Dong et al., 2020 & GEO: GSE138688 \\
\hline $\begin{array}{l}\text { Naive Human Embryonic Stem Cells Can } \\
\text { Give Rise to Cells with a Trophoblast-like } \\
\text { Transcriptome and Methylome }\end{array}$ & Cinkornpumin et al., 2020 & GEO: GSE152101 \\
\hline \multicolumn{3}{|l|}{ Experimental models: Cell lines } \\
\hline Human embryonic stem cell line: H9 (WA09) & WiCell Research Institute & hPSCreg ID: WAe009-A \\
\hline $\begin{array}{l}\text { Human induced pluripotent stem cell } \\
\text { line: 409B2 }\end{array}$ & Okita et al., 2011 & N/A \\
\hline $\begin{array}{l}\text { Human induced pluripotent stem cell line: } \\
\text { AdiPS } 1\end{array}$ & University of Cambridge & hPSCreg ID: CAMi004-A \\
\hline Human choriocarcinoma: JAR & ATCC & Cat\#HTB-144 \\
\hline human trophoblast stem cell line: СТЗ0 & Riken BRC & Cat\#RCB4938 \\
\hline \multicolumn{3}{|l|}{ Experimental models: Organisms/strains } \\
\hline Cynomolgus monkeys (Macaca fascicularis) & $\begin{array}{l}\text { the Experimental Animal Center of Shiga } \\
\text { University }\end{array}$ & N/A \\
\hline \multicolumn{3}{|l|}{ Oligonucleotides } \\
\hline $\begin{array}{l}\text { See Table S5 for the RT-qPCR primers used } \\
\text { in this study }\end{array}$ & This paper & Table S5 \\
\hline $\begin{array}{l}\text { Primer: human ELF5-2b BiS }-483 \mathrm{~F} \\
\text { (Forward; first PCR): } \\
\text { GGAAATGATGGATATTGAATTGA }\end{array}$ & Lee et al., 2016 & $\mathrm{~N} / \mathrm{A}$ \\
\hline $\begin{array}{l}\text { Primer: human ELF5-2b BiS +31R (Reverse; } \\
\text { first PCR): } \\
\text { CAATAAAAATAAAAACACCTATAACC }\end{array}$ & Lee et al., 2016 & N/A \\
\hline $\begin{array}{l}\text { Primer: human ELF5-2b BiS - } 432 \mathrm{~F} \\
\text { (Forward; second PCR): } \\
\text { GAGGTITAATATTGGGTTATAATG }\end{array}$ & Lee et al., 2016 & $\mathrm{~N} / \mathrm{A}$ \\
\hline $\begin{array}{l}\text { Primer: human ELF5-2b BiS -3R (Reverse; } \\
\text { second PCR): } \\
\text { ATAAATAACACCTACAAACAAATCC }\end{array}$ & Lee et al., 2016 & N/A \\
\hline $\begin{array}{l}\text { Primer: DNA seq primer in pCR-XL-TOPO } \\
\text { vector: GACCATGATTACGCCAAGCTA }\end{array}$ & This paper & N/A \\
\hline hsa-miR-518c-5p miScript Primer Assay & QIAGEN & Cat\#MS00038612 \\
\hline hsa-miR-520c-3p miScript Primer Assay & QIAGEN & Cat\#MS00007413 \\
\hline hsa-miR-519d miScript Primer Assay & QIAGEN & Cat\#MS00004508 \\
\hline Hs_RNU6-2_11 miScript Primer Assay & QIAGEN & Cat\#MS00033740 \\
\hline \multicolumn{3}{|l|}{ Recombinant DNA } \\
\hline pCR-XL-TOPO vector & Thermo Fisher Scientific & Cat\#K453020 \\
\hline pCR-BluntII-TOPO vector & Thermo Fisher Scientific & Cat\#K450245 \\
\hline KW908_pIRESeGFP-delTKneo & This paper & N/A \\
\hline pX330-U6-Chimeric_BB-CBh-hSpCas9 & Cong et al., 2013 & Cat\#42230; RRID: Addgene_42230 \\
\hline
\end{tabular}




\begin{tabular}{|c|c|c|}
\hline \multicolumn{3}{|l|}{ Continued } \\
\hline REAGENT or RESOURCE & SOURCE & IDENTIFIER \\
\hline \multicolumn{3}{|l|}{ Software and algorithms } \\
\hline Graphpad Prism 9 & GraphPad Software & $\begin{array}{l}\text { https://www.graphpad.com/scientific- } \\
\text { software/prism/; RRID:SCR_002798 }\end{array}$ \\
\hline FlowJo software 10.6.1 & FlowJo, LCC & $\begin{array}{l}\text { https://www.flowjo.com/; } \\
\text { RRID:SCR_008520 }\end{array}$ \\
\hline Imaging Software CL-Quant (v3.31) & Nikon Intech & $\begin{array}{l}\text { https://www.nikon.com/products/ } \\
\text { microscope-solutions/lineup/integrated/ } \\
\text { cl-quant/ }\end{array}$ \\
\hline Incucyte Base Software & Sartorius & $\begin{array}{l}\text { https://www.essenbioscience.com/en/ } \\
\text { products/software/incucyte-base- } \\
\text { software/ }\end{array}$ \\
\hline Leica Application Suite X & Leica & $\begin{array}{l}\text { https://www.leica-microsystems.com/; } \\
\text { RRID:SCR_013673 }\end{array}$ \\
\hline Zen 2.3 SP1 & Carl Zeiss & $\begin{array}{l}\text { https://www.zeiss.com/microscopy/int/ } \\
\text { products/microscope-software/zen.html; } \\
\text { RRID:SCR_018163 }\end{array}$ \\
\hline ImageJ v1.53 g & $\mathrm{NIH}$ & $\begin{array}{l}\text { https://imagej.nih.gov/ij/; } \\
\text { RRID:SCR_003070 }\end{array}$ \\
\hline R 3.5 .1 & The R Foundation for Statistical Computing & http://www.R-project.org/ \\
\hline cutadapt-1.16 & Martin, 2011 & $\begin{array}{l}\text { https://cutadapt.readthedocs.io/en/v1.16/ } \\
\text { index.html }\end{array}$ \\
\hline HISAT v2.1.0 & Kim et al., 2019 & $\begin{array}{l}\text { https://kbase.us/applist/apps/kb_hisat2/ } \\
\text { align_reads_using_hisat2/release }\end{array}$ \\
\hline GENCODE v30 & Frankish et al., 2019 & https://www.gencodegenes.org/ \\
\hline HTSeq-count v0.11.2 & Anders et al., 2015 & $\begin{array}{l}\text { https://github.com/genepattern/ } \\
\text { HTSeq.Count }\end{array}$ \\
\hline edgeR v3.24.3 & McCarthy et al., 2012 & $\begin{array}{l}\text { https://bioconductor.org/packages/ } \\
\text { release/bioc/html/edgeR.html }\end{array}$ \\
\hline DAVID 6.8 & Huang et al., 2009 & https://david.ncifcrf.gov/home.jsp \\
\hline Seurat 3.2.3 & Butler et al., 2018 & https://satijalab.org/seurat/ \\
\hline Monocle 2.18.0 & Qiu et al., 2017 & $\begin{array}{l}\text { http://cole-trapnell-lab.github.io/monocle- } \\
\text { release/ }\end{array}$ \\
\hline Cell Ranger 5.0.1 & N/A & $\begin{array}{l}\text { https://support.10xgenomics.com/single- } \\
\text { cell-gene-expression/software/pipelines/ } \\
\text { latest/what-is-cell-ranger }\end{array}$ \\
\hline Maternal-Fetal Interface & Vento-Tormo et al., 2018 & $\begin{array}{l}\text { https://maternal-fetal-interface.cellgeni. } \\
\text { sanger.ac.uk/ }\end{array}$ \\
\hline
\end{tabular}

\section{RESOURCE AVAILABILITY}

\section{Lead contact}

Further information and requests for resources or reagents should be directed to and will be fulfilled by the lead contact, Yasuhiro Takashima (y.takashima@cira.kyoto-u.ac.jp).

Materials availability

All stable reagents generated in this study are available from the lead contact.

Data and code availability

The RNA sequencing data reported in this paper is in NCBI Gene Expression Omnibus under accession number GEO: GSE144994 and GEO: GSE167924.

\section{EXPERIMENTAL MODEL AND SUBJECT DETAILS}

All cells were cultured in $5 \% \mathrm{O}_{2}, 5 \% \mathrm{CO}_{2}$ except where noted otherwise. 


\section{Pluripotent Stem Cell Cultures}

Culture of human primed pluripotent stem cells

The human ESC line H9 (WiCell Research Institute) and the human iPSC lines 409B2 (Okita et al., 2011) and AdiPS (Takashima et al., 2014) were cultured on mouse embryonic fibroblast (MEF) cells $\left(1 \times 10^{6}\right.$ cells per 6 -well plate).

Primed human PSCs were maintained in DMEM/Ham's F-12 (Nacalai Tesque, Cat. 08460-95) with 20\% Knockout Serum Replacement (KSR; Thermo Fisher Scientific, Cat. 10828028), 1\% nonessential amino acids (Thermo Fisher Scientific, Cat. 11140-050), 4 ng/ $\mathrm{ml}$ recombinant human basic fibroblast growth factor 2 (bFGF; Oriental Yeast, Cat. NIB 47079000), and $0.1 \mathrm{mM} 2$-mercaptoethanol (2ME; Sigma-Aldrich, Cat.M3148). Cultures were passaged every 5-7 days as small clumps by dissociation buffer containing $0.025 \%$ Trypsin (Thermo Fisher Scientific, Cat. 15090-046), 1 mg/ml Collagenase IV (Thermo Fisher Scientific, Cat. 17104-019), 20\% KSR, and $1 \mu \mathrm{M} \mathrm{CaCl}_{2}$.

Naive human PSCs were maintained in t2iLGö medium, which consists of N2B27 (Ndiff227: Takara Bio, Cat. Y40002) with $1 \mu \mathrm{M}$ PD0325901 (PD03; Tocris, Cat. 4192), $1 \mu \mathrm{M}$ CHIR99021 (CH; Sigma-Aldrich, Cat. SML1046), 10 ng/ml Recombinant human LIF (hLIF; Peprotech, Cat. 300-05), and $2 \mu \mathrm{M}$ Gö6983 (Gö; Tocris, Cat. 2285), as previously described (Takashima et al., 2014). Naive PSCs were passaged every 3-5 days using Accutase (Sigma-Aldrich, Cat. A6964).

Chemical conversion to naive PSCs was performed as previously described (Guo et al., 2017). Primed PSCs $\left(1 \times 10^{4}\right.$ cells/cm $\left.{ }^{2}\right)$ were seeded on MEF feeder cells in primed PSC medium with $10 \mu \mathrm{M} \mathrm{Y-27632.} \mathrm{On} \mathrm{the} \mathrm{next} \mathrm{day,} \mathrm{the} \mathrm{medium} \mathrm{was} \mathrm{switched} \mathrm{to} \mathrm{cRM-1}$ (N2B27 + $1 \mu \mathrm{M}$ PD03, $10 \mathrm{ng} / \mathrm{ml}$ hLIF, and $1 \mathrm{mM}$ valproic acid sodium salt (VPA; Sigma-Aldrich, Cat. P4543)). On day 3, the medium was replaced with cRM-2 (N2B27 + $1 \mu \mathrm{M}$ PD03, $10 \mathrm{ng} / \mathrm{ml} \mathrm{hLIF,} 2 \mu \mathrm{M}$ Gö, and $2 \mu \mathrm{M}$ XAV939 (Sigma-Aldrich, Cat. X3004)). Domeshaped naive colonies were observed around two weeks after plating. Cells were split every 5-7 days after dissociation with Accutase. Reset cells were passaged and maintained on MEF feeders in t2iLGö. Chemical conversion to naive PSCs using 5iLA was also performed as previously described (Theunissen et al., 2014, 2016). $2 \times 10^{4}$ cells $/ \mathrm{cm}^{2}$ were seeded on MEF feeder cells under primed PSC medium with $10 \mu \mathrm{M}$ Y-27632. On the next day, the medium was switched to 5iLA media (Ndiff227 supplemented with $1 \mu \mathrm{M}$ PD03, $1 \mu \mathrm{M} \mathrm{CH}, 1 \mu \mathrm{M}$ WH-4-023 (A Chemtek, Cat. H620061), $0.5 \mu \mathrm{M}$ SB590885 (R\&D systems, Cat. 2650), 10 $\mu \mathrm{M}$ Y-27632, $10 \mathrm{ng} / \mathrm{ml} \mathrm{hLIF}$, and $20 \mathrm{ng} / \mathrm{ml}$ Activin A (R\&D, Cat. 338-AC-010)). After conversion to naive PSCs, the cells were maintained in t2iLGö on MEF feeder cells.

\section{Cynomolgus Monkey Specimens}

Experimental procedures using cynomolgus monkeys were approved by the Animal Care and Use Committee of Shiga University of Medical Science. The procedures in cynomolgus monkeys for oocyte collection, intra-cytoplasmic sperm injection (ICSI), pre-implantation embryo culture, and transfer of pre-implantation embryos into foster mothers were performed as described previously with minor modifications (Nakamura et al., 2016; Yamasaki et al., 2011). Ovulation induction with follicle stimulating hormone (Gonapure; ASKA Pharmaceutical) was performed by embedding an implantable and programmable micro-fusion device (iPRECIO; Primetech Corporation) subcutaneously. The day when the ICSI was performed was designated as embryonic day (E)0. The progression of the pre-implantation development of cynomolgus monkeys was highly similar to that of rhesus monkeys (Wolf et al., 2004) but was somewhat slower than that of humans (Wong et al., 2010). For embryo transfer, 4 to 5 two-cell to blastocyst-stage embryos were selected and transferred into an appropriate recipient female. For the detection of pregnancy of early post-implantation embryos, implanted embryos were monitored by ultrasonography around E13, and the implanted uterus was surgically removed and bisected for the isolation of embryos.

\section{Clinical Samples}

All tissue samples used for this study were obtained with written informed consent from all participants in accordance with the guidelines in The Declaration of Helsinki 2000. Human chorionic villi of elective abortions were obtained from Kawamura Ladies Clinic and Adachi Hospital (5-11 gestational weeks). The tissue donations were made entirely voluntarily by women undergoing termination of pregnancy. Donors were asked to give explicit written consent for the fetal material to be collected, and only after they had been counselled about the termination of their pregnancy. Gestational age was estimated with a combination of last menstrual period and ultrasonography. The use of all human prenatal samples for the work described in this study was approved by ethics committee at the Center for iPS Cell Research \& Application (CiRA), Kyoto University.

\section{METHOD DETAILS}

\section{Differentiation into nTEs}

Naive PSCs were seeded on Laminin-E8 $\left(0.15 \mu \mathrm{g} / \mathrm{cm}^{2}\right.$ iMatrix 511 silk; Nippi) at $2 \times 10^{4} \mathrm{cells} / \mathrm{cm}^{2}$. The Laminin-E8-coated dish was pre-incubated at $37^{\circ} \mathrm{C}$ for at least $30 \mathrm{~min}$. The initial induction medium was composed of Ndiff227, $2 \mu \mathrm{M}$ A83-01 (ALK4/5/7 inhibitor; Tocris), and $2 \mu \mathrm{M}$ PD03. The following day, the medium was changed to Ndiff227, $2 \mu \mathrm{M} \mathrm{A83-01,2 \mu M} \mathrm{PD03,} \mathrm{and} 1 \mu \mathrm{g} / \mathrm{ml} \mathrm{JAK}$ inhibitor I (Merck, Cat. 420099-1 MGCN). The medium was changed again the next day. $10 \mathrm{ng} / \mathrm{ml}$ recombinant human BMP4 (R\&D systems) was optionally added for 24 hours after the induction. Cells were dissociated with Accutase for 20-30 min. 
Culture of nCTs

TACSTD2 $^{+}$ENPEP $^{+}$nTEs on day 3 were sorted and cultured in ACE medium (Ndiff227, $1 \mu \mathrm{M} \mathrm{A83-01,} 2 \mu \mathrm{M} \mathrm{CH}$, and $50 \mathrm{ng} / \mathrm{ml}$ EGF (R\&D systems, Cat.236-EG)) on Laminin-E8 $\left(0.15 \mu \mathrm{g} / \mathrm{cm}^{2}\right)$ at $\left.4 \times 10^{4} \mathrm{cell} / \mathrm{s} / \mathrm{cm}^{2}\right)$. The culture medium was replaced every two days. Cells were passaged every three to six days by dissociation with Accutase for 10-15 min and seeded at a 1:3-1:4 split ratio. $10 \mu \mathrm{M}$ Y-27632 was added for every passage. Cells were cryopreserved in Stem-Cellbanker (Takara Bio) and stored in a deep freezer at $-80^{\circ} \mathrm{C}$.

Differentiation into nSTs

nCTs were seeded on Col IV $(1 \mu \mathrm{g} / \mathrm{ml})$ or Laminin-E8 $\left(0.15 \mu \mathrm{g} / \mathrm{cm}^{2}\right)$ at $1 \times 10^{4} \mathrm{cells} / \mathrm{cm}^{2}$. ST medium was composed of DMEM/Ham's F-12 supplemented with $0.1 \mathrm{mM}$ 2ME, 0.3\% BSA, 1\% ITS-X supplement (Life Technologies), 4\% KSR, $2 \mu \mathrm{M}$ forskolin (cAMP activator; Wako, Cat. 067-02191), and $2.5 \mu \mathrm{M} \mathrm{Y-27632,} \mathrm{as} \mathrm{previously} \mathrm{described} \mathrm{(Okae} \mathrm{et} \mathrm{al.,} \mathrm{2018).} \mathrm{ST} \mathrm{medium} \mathrm{was} \mathrm{replaced} \mathrm{at} \mathrm{day} 3$ and cultured for three additional days. Cells were incubated in $21 \% \mathrm{O}_{2}, 5 \% \mathrm{CO}_{2}$ in a humidified incubator at $37^{\circ} \mathrm{C}$.

\section{Differentiation into nEVTs}

nCTs were seeded on Col IV $(1 \mu \mathrm{g} / \mathrm{ml})$ or Laminin-E8 $\left(0.15 \mu \mathrm{g} / \mathrm{cm}^{2}\right)$ at $0.8 \times 10^{4} \mathrm{cells} / \mathrm{cm}^{2}$. EVT-1 medium was composed of DMEM/ Ham's F-12 supplemented with $0.1 \mathrm{mM}$ 2ME, 0.3\% BSA, 1\% ITS-X supplement, 4\% KSR, $7.5 \mu \mathrm{M}$ A83-01, $100 \mathrm{ng} / \mathrm{ml} \mathrm{NRG1}$ (Cell Signaling, Cat. 5218SC), and $2.5 \mu \mathrm{M} \mathrm{Y-27632,} \mathrm{as} \mathrm{previously} \mathrm{described} \mathrm{(Okae} \mathrm{et} \mathrm{al.,} \mathrm{2018).} \mathrm{After} \mathrm{the} \mathrm{cells} \mathrm{were} \mathrm{plated,} \mathrm{Geltrex} \mathrm{(Thermo}$ Fisher Scientific, Cat. A1413302) was added to a final concentration of $2 \%$. EVT-1 medium was replaced on day 3 with EVT-2 medium (DMEM/Ham's F-12 supplemented with $0.1 \mathrm{mM}$ 2ME, 0.3\% BSA, 1\% ITS-X supplement, 4\% KSR, $7.5 \mu \mathrm{M}$ A83-01, and $2.5 \mu \mathrm{M} \mathrm{Y-}$ 27632), and Geltrex was added to a final concentration of $0.5 \%$. On day 6 after the EVT induction, the cells were dissociated into single cells with Accutase for 10-15 min and seeded on a new Col IV- or Laminin-E8-coated plate at a 1:2-1:3 split ratio. The cells were cultured in EVT-3 medium (DMEM/Ham's F-12 supplemented with $0.1 \mathrm{mM}$ 2ME, 0.3\% BSA, $1 \%$ ITS-X supplement, $7.5 \mu \mathrm{M}$ A83-01, and $2.5 \mu \mathrm{M}$ Y-27632), and Geltrex was added to a final concentration of $0.5 \%$. The cells were analyzed on day 8 after the EVT induction and incubated in $21 \% \mathrm{O}_{2}, 5 \% \mathrm{CO}_{2}$ in a humidified incubator at $37^{\circ} \mathrm{C}$.

\section{Culture of nCT organoids}

nCT-organoids were cultured as trophoblast organoids (Turco et al., 2018). $2-4 \times 10^{5} \mathrm{nCTs}$ were resuspended in $500 \mu \mathrm{L}$ growth-factor-reduced Matrigel (Corning, Cat. 356231) on ice. Matrigel drops $(25 \mu l)$ including nCTs were plated per well into a 48 -well culture plate (Cellstar, Cat. 677-180), which was then incubated in a humidified incubator at $37^{\circ} \mathrm{C}$ for $15 \mathrm{~min}$. The firm drops were overlaid with trophoblast organoid medium (Ndiff227 supplemented with $1.25 \mathrm{mM} \mathrm{N}$-Acetyl-L-cysteine (Sigma, Cat. A2921201), $2 \mathrm{mM} \mathrm{L-}$ glutamine, $0.5 \mu \mathrm{M}$ A83-01, $1.5 \mu \mathrm{M} \mathrm{CH}, 50 \mathrm{ng} / \mathrm{ml} \mathrm{EGF,} 80 \mathrm{ng} / \mathrm{ml}$ R-spondin 1 (R\&D systems, Cat. 4645-RS-100), $100 \mathrm{ng} / \mathrm{ml} \mathrm{bFGF}$, $50 \mathrm{ng} / \mathrm{ml}$ HGF (Peprotech, Cat. 100-39), $2.5 \mu$ M PGE2 (Sigma, Cat. P0409), and $2.5 \mu \mathrm{M}$ Y-27632). Trophoblast organoid medium was replaced every 2-3 days. Organoids were incubated in $5 \% \mathrm{O}_{2}, 5 \% \mathrm{CO}_{2}$ in a humidified incubator at $37^{\circ} \mathrm{C}$ and passaged every 7-10 days by mechanical disruption with a Picus NxT electronic single channel electronic pipette (Sartorius) on a mix cycle of 99 rounds (4-5 times), maximum speed. The organoids were cryopreserved in Stem-Cellbanker and stored in a deep freezer at $-80^{\circ} \mathrm{C}$.

\section{Differentiation into nEVT from nCT organoids}

EVT differentiation was carried through the modification of a protocol described previously (Okae et al., 2018; Turco et al., 2018). After one passage, $\mathrm{nCT}$ organoids were maintained in trophoblast organoid medium for 3-4 days and then in EVT-1 medium. EVT-1 medium was replaced on day 3 with EVT-2 medium. On day 6 after the EVT induction, the medium was switched to EVT-3 medium. The medium was changed again after 3 days.

Culture of BAP-treated primed pluripotent stem cells

Human primed PSCs were dissociated into single cells with trypsin/EDTA (Nacalai Tesque). The cells were plated on a Laminin-E8coated dish at a density of $2 \times 10^{4} \mathrm{cells} / \mathrm{cm}^{2}$ and cultured with MEF-conditioned medium supplemented with $10 \mathrm{ng} / \mathrm{ml} \mathrm{BMP} 4,1 \mu \mathrm{M}$ A83-01, $0.1 \mu \mathrm{M}$ PD173074 (FGF2 signaling inhibitor; Selleck, Cat. S1264), and $10 \mu \mathrm{M}$ Y-27632, as described previously with some modifications (Amita et al., 2013). DMEM/Ham's F-12 medium containing 0.1 mM 2ME, $1 \%$ ITS-X supplement, $1 \%$ NEAA, 2 mM Lglutamine, and $20 \% \mathrm{KSR}$ was cultured on MEF for 24 hours, and the supernatant was collected and used as MEF-conditioned medium. The medium was changed daily.

Culture of BMP4- and IWP2-treated primed pluripotent stem cells

Human primed PSCs were dissociated into single cells with trypsin/EDTA. The cells were plated on a Geltrex-coated dish at a density of $2 \times 10^{4} \mathrm{cells} / \mathrm{cm}^{2}$ and cultured with Stemfit AK02N (Reprocell) and $10 \mu \mathrm{M} \mathrm{Y-27632.} \mathrm{On} \mathrm{the} \mathrm{next} \mathrm{day,} \mathrm{the} \mathrm{medium} \mathrm{was} \mathrm{switched} \mathrm{to}$ differentiation medium (KnockOut DMEM/Ham's F-12 medium containing $10 \mathrm{ng} / \mathrm{ml} \mathrm{BMP4,} 2 \mu \mathrm{M}$ IWP2, $1 \%$ ITS supplement, 2 mM Lglutamine, $543 \mu \mathrm{g} / \mathrm{ml} \mathrm{NaHCO}$, and $2 \% \mathrm{BSA}$ ), as described previously (Horii et al., 2019). The medium was changed daily. The cells were analyzed on day 4 after the CT-like cell induction and incubated in $21 \% \mathrm{O}_{2}, 5 \% \mathrm{CO}_{2}$ in a humidified incubator at $37^{\circ} \mathrm{C}$. 
Culture of human trophoblast stem cells

CT30 cells were cultured as described previously (Okae et al., 2018). The culture medium was composed of DMEM/Ham's F-12 supplemented with $0.1 \mathrm{mM}$ 2ME, 0.3\% BSA, 0.2\% FBS, 1\% ITS-X supplement, $1.5 \mu \mathrm{g}$ L-ascorbic acid (Sigma-Aldrich), 0.5 $\mu \mathrm{M} \mathrm{A83-01,}$ $2 \mu \mathrm{M} \mathrm{CH}, 50 \mathrm{ng} / \mathrm{ml}$ EGF, $1 \mu \mathrm{M}$ SB431542 (Tocris), $0.8 \mathrm{mM} \mathrm{VPA}$, and $5 \mu \mathrm{M}$ Y-27632. The cells were cultured on a Col IV-coated well dish, passaged every 2-3 days by dissociation with TrypLE at a 1:2-1:4 split ratio, and then incubated in $21 \% \mathrm{O}_{2}, 5 \% \mathrm{CO}_{2}$ in a humidified incubator at $37^{\circ} \mathrm{C}$. Finally, the cells were cryopreserved in Cell Banker 1 (Takara Bio) and stored in a deep freezer at $-80^{\circ} \mathrm{C}$.

\section{Culture of JAR}

JAR cells were cultured as described previously. The cells were plated on gelatin-coated dish at a density of $5 \times 10^{3}$ cells $/ \mathrm{cm}^{2}$ and cultured with RPMI-1640 medium supplemented with 10\% FBS. The medium was changed every 2 days. The cells were incubated in $21 \% \mathrm{O}_{2}, 5 \% \mathrm{CO}_{2}$ in a humidified incubator at $37^{\circ} \mathrm{C}$. At subconfluency, the cells were passaged by dissociation with trypsin/EDTA for 5-15 min, seeded at a 1:3-1:6 split ratio, and then plated, cryopreserved in Cell Banker 1 (Takara Bio) and stored in a deep freezer at $-80^{\circ} \mathrm{C}$.

\section{Generation of CDX2-GFP reporter cell line}

An IRES-eGFP-loxp-human beta actin promoter-NeoR-DeltaTK-loxp cassette from the plasmid KW908_pIRESeGFP-delTKneo was inserted just before the CDX2 stop codon using the CRISPR/Cas9 system. The sequence 5'- CCCGGTGGGTCACTGGGTGACGG $-3^{\prime}$ was selected as the gRNA. Human CDX2 homology arms were $827 \mathrm{bp}$ and $644 \mathrm{bp}$ for the $5^{\prime}$ and $3^{\prime}$ arms, respectively. Correctly targeted clones were identified by genomic PCR. Human beta actin promoter-NeoR selection cassette was excised by pCAG-CreIRES2-GFP plasmid.

\section{Isolation of human cytotrophoblast}

Whole chorionic villi were cut into small pieces and enzymatically digested three times in a solution containing $0.25 \%$ Trypsin-EDTA solution, $1 \mathrm{mg} / \mathrm{ml}$ collagenase IV, $200 \mathrm{U} / \mathrm{mL}$ DNase (Sigma-Aldrich), $25 \mathrm{mM} \mathrm{HEPES}$, and DMEM/F' 12 medium with agitation at $37^{\circ} \mathrm{C}$. Pooled cell suspensions were filtered through a $70 \mu \mathrm{m}$ mesh filter (Corning). After the lysis of erythrocytes in RBC lysis solution (Santa Cruz Biotechnology), CTs were purified using a Alexa Fluor 488-conjugated anti-TACSTD2 antibody, a PE-conjugated anti-CD249 antibody, and biotin-conjugated anti-SIGLEC6 antibody. The TACSTD2 ${ }^{+}$ENPEP ${ }^{+}$SIGLEC6 ${ }^{+}$fraction was collected for RNA-seq samples of in vivo CT.

\section{Bisulfite sequencing of ELF5 promoter}

Genomic DNA was isolated using the DNeasy Blood \& Tissue kit (QIAGEN), and 100-400 ng of genomic DNA was processed for bisulfite conversion using the EpiTect Bisulfite kit (QIAGEN) following the manufacturer's instructions. Nested PCR was performed with Quick Taq HS DyeMix (Toyobo) on a Veriti 96-Well Thermal Cycler (Applied Biosystems). The first PCR (10 cycles) was carried out with ELF5-2b (ELF5-201) BiS-483F and +31R primers. Ten percent of the first PCR products were used for the second PCR (35 cycles) at an annealing temperature of $50^{\circ} \mathrm{C}$ using ELF5-2b BiS-432F and $-3 R$ primers. The gel-purified PCR amplicons were inserted into TOPO-XL PCR cloning vectors (Thermo Scientific), and the products were used to transform Library Efficiency DH5 $\mathrm{a}$ Chemically Competent Cells (Thermo Scientific). After purification with ExoSAP-IT Express PCR Cleanup Reagents (Thermo Scientific), at least eight clones were sequenced for each sample.

\section{Immunocytochemistry}

Cells and organoids were fixed with $4 \%$ paraformaldehyde (PFA, Nakalai Tesque) solution for 10 min at room temperature, permeabilized with $1 \%$ BSA/PBS $+0.5 \%$ Triton X-100 for 1 hour at room temperature, and blocked with $5 \%$ donkey serum (Jackson ImmunoResearch, Cat. 017-000-121)/PBS + 0.05\% Tween-20 (PBS-BT) for 2 hours at room temperature. Primary antibodies were diluted in PBS-BT and incubated overnight at $4^{\circ} \mathrm{C}$. After two washes with PBS-BT, the cells were incubated in PBS-BT for 12 hours at $4^{\circ} \mathrm{C}$. Secondary antibodies were AlexaFluor conjugated, diluted 1:1000 in PBS-BT, and incubated overnight at $4^{\circ} \mathrm{C}$. Nuclei were stained with 4,6-diamidino-2-phenylindole (DAPI, Sigma-Aldrich). Images were acquired using a TSC-8 (Leica, Germany) or LSM710 (Zeiss, Germany) confocal laser scanning microscope. Antibody details are listed in the Key resources table.

\section{Immunohistochemistry}

Cynomolgus monkey embryos in vivo and human clinical samples were fixed in $10 \%$ buffered formalin for 24 hours and embedded in paraffin. Serial sections were taken every $200 \mu \mathrm{m}$. After the sections were deparaffinized, microwave antigen retrieval was performed by incubation with Histo VT one (Nakalai Tesque) for $20 \mathrm{~min}$. After tissue sections were permeabilized with 1\% BSA/PBS + 0.5\% Triton X-100 for 1 hour at room temperature, they were incubated with PBS-BT for 30 min at room temperature. Subsequently, primary antibodies were diluted in PBS-BT and incubated overnight at $4{ }^{\circ} \mathrm{C}$. Secondary antibodies were diluted 1:500 in PBS-BT and incubated overnight at $4{ }^{\circ} \mathrm{C}$. Nuclei were stained with 4,6-diamidino-2-phenylindole (DAPI) and mounted in VECTASHIELD mounting medium (Vector Laboratories). Images were acquired using a TSC-8 or LSM710 microscope. Antibody details are provided in the Key resources table. 
Conventional scanning electron microscopy

Monolayer cell cultures on small glass coverslips $(\varnothing 6 \mathrm{~mm})$ were chemically fixed with $2.5 \%$ glutaraldehyde (GA) and $2 \%$ PFA in $\mathrm{NaHCa}$ buffer (including $100 \mathrm{mM} \mathrm{NaCl}, 30 \mathrm{mM} \mathrm{HEPES}, 2 \mathrm{mM} \mathrm{CaCl}_{2}$, adjusted at $\mathrm{pH} 7.4$ with $\mathrm{NaOH}$ ) for at least a few hours at room temperature. After several washes with $0.1 \mathrm{M}$ cacodylate buffer $(\mathrm{pH} 7.4)$, the cultures were proceeded to post-fixation with $1 \%$ osmium tetroxide $1 \%$ potassium ferrocyanide in $0.1 \mathrm{M}$ cacodylate buffer for 1 hour. After several washes in distilled water, a second post-fixation was performed with $5 \%$ uranyl acetate solution overnight at $4{ }^{\circ} \mathrm{C}$ in a dark refrigerator and then dehydrated with a series of ethanol washes (from $70 \%$ to absolute 100\%). Finally, after special treatment with hexamethyldisilazane (HMDS, SigmaAldrich, St. Louis USA), the dried specimens were sputter-coated with pure gold (EMITECH k950K, Quorum Technologies, Kent UK). Fine observation was performed using a FEI Quanta FEG250 scanning electron microscope (Thermo Fischer Scientific, Oregon USA).

Karyotype analysis

H9 naive human ES cell-derived CT stem cells at passage 10 of culture with ACE medium were incubated with metaphase arrest solution (Genial Helix) for 1.5 hours. The treated cells were dissociated into single cells, resuspended by $0.075 \mathrm{M} \mathrm{KCl} \mathrm{prewarmed}$ to $37^{\circ} \mathrm{C}$, and incubated for 10 minutes. After cell fixation using $75 \%$ methanol and $25 \%$ acetic acid, the fixed cells were dropped on the slides and blow-dried. The slides were stained in Giemsa solution. Karyotype images (30 cells were analyzed) were obtained with a BX-51 microscope (OLYMPUS, Tokyo, JAPAN), and the number of chromosomes was counted manually. Similarly, experiments were conducted using chorionic villi-derived CT stem cells at passage 35.

\section{Flow cytometry}

After dissociation by Accutase at $37^{\circ} \mathrm{C}$, the cells were incubated in basal medium for 30 min at $37^{\circ} \mathrm{C}$. After washes with $\mathrm{HBSS}$ (Thermo Fisher Scientific) and BSA (Sigma-Aldrich) (1\% BSA/HBSS), the cells were incubated with $1 \%$ BSA/HBSS for 30 min on ice. Primary and secondary antibody incubations were performed for 30 min each in $1 \%$ BSA/HBBS on ice, and the cells were washed one time with 1\% BSA/HBBS. Streptavidin-APC (Biolegend) was used as the secondary antibody for biotin-conjugated primary antibodies. Flow cytometry analysis and cell sorting was performed using a BD LSR Fortessa (BD Biosciences, United States) or a BD FACSAria II (BD Biosciences), and the data were analyzed using FlowJo software (LLC).

Quantitative real-time PCR (mRNA \& miRNA)

Cellular RNA was extracted using the RNeasy Mini kit (QIAGEN) following the manufacturer's instructions. MicroRNA (miRNA) was extracted using the Direct-zol RNA Miniprep (Zymo Research). First-strand cDNA was synthesized from 1000 ng RNA using SuperScript IV Reverse Transcriptase (Thermo Fisher Scientific) according to the manufacturer's instructions. cDNA for miRNA quantitative real-time PCR was synthesized using the miScript II RT kit (QIAGEN). The cDNA was diluted 20-fold. Real-time PCR reactions were performed with the Quantstudio 12K Flex real-time PCR and Quantstudio 3 real-time PCR systems (Applied Biosystems, Foster City, CA, USA) using PowerUp SYBR Green Master Mix (Applied Biosystems) for mRNA and the miScript SYBR Green PCR kit (QIAGEN) for miRNA. Samples for mRNA were run as technical triplicates, and the results were analyzed using the delta-delta cycle threshold approach with GAPDH as the endogenous control. In the same way, results for miRNA were analyzed using the delta-delta cycle threshold approach with RNU6-2 as the endogenous control. All original primers for mRNA were designed using PrimerBlast (https://www.ncbi.nlm.nih.gov/tools/primer-blast/). TaqMan Assays (Applied Biosystems) for hsa-miRNA were performed in miR518c-5p, hsa-miR-520c-3p, and hsa-miR-519d. The results were analyzed using QuantStudio Design\&Analysis Software v1.4.1 (Thermo Fisher Scientific). The RT-qPCR primers used in this study are listed in Table S5.

\section{Western blot analysis}

For western blot analysis, $1 \times 10^{6}$ cells were lysed with RIPA buffer (Nakalai Tesque). SDS sample buffer was added, and the mixture was incubated at $95^{\circ} \mathrm{C}$ for $5 \mathrm{~min}$. To detect phosphorylated (p)SMAD1/5, pSMAD2, pERK1/2 and pSTAT3, cells were treated with Phosphatase Inhibitor Cocktail (Nakalai Tesque) prior to the lysis. The extracted proteins were separated on Bolt 4 to $12 \%$, BisTris, $1.0 \mathrm{~mm}$, Mini Protein Gel (Thermo Fisher) and blotted onto Immobilon-P PVDF Membrane transfer membrane (Merck, Cat. IPVH00010) by using a Mini PROTEAN Tetra Cell (Bio-rad). The transferred membranes were incubated with the following primary antibodies: mouse anti-alpha-Tubulin (Sigma-Aldrich, Cat. T6199), rabbit anti-pSMAD1/5 IgG (CST, Cat. 9516), rabbit anti-pSMAD2 IgG (CST, Cat. 3101), rabbit anti-pERK1/2 IgG (CST, Cat. 4370), and rabbit anti-pSTAT3 IgG (CST, Cat. 9131). The primary antibodies were detected with anti-rabbit IgG, HRP-linked antibody (Cat. 7074), and anti-mouse IgG, HRP-linked antibody (Cat. 7076) followed by detection using Luminata Forte Western HRP substrate (Merck, Cat. WBLUF0500). Chemiluminescence images were acquired using a ImageQuant LAS 4000 (GE Healthcare).

\section{Fusion event analysis}

The fusion index represents the percentage of cell-cell fusion events. Syncytia were defined as cells with at least three nuclei. The number of DAPI-stained nuclei and syncytia were counted. The fusion index was calculated using the following formula: $[(\mathrm{N}-\mathrm{S}) / \mathrm{T}] \mathrm{x}$ 100. N, the number of nuclei in the syncytia; S, the number of syncytia; $T$, total number of nuclei counted. 


\section{ELISA of hCG}

$\mathrm{nCTs}$ were seeded on Laminin-E8 $\left(0.15 \mu \mathrm{g} / \mathrm{cm}^{2}\right)$ at a density of $1 \times 10^{4}$ cells $/ \mathrm{cm}^{2}$ and differentiated into nSTs as described above. ST medium was replaced at day 3 . The supernatant was collected at day 6 and stored at $-80^{\circ} \mathrm{C}$ until use. As controls, nCTs were seeded on Laminin-E8 $\left(0.15 \mu \mathrm{g} / \mathrm{cm}^{2}\right)$ at a density of $1 \times 10^{4} \mathrm{cells} / \mathrm{cm}^{2}$ and cultured in ACE medium. On day 3 , the supernatant was collected and stored at $-80^{\circ} \mathrm{C}$ until use. hCG ELISA (Abcam; Cat. ab100533) was performed using $100 \mu \mathrm{L}$ supernatant in triplicate alongside $\mathrm{hCG}$ standards according to the manufacturer's instructions. Absorbance at $450 \mathrm{~nm}$ and $570 \mathrm{~nm}$ was monitored by a multimode plate reader (2104 Envision; PerkinElmer Inc, Waltham, MA, USA). As a positive control, maternal serum hCG was also examined in the same experiment. The concentration of secreted hCG in the supernatants was calculated from the line formula of the standard plots in Graphpad Prism.

\section{Killing assay}

The antigen-specific responses of decidual NK cells were measured by the BM-HT assay (N-SPC Non-Radioactive Cellular Cytotoxicity Assay Kit, TECHNO SUZUTA, Japan). In brief, $1 \times 10^{6}$ target nCTs or nEVTs were cultured with $2.5 \mu \mathrm{L}$ BM-HT for 15 minutes. Then 5,000 target cells/well were co-cultured at various effector/target (E/T) ratios with effector decidual NK cells for 1 hour. Released BM$\mathrm{HT}$ in the supernatant was mixed with Eu-solution, and luminescence was measured by a Nivo TM plate reader (PerkinElmer). CD45 ${ }^{+-}$ $\mathrm{CD}_{56}{ }^{+} \mathrm{CD}^{-}$decidual NK cells were collected from 6 gestational week placenta, expanded by mixing with irradiated human PBMC, and co-cultured in a-MEM medium in the presence of $10 \mathrm{ng} / \mathrm{ml} \mathrm{IL-7,} 10 \mathrm{ng} / \mathrm{ml} \mathrm{IL-15}$ (Peprotech), and $2 \mu \mathrm{g} / \mathrm{ml}$ Phytohemagglutinin PHA-P (Sigma).

\section{Time-lapse analysis}

For the time-lapse analysis of nCTs, time-lapse phase-contrast microscopy was performed using a Biostation CT (Nikon-Intech, Tokyo, JAPAN). Images were acquired every 40 minutes over a course. MP4 movies were generated using a CL-Quant Ver3.31 (NikonIntech, Tokyo, JAPAN). For the time-lapse analysis of nEVT differentiation from nCTorganoids, time-lapse phase-contrast microscopy was performed using an Incucyte S3 (Sartorius). Images were acquired every 90 minutes over a course. MP4 movies were generated using Incucyte Base Software 2019B Rev3 (Sartorius).

RNA sequencing and data analysis

Total RNA was isolated using the miRNeasy Mini kit. The purity of the extracted RNA was evaluated using a NanoDrop 2000 spectrophotometer (Thermo Fisher Scientific), and the concentration of the RNA was assessed using a Qubit 3.0 fluorometer (Thermo Fisher Scientific). The library was constructed by using $200 \mathrm{ng}$ total RNA and the TruSeq Stranded mRNA LT Sample Prep Kit (Illumina). Sequencing was performed on a NextSeq 500 using the High Output v2.5 kit (75 cycles, FC-404-2005; Illumina). The sequenced reads were trimmed to remove low-quality bases and adaptor sequences using cutadapt-1.16 (Martin, 2011). The trimmed reads were mapped to the human reference genome (hg38) using HISAT v2.1.0 with GENCODE v30 (Frankish et al., 2019). The uniquely mapped reads were summarized at the gene level using HTSeq-count v0.11.2 (Anders et al., 2015), and the expression level of each gene was normalized using edgeR v3.24.3 (McCarthy et al., 2012). Low-expression genes across all samples were excluded from subsequent analyses. CPM (counts per million reads) values were used as gene expression levels, whereas FPKM values were used only for comparison analysis with cynomolgus monkeys (Figure $7 \mathrm{~A}$ ). For heatmaps, expression values were normalized to the median or mean of all datasets or a specific condition. Representations of heatmaps, correlation analyses, hierarchical clustering analyses, and principal component analyses (PCA) were performed using R software (v3.5.1). Gene Ontology analysis was performed using DAVID 6.8 (Huang et al., 2009).

Single cell RNA sequencing and data analysis

Cultured cells were dissociated with Accutase. Single cells were collected using a BD FACSAria II (BD Biosciences). nTEs_D2 and nTEs_D3 were purified with TACSTD2 antibody. Single-cell suspensions were loaded into a Chromium Single Cell Controller instrument (10x Genomics) to generate single-cell gel beads in emulsion. 10x Genomics v.3.0 libraries were prepared according to the manufacturer's instructions. All samples were multiplexed together and sequenced on an Illumina HiSeq 4000 with paired-end sequencing. scRNA-seq data were mapped and quantified using Cell Ranger pipelines (v.5.0.1, 10x Genomics) against the hg38 human reference genome (refdata-gex-GRCh38-2020-A, 10x Genomics). The raw counts data were imported into the Seurat package (v.3.2.3) (Butler et al., 2018). Cells with nfeature $>4,000$, nCount between 15,000 and 150,000, and low mitochondrial gene expression (<15\%) were further analyzed. The raw counts were normalized by the SCtransform method in the Seurat package. tSNE analysis and clustering were performed using the Seurat RunTSNE function with default parameters (dims = 1:50) and 'FindClusters' function with the resolution set at 0.5. Monocle (v.2.18.0) was used to perform the trajectory analysis (Qiu et al., 2017). Module scores for cell type specific genes (Xiang et al., 2020) were calculated by Seurat's AddModuleScore function and visualized in trajectory.

\section{Comparison of gene expressions between humans and cynomolgus monkeys}

To compare gene expressions between humans and cynomolgus monkeys, common genes listed in the cynomolgus monkeys-humans one-to-one annotation table were used as described previously (Nakamura et al., 2016; Nakamura et al., 2017). Trophoblast ontogenic gene set was defined by published cynomolgus monkey scRNA-seq data (Nakamura et al., 2016). 


\section{CellPress}

\section{Cell Stem Cell

\section{QUANTIFICATION AND STATISTICAL ANALYSIS}

Quantification methods are described in the figure legends or detailed here in STAR Methods. The exact number of replicates used are indicated within individual figure legends. Results are expressed as the means, and error bars represent SD unless otherwise indicated. If not otherwise indicated, statistical significance was determined by unpaired two-tailed Student's t test using GraphPad Prism 9 or $\mathrm{R}\left({ }^{\star \star \star *}, \mathrm{p} \leq 0.0001 ;{ }^{* \star \star}, \mathrm{p} \leq 0.001 ;{ }^{* \star}, \mathrm{p} \leq 0.01 ;{ }^{*}, \mathrm{p} \leq 0.05\right.$, ns = not significant). In all cases, the data was assumed to meet $\mathrm{t}$ test requirements (normal distribution and similar variance), and differences were considered to be statistically significant when $P$ values were less than 0.05 . 